\title{
Auroral electrojets and boundaries of plasma domains in the magnetosphere during magnetically disturbed intervals
}

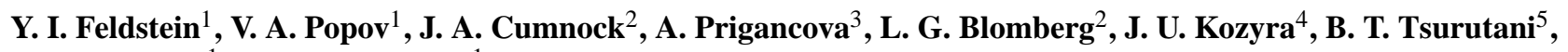 \\ L. I. Gromova ${ }^{1}$, and A. E. Levitin ${ }^{1}$ \\ ${ }^{1}$ Institute of Terrestrial Magnetism, Ionosphere and Radio Wave Propagation, Troitsk, Moscow Region, Russia \\ ${ }^{2}$ Alfvén Laboratory, Royal Institute of Technology, Stockholm, Sweden \\ ${ }^{3}$ Geophysical Institute, Slovak Academy of Sciences, Bratislava, Slovakia \\ ${ }^{4}$ Space Physics Research Laboratory, University of Michigan, Ann Arbor, MI, USA \\ ${ }^{5}$ Jet Propulsion Laboratory, Pasadena, CA, USA
}

Received: 16 January 2006 - Revised: 15 May 2006 - Accepted: 17 July 2006 - Published: 13 September 2006

\begin{abstract}
We investigate variations in the location and intensity of the auroral electrojets during magnetic storms and substorms using a numerical method for estimating the equivalent ionospheric currents based on data from meridian chains of magnetic observatories. Special attention was paid to the complex structure of the electrojets and their interrelationship with diffuse and discrete particle precipitation and field-aligned currents in the dusk sector. During magnetospheric substorms the eastward electrojet (EE) location in the evening sector changes with local time from cusp latitudes $\left(\Phi \sim 77^{\circ}\right)$ during early afternoon to latitudes of diffuse auroral precipitation $\left(\Phi \sim 65^{\circ}\right)$ equatorward of the auroral oval before midnight. During the main phase of an intense magnetic storm the eastward currents in the noon-early evening sector adjoin to the cusp at $\Phi \sim 65^{\circ}$ and in the pre-midnight sector are located at subauroral latitude $\Phi \sim 57^{\circ}$. The westward electrojet (WE) is located along the auroral oval from evening through night to the morning sector and adjoins to the polar electrojet (PE) located at cusp latitudes in the dayside sector. The integrated values of the eastward (westward) equivalent ionospheric current during the intense substorm are $\sim 0.5 \mathrm{MA}(\sim 1.5 \mathrm{MA})$, whereas they are $0.7 \mathrm{MA}(3.0 \mathrm{MA})$ during the storm main phase maximum. The latitudes of auroral particle precipitation in the dusk sector are identical with those of both electrojets. The EE in the evening sector is accompanied by particle precipitation mainly from the Alfvén layer but also from the near-Earth part of the central plasma sheet. In the lower-latitude part of the EE the field-aligned currents (FACs) flow into the ionosphere (Region 2 FAC), and at its higher-latitude part the FACs flow

Correspondence to: A. Prigancova

(geofpria@savba.sk)
\end{abstract}

out of the ionosphere (Region 1 FAC). During intense disturbances, in addition to the Region 2 FAC and the Region 1 FAC, a Region 3 FAC with the downward current was identified. This FAC is accompanied by diffuse electron precipitation from the plasma sheet boundary layer. Actually, the triple system of FAC is observed in the evening sector and, as a consequence, the WE and the EE overlap. The WE in the evening sector comprises only the high-latitude periphery of the plasma precipitation region and corresponds to the Hall current between the Region 1 FAC and Region 3 FAC. During the September 1998 magnetic storm, two velocity bursts $(\sim 2-4 \mathrm{~km} / \mathrm{s})$ in the magnetospheric convection were observed at the latitudes of particle precipitation from the central plasma sheet and at subauroral latitudes near the ionospheric trough. These kind of bursts are known as subauroral polarization streams (SAPS). In the evening sector the Alfvén layer equatorial boundary for precipitating ions is located more equatorward than that for electrons. This may favour northward electric field generation between these boundaries and may cause high speed westward ions drift visualized as SAPS. Meanwhile, high speed ion drifts cover a wider range of latitudes than the distance between the equatorward boundaries of ions and electrons precipitation. To summarize the results obtained a new scheme of 3-D currents in the magnetosphere-ionosphere system and a clarified view of interrelated 3-D currents and magnetospheric plasma domains are proposed.

Keywords. Magnetospheric physics (Current systems; Electric fields; Magnetosphere-ionosphere interactions; Storms and substorms)

Published by Copernicus GmbH on behalf of the European Geosciences Union. 


\section{Introduction}

The westward and eastward auroral electrojets are characteristic features of the ionospheric current systems at high latitudes during magnetospheric substorms and magnetic storms (Chapman, 1935). The current system obtained and named by Chapman as solar-daily disturbed variation (SD) has influenced the study of geomagnetic disturbances to a high degree and become the standard model. This was a major paradigm for a few decades. The SD current system consists of a pair of electrojets along the auroral zone as a circular belt with a centre in the geomagnetic pole. The WE in the morning sector, the EE in the evening sector, and their return currents in the polar cap and in lower latitudes are usually considered. During magnetic storms the current intensity in the WE can reach as much as a few MA, whereas the EE is several times less intense. The consequent magnetic disturbances on the Earth's surface can be as high as $3000 \mathrm{nT}$.

Harang (1946) used data from a meridian chain of observatories for investigating the current system morphology. He found a discontinuity between the WE and EE at auroral zone latitudes, but not along (yet unidentified that time) the auroral oval (AO). In the dusk sector intense currents overlap each other (in the sense that the EE and WE coexist at the same time but at different latitudes) and the westward current is located poleward from the eastward one. Meanwhile, in the large-scale current system the electrojets were usually placed along the auroral zone (Harang, 1951). However, similar intensification of the equivalent current also exists in the late dusk sector of the Chapman current system. Hence, the Harang study presented no drastic revision of the conceptions regarding the structure of the high-latitude current system. As before, the electrojets were associated with the auroral zone. At that time the generation of electrojets and ionospheric current systems during magnetic disturbances was most comprehensively explained in terms of the dynamo theory of geomagnetic disturbances (Nagata and Fukushima, 1952; Fukushima, 1953).

In the early sixties the paradigm of the auroral zone was replaced by a new paradigm. It was a conception of the AO, as Akasofu (2002) stressed. The region of the most frequent and intense particle precipitation is located along the AO. The change in the paradigm has been accompanied by a new conception of the large-scale model of the equivalent ionospheric currents distribution at high latitudes. According to the new model suggested by Feldstein (1963), Akasofu et al. (1965), Feldstein and Zaitzev (1965) the electrojet with a westward current flowing along the AO (all longitudes included) changes its intensity with local time. The intensity reaches its maximum during the early morning hours.

In Sect. 2, there is a brief description of the numerical method for the estimation of equivalent ionospheric currents using magnetic field observations along meridian chains of ground-based vector magnetometers. This method, discussed in detail earlier (Popov and Feldstein, 1996; Popov et al., 2001), allows not only for the determination of the latitudinal distribution of the ionospheric current intensity, but also for the separation of the contributions to the observed geomagnetic variations of the fields from external (ionospheric and magnetospheric) and internal (induced by telluric currents) sources.

In Sect. 3 this method is applied to analyse the dynamics of auroral electrojets using data from three magnetometer chains within the intervals of the 25 September 1998 magnetic storm and of the substorms on 24 September 1998, preceding the beginning of the magnetic storm main phase. Data from three chains, namely the Greenland West Coast chain (GWC), the Scandinavian chain (IMAGE), and the magnetometer chain of the Canadian Space Agency (CANOPUS), are used. Both the location of the auroral electrojets in the ionosphere and their motion are closely associated with the dynamics of different characteristic plasma domains in the distant magnetosphere at geocentric distances from $\sim 4$ to $50 R_{E}$ (Akasofu, 1968; Kivelson and Russell, 1995). The location of electrojet boundaries is associated with and defined by the level of magnetic disturbances and by the phases of substorms and storms.

In Sect. 4 the interconnection of the auroral electrojets with different characteristic types of precipitation into the upper atmosphere is considered and then analysed in detail in Sect. 4.2. In Sect. 4.3 the interrelationship of plasma precipitation region boundaries and such phenomena as ionospheric plasma density, large-scale plasma convection (including SAPS generation), and the structure of large-scale field-aligned currents at ionospheric altitudes in the evening and night sectors during substorms and different phases of a magnetic storm were considered.

In Sect. 5 the structure of the magnetic field variations in the EE is discussed and generalized schemes for spacetime distribution of auroral electrojets at ionospheric altitudes during magnetospheric substorms (Fig. 15d) and magnetic storm main phase (Fig. 15e) are presented. In addition, the DMSP measurements of FACs and electric fields were compared with the results of electromagnetic modelling of the inner magnetosphere known for some recent models. Taking into account the current conclusions reported in Sect. 3 and Sect. 4, the basic 3-D current systems in the magnetosphere are discussed and their interrelation with various magnetospheric plasma domains is considered and presented (Fig. 16) in Sect. 5.4.

In Sect. 6 the main results are summarized.

\section{Modelling of equivalent ionospheric currents based on meridian magnetometer chain data}

To define the direction and intensity of the equivalent current at ionospheric altitudes measurements of variations in the geomagnetic field on the Earth's surface are usually used. The direction of the linear current in a thin ionospheric layer can 
be found by rotating the horizontal magnetic disturbance vector (with components conventionally labelled $\Delta X$ and $\Delta Y$ ) clockwise $90^{\circ}$. The components of the horizontal equivalent current density $j_{x}$ and $j_{y}$ are calculated from:

$j_{x}(\mathrm{~A} / \mathrm{m})=(k / 2 \pi) 10^{-2} \Delta Y(\mathrm{nT})$,

$j_{y}(\mathrm{~A} / \mathrm{m})=(k / 2 \pi) 10^{-2} \Delta X(\mathrm{nT})$,

where $k$ is a correction factor, accounting for currents induced within the Earth's interior (Kamide and Akasofu, 1974). The $k$ factor is estimated to be in the range $2 / 3-3 / 4$. This approach was used by Kamide and Akasofu when investigating the WE profile across the Alaska meridian chain of observatories at $60.9-83.0^{\circ}$ latitude during several substorms.

A similar approach was used by Baumjohann et al. (1980) to determine the equivalent ionospheric current density and direction in the region of the eastward electrojet using the Scandinavian Magnetometer Array measurements. Most of the magnetometers are located along north-south lines and the spacing between the instruments varies from 100 to $150 \mathrm{~km}$. Later, a more complicated technique has been used to determine the global instantaneous distributions of equivalent ionospheric currents during substorms. Based on data from 70 magnetic observatories, including six meridional chains of magnetometers, Kamide et al. (1982) obtained the spatial distribution of ionospheric and field-aligned current densities for four UT cross sections during a substorm on 19 March 1978. They used an improved version of the computer algorithm by Kamide et al. (1981). "Instantaneous" patterns of electric fields and currents in the high-latitude ionosphere were deduced by combining measurements of ionospheric ion drift velocities and ground-based magnetometer observations (Kamide and Kokubun, 1996). For this purpose an updated version of the assimilative mapping of the ionospheric electrodynamics (AMIE) technique of Richmond and Kamide (1988) was used. An overview of various techniques used for simulations of the equivalent currents from groundbased magnetometer data was given by Untiedt and Baumjohann (1993).

Kotikov et al. (1991) developed a practical inversion scheme to infer the fine structure of the auroral electrojet by utilizing a series of linear ionospheric currents (50 altogether) of different intensities located at the $100 \mathrm{~km}$ altitude. The current distribution was adjusted to fit measurements on the Earth's surface. Olsen (1996) used a similar approach to determine ionospheric currents from satellite magnetic field observations. Popov and Feldstein (1996) and Popov et al. (2001) suggested a refinement of the Kotikov method by approximating the auroral electrojets with a series of narrow current strips of finite width. The strips with currents of different intensities were distributed along a geomagnetic meridian at the $115 \mathrm{~km}$ altitude over the range of latitudes covered by the ground magnetometer stations. Both the accuracy of the method and its spatial resolution were considered in detail by Popov et al. (2001). The suitability of the method for estimating the equivalent ionospheric currents from meridian chain data was demonstrated. Below, the refined method of Popov and Feldstein (1996) is applied to some substorms and a magnetic storm in September 1998, in order to obtain the location and distribution of eastward and westward electrojet intensities as a function of latitude. The intensity variations of ionospheric currents depend on UT. Such variations have two causes: i) temporal variations of the intensity, as well as the distribution of the global ionospheric current system; ii) the fact that the Earth (and, thus, the magnetometer chain) rotates under the current pattern which is approximately fixed relative to the Sun's direction. The algorithm used for calculating the ionospheric current intensities is based on a number of assumptions:

- the equivalent ionospheric currents are plane sheet currents;

- the currents are composed of 100 narrow, infinitely long strips, each carrying either an eastward or westward current; the current densities may change from one strip to another but they are uniform within each strip;

- the observed ground magnetic fields are produced by ionospheric currents and the associated induced currents in the Earth;

- the electrical conductivity of the solid Earth does not vary in the direction normal to the magnetometer chain.

For our study we use data from three meridian magnetometer chains covering a wide range of corrected geomagnetic latitudes:

- the IMAGE chain along the $110^{\circ} \mathrm{CG}$ longitude meridian, local geomagnetic midnight occurs at 21:00 UT;

- the GWC chain along the $40^{\circ} \mathrm{CG}$ longitude meridian, local geomagnetic midnight occurs at 02:30 UT;

- the CANOPUS chain along the $330^{\circ}$ CG longitude meridian, local geomagnetic midnight occurs at 06:30 UT.

Geographic and geomagnetic co-ordinates of high-latitude stations for these chains, data from which were used for the equivalent current inversion, are listed in Table 1.

The observed magnetic field variations in the vertical $Z$ (downward) and horizontal $H$ (northward) components at each station is a superposition of fields due to external and internal sources. At any point $l$ along the meridian:

$$
\begin{aligned}
& H_{\mathrm{ext}}(l)=\frac{1}{2}\left[H(l)+\frac{1}{\pi} \int_{-\infty}^{+\infty} \frac{Z(\xi)}{\xi-l} d \xi\right], \\
& Z_{\mathrm{ext}}(l)=\frac{1}{2}\left[Z(l)-\frac{1}{\pi} \int_{-\infty}^{+\infty} \frac{H(\xi)}{\xi-l} d \xi\right] .
\end{aligned}
$$


Table 1. High-latitude stations of three magnetometer chains for the epoch 1998. Geographic and corrected geomagnetic latitudes (Lat) and longitudes (Long) are also given.

\begin{tabular}{|c|c|c|c|c|c|c|}
\hline \multicolumn{7}{|l|}{ IMAGE } \\
\hline \multirow[b]{2}{*}{ Station } & \multirow[b]{2}{*}{ IAGA code } & & \multicolumn{2}{|c|}{ Geographic } & \multicolumn{2}{|c|}{ Corrected geom. } \\
\hline & & & Lat & Long & Lat & Long \\
\hline Ny Ålesund & NAL & & 78.92 & 11.95 & 76.07 & 112.25 \\
\hline Longyearbyen & LYR & & 78.20 & 15.82 & 75.12 & 113.00 \\
\hline Hornsund & HOR & & 77.00 & 15.60 & 74.02 & 110.48 \\
\hline Hopen Island & HOP & & 76.51 & 25.01 & 72.93 & 115.91 \\
\hline Bear Island & BJN & & 74.50 & 19.20 & 71.33 & 108.73 \\
\hline Troms $\varnothing$ & TRO & & 69.66 & 18.94 & 66.54 & 103.44 \\
\hline Muonio & MUO & & 68.02 & 23.53 & 64.62 & 105.70 \\
\hline Pello & PEL & & 66.90 & 24.08 & 63.46 & 105.38 \\
\hline Oulujärvi & OUL & & 64.52 & 27.23 & 60.89 & 106.54 \\
\hline Hankasalmi & HAN & & 62.30 & 26.65 & 58.62 & 104.99 \\
\hline Nurmijärvi & NUR & & 60.50 & 24.65 & 56.81 & 102.54 \\
\hline \multicolumn{7}{|l|}{ GWC } \\
\hline \multirow[b]{2}{*}{ Station } & \multirow{2}{*}{$\begin{array}{l}\text { Alternative } \\
\text { (former) name }\end{array}$} & \multirow{2}{*}{$\begin{array}{l}\text { IAGA } \\
\text { code }\end{array}$} & \multicolumn{2}{|c|}{ Geographic } & \multicolumn{2}{|c|}{ Corrected geom. } \\
\hline & & & Lat & Long & Lat & Long \\
\hline Qaanaaq & Thule & THL & 77.47 & 290.77 & 85.39 & 33.32 \\
\hline Savissivik & & SVS & 76.02 & 294.90 & 83.64 & 35.91 \\
\hline Kullorsuaq & & KUV & 74.57 & 302.82 & 81.22 & 44.51 \\
\hline Upernavik & & UPN & 72.78 & 303.85 & 79.49 & 42.02 \\
\hline Uummannaq & Umanaq & UMQ & 70.68 & 307.87 & 76.90 & 43.93 \\
\hline Qeqertarsuaq + & Godhavn & GDH & 69.25 & 306.47 & 75.80 & 40.39 \\
\hline Attu & & ATU & 67.93 & 306.43 & 74.56 & 39.00 \\
\hline Kangerlussuaq & Sondre Stromfjord & STF & 67.02 & 309.28 & 73.16 & 41.74 \\
\hline Maniitsoq & Sukkertoppen & SKT & 65.42 & 307.10 & 71.99 & 37.97 \\
\hline Nuuk & Godthab & GHB & 64.17 & 308.27 & 70.56 & 38.53 \\
\hline Paamiut & Frederikshab & FHB & 62.00 & 310.32 & 68.01 & 39.65 \\
\hline Narsarsuaq + & & NAQ & 61.18 & 314.56 & 66.31 & 43.91 \\
\hline \multicolumn{7}{|l|}{ CANOPUS } \\
\hline & & & \multicolumn{2}{|c|}{ Geographic } & \multicolumn{2}{|c|}{ Corrected geom. } \\
\hline Station & IAGA code & & Lat & Long & Lat & Long \\
\hline Taloyoak & TLO & & 69.54 & 266.45 & 79.11 & 328.58 \\
\hline Rankin Inlet & RIT & & 62.82 & 267.89 & 73.06 & 334.48 \\
\hline Eskimo Point & EKP & & 61.11 & 265.95 & 71.35 & 331.59 \\
\hline Fort Churchill & FCC & & 58.76 & 265.92 & 69.13 & 332.08 \\
\hline Gillam & GIM & & 56.38 & 265.36 & 66.82 & 331.64 \\
\hline Island Lake & ISL & & 53.86 & 265.34 & 64.39 & 332.02 \\
\hline Pinawa & PIN & & 50.20 & 263.96 & 60.67 & 330.46 \\
\hline
\end{tabular}

The infinite integrals are truncated and computed over $4^{\circ}$ of latitude beyond the range of the magnetometer chains, in order to achieve a smoothness of the field at the equatorward and poleward edges of the magnetometer chains. The magnitude of $H$ at the end points of the simulation interval is $10 \%$ of the $H$ values at the boundaries of the magnetometer chain $\left( \pm 4^{\circ}\right)$, and the magnitude of $Z$ is $40 \%$ of the $Z$ values at the highest and lowest stations $\left( \pm 4^{\circ}\right)$, respectively. We assume that the magnitude of magnetic field variations outside of this extended region is negligible. The intervals of the extrapolated magnetic field components values should not be taken into account when interpreting the results of calculation.

According to the Biot-Savart law, the magnetic field disturbance at any point $l$ along the geomagnetic meridian at the Earth's surface, due to a single current strip, is given by

$$
\begin{aligned}
& H_{\text {ext }}(l)=\frac{j_{i}}{2 \pi}\left(\arctan \frac{x_{i}+d}{h}-\arctan \frac{x_{i}-d}{h}\right) \\
& Z_{\text {ext }}(l)=\frac{j_{i}}{4 \pi} \ln \left(\frac{h^{2}+\left(x_{i}+d\right)^{2}}{h^{2}+\left(x_{i}-d\right)^{2}}\right),
\end{aligned}
$$


where $j_{i}$ is the current density in the $i$ th strip, $d, h$, and $x_{i}$ are the half-width, altitude, and the distance from the observation point to the ground projection of the centre of the $i$ th strip, respectively.

Using these expressions for each of the $K$ magnetometers in the chain we obtain $2 K$ equations to determine the current densities in $N$ strips. If $N>2 \mathrm{~K}$, the problem is underdetermined and the solution is not unique. In order to constrain the solution, the regularization method developed by Tikhonov and Arsenin (1977) is used. This procedure can be applied to either one of the observed $H$ and $Z$ magnetic field components separately. Residual functions are constructed, one for $H$ and another for the $Z$ component, that provide a measure of the difference between observed and modelled ground magnetic fields, plus a "regularization" term. By minimizing the residual function we obtain current distributions "producing" magnetic field strengths which are close to those observed at the magnetometer locations. The residual function has a minimum when either the cumulative squared differences between current intensities in adjacent strips is minimal (for $H$ component), or the total squared current over all strips is minimal (for $Z$ component). Assuming that all assumptions of our model hold, the $H$ and $Z$ based reconstructions of the ionospheric currents are almost identical. A significant mismatch between the currents reconstructed from the $H$ and $Z$ component data is likely to imply a violation of the initial model assumptions. The calculations of the current density associated with the electrojets were carried out using both magnetic components. The results obtained were compared in order to assess the level of confidence for the current density profiles determined. Modelling was done based on 100 current strips and with the regularization parameters chosen as $\alpha=\beta=5 \times 10^{-7}$. The introduction of regularization parameters into model calculations and option of their values was considered in Popov et al. (2001). This allows the modelling to resolve one or two latitudinal peaks if they can be distinguished in the original current distribution.

\section{High-latitude magnetic field variations at the Earth's surface due to external sources}

\subsection{Interplanetary and geophysical situations}

The time interval of 24-25 September 1998 was selected for the analysis. It includes the GEM (Geospace Environment Modeling) magnetic storm (on 25 September) and the preceding magnetospheric substorms (on 24 September). Space weather conditions can be followed using data on solar wind and IMF parameters (1-min averages) on board the ACE spacecraft (GSM coordinates in Re are $\mathrm{X}=241, \mathrm{Y}=-18$, $\mathrm{Z}=27$ ). Figure 1 shows 1 -min averages of the following interplanetary parameters (from top to bottom): IMF intensity $B$, north-south $B_{z}$ component, solar wind plasma density $N$ and velocity $V$, solar wind ram pressure $P$, and plasma $\beta$ (a ratio of plasma and magnetic pressures). The geophysical situation in Fig. 1 is characterized by the 1-min averages of geomagnetic indices Sym-H, AU, and AL (data from the Kyoto WDC). The indices AU (AL) define the maximum intensity of the magnetic fields generated by currents in the eastward (westward) directions derived from the data of the longitudinal chain of magnetic observatories at auroral latitudes. The Sym-H index characterizes magnetic field variations derived from low- and mid-latitude data supplied by the longitudinal magnetometer chain. The Sym-H index is a mean value of the variations of the magnetic field horizontal component calculated for longitudes in a similar way as the $D_{s t}$ index.

Early on 24 September, from 00:00 to 10:00 UT, a few successive substorms characterized by indices $\mathrm{AU} \sim 280 \div 510 \mathrm{nT}$ and $\mathrm{AL} \sim(-250 \div-800 \mathrm{nT})$ were observed. These substorms were associated with increases of $V$ from $\sim 430 \mathrm{~km} / \mathrm{s}$ to $\sim 530 \mathrm{~km} / \mathrm{s}$ and $N$ variations from $\sim 5 \mathrm{~cm}^{-3}$ to $\sim 10 \mathrm{~cm}^{-3} ; P$ persisted at the level of $\sim 2.0 \mathrm{nPa}$, with slight fluctuations ranged within $\sim 0.3 \mathrm{nPa}$, the southward IMF $B_{z}$ component changed to $-7 \mathrm{nT}, \beta$ variations were within $2.5 \div 0.8$, and the Sym-H value reached $-55 \mathrm{nT}$. These variations of geomagnetic and interplanetary parameters are characteristic for substorms accompanied by the IMF southward turning. During 10:00-15:00 UT the geomagnetic activity indices give evidence of a lower level of disturbances: AU $50 \div 100 \mathrm{nT}$, AL $\sim(-100 \div-200 \mathrm{nT})$, Sym-H $\sim(-15 \div-30 \mathrm{nT})$. During these calm field conditions the IMF is $B \sim 10 \mathrm{nT}$ with $B_{z} \sim 0 \mathrm{nT}$ and values of other solar wind parameters quite normal for quiet conditions: $V \sim 450 \mathrm{~km} / \mathrm{s}, N \sim 5 \mathrm{~cm}^{-3}, P \sim 2 \mathrm{nPa}, \beta \sim 0.8 \div 1.2$.

After 15:00 UT $B_{z}$ becomes southward, although there are numerous direction turnings. This leads to continuous prestorm geomagnetic activity. The extreme value of $\mathrm{AL} \sim-1100 \mathrm{nT}, \mathrm{AU} \sim 300 \mathrm{nT}$ during the most intense substorm before the storm sudden commencement is related to $\sim 22: 00$ UT. Sym-H decreases to $\sim-40 \mathrm{nT}, P$ increases to $3.5 \mathrm{nPa}, V \sim 450 \mathrm{~km} / \mathrm{s}, \beta$ enhances at first to the 1.6 level and again decreases to $\sim 1.0$.

The geomagnetic activity was initiated by a fast forward shock compression of the magnetosphere near the end of the day of 24 September 1998. The shock preceeded an interplanetary coronal mass ejection (ICME) which was present on 25 September 1998. A large $D_{s t}=-207 \mathrm{nT}$ magnetic storm was initiated by sheath southward magnetic fields and extended by magnetic cloud southward magnetic fields.

The details are as follows. The fast shock is noted at ACE at 23:12 UT on 24 September (the first vertical dotted line in Fig. 1). This is identified by a magnetic field magnitude increase from 15.2 to $40.5 \mathrm{nT}$ and a density from 10.0 to $22.4 \mathrm{~cm}^{-3}$. The ram pressure increases from $3.4 \mathrm{nPa}$ to $14.2 \mathrm{nPa}$ at the shock. The Sym-H value is $\sim-44 \mathrm{nT}$ prior to the shock. At the time of the shock impingement at $\sim 23: 47$ UT there is a storm sudden commencement (SSC) which increases Sym-H from $-44 \mathrm{nT}$ to $\sim 0 \mathrm{nT}$ (the second vertical dotted line in Fig. 1). Hence, there is a propagation 


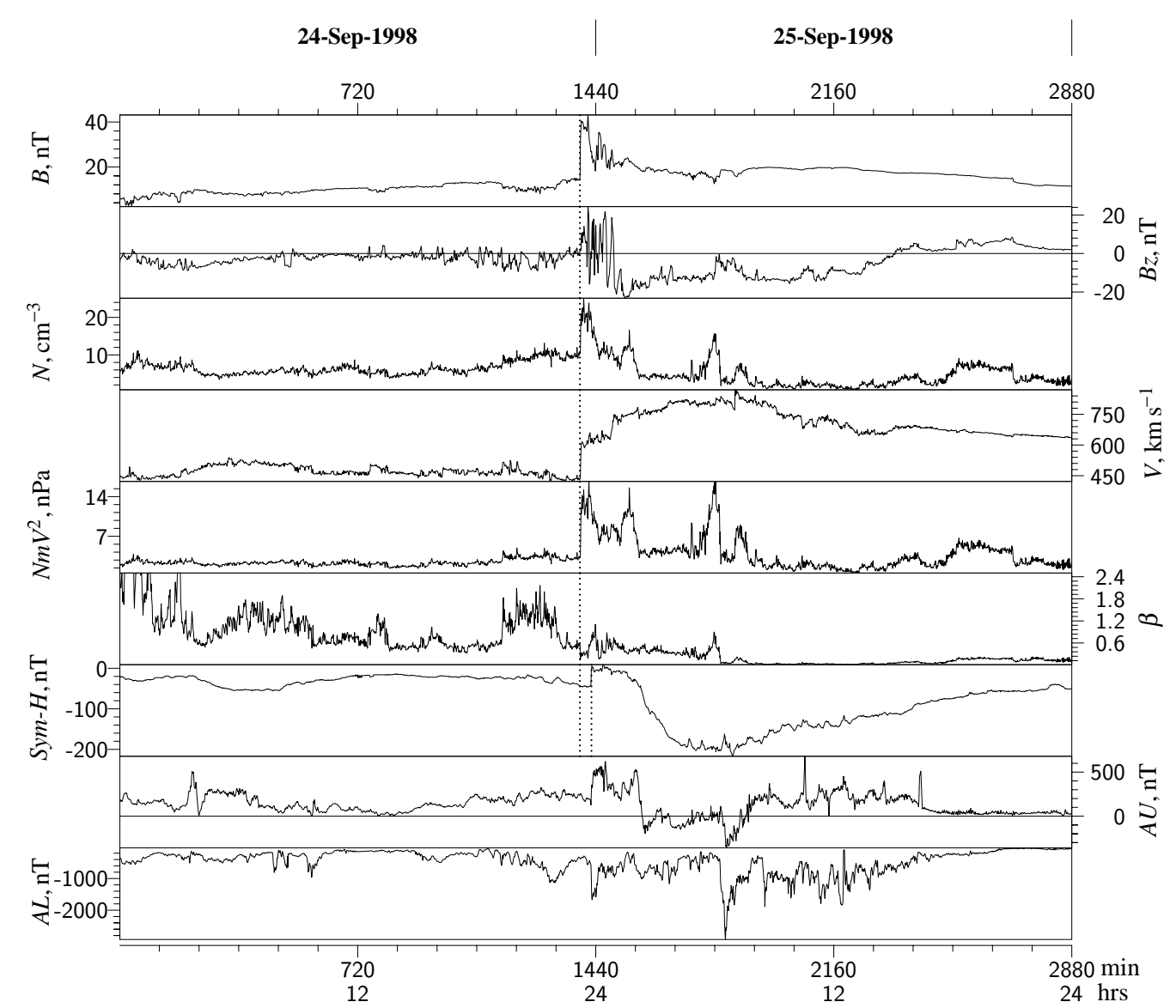

Fig. 1. Solar wind, IMF on board the ACE spacecraft and geomagnetic indices (1-min averages) from top to bottom: IMF intensity $B$, north-south $B_{z}$ component, solar wind plasma density $N$ and velocity $V$, solar wind ram pressure $P$, and plasma $\beta$ (a ratio of plasma and magnetic pressures), indices Sym-H, AU, and AL on 24-25 September 1998.

delay of $35 \mathrm{~min}$ of the shock from ACE to the magnetosphere. One also notes the short $(20 \mathrm{~min})$, sudden decrease in the AL index by $-1100 \mathrm{nT}$ (up to $-1670 \mathrm{nT}$ ) at that time. This is most likely a substorm triggered by the shock (Zhou and Tsurutani, 2001; Tsurutani and Zhou, 2003).

The magnetic storm main phase begins at about 01:15 UT on 25 September. This is caused by an intense southward $B_{z}$ in the sheath region following the interplanetary shock. The $B_{z}$ component is highly oscillatory at and immediately behind the shock. At 01:28 UT it reaches a maximum negative value of $-23.2 \mathrm{nT}$ and remains a relatively steady $-14 \mathrm{nT}$ from that time until 06:01 UT. This is sheath plasma and fields. The storm main phase is developed by this sheath southward $B_{z}$. The peak Sym-H value of $-217 \mathrm{nT}$ is reached at 06:03 UT.

There is a sharp interplanetary discontinuity that occurs at 06:15 UT. This can be noted in the $B_{x}$ and $B_{y}$ components (not shown) and the $B_{z}$ component. $B_{z}$ increases from $-10 \mathrm{nT}$ to $-0.4 \mathrm{nT}$. There is also a density decrease and a ram pressure decrease at that time. The plasma beta value also decreases to less than 0.1. The IMF magnitude of $\sim 18.5 \mathrm{nT}$ is smooth after this time. The low beta and high intensity, smooth magnetic fields identify this interval (up to the end of 25 September) as the magnetic cloud portion of the interplanetary CME (coronal mass ejection). It should be noted that the largest substorm expansion phase of the entire storm occurs at the time of the discontinuity. AL decreases from $-400 \mathrm{nT}$ to $-3000 \mathrm{nT}$ at 06:32 UT, a very huge event.

After the $B_{z}$ increases (at the discontinuity), it decreases once again to $-13 \mathrm{nT}$ and this maintains the storm main phase and elongates the recovery phase. According to the Sym$\mathrm{H}$ index the storm maximum depression lasts during 05:0009:00 UT, with the values ranging between $-200 \div-217 \mathrm{nT}$. The recovery phase starts with a rapid recovery of Sym-H until 16:00 UT, followed by a substantially slower recovery.

According to the $\mathrm{AU}$ index, the eastward current delays during the storm main phase. Positive values of the AU magnetic field become practically close to $0 \mathrm{nT}$ or even change to negative values. Such particular AU index variations can arise for two reasons, either because of a real weakening (or even disappearance) of the auroral eastward currents or because of their displacement equatorward from auroral to 


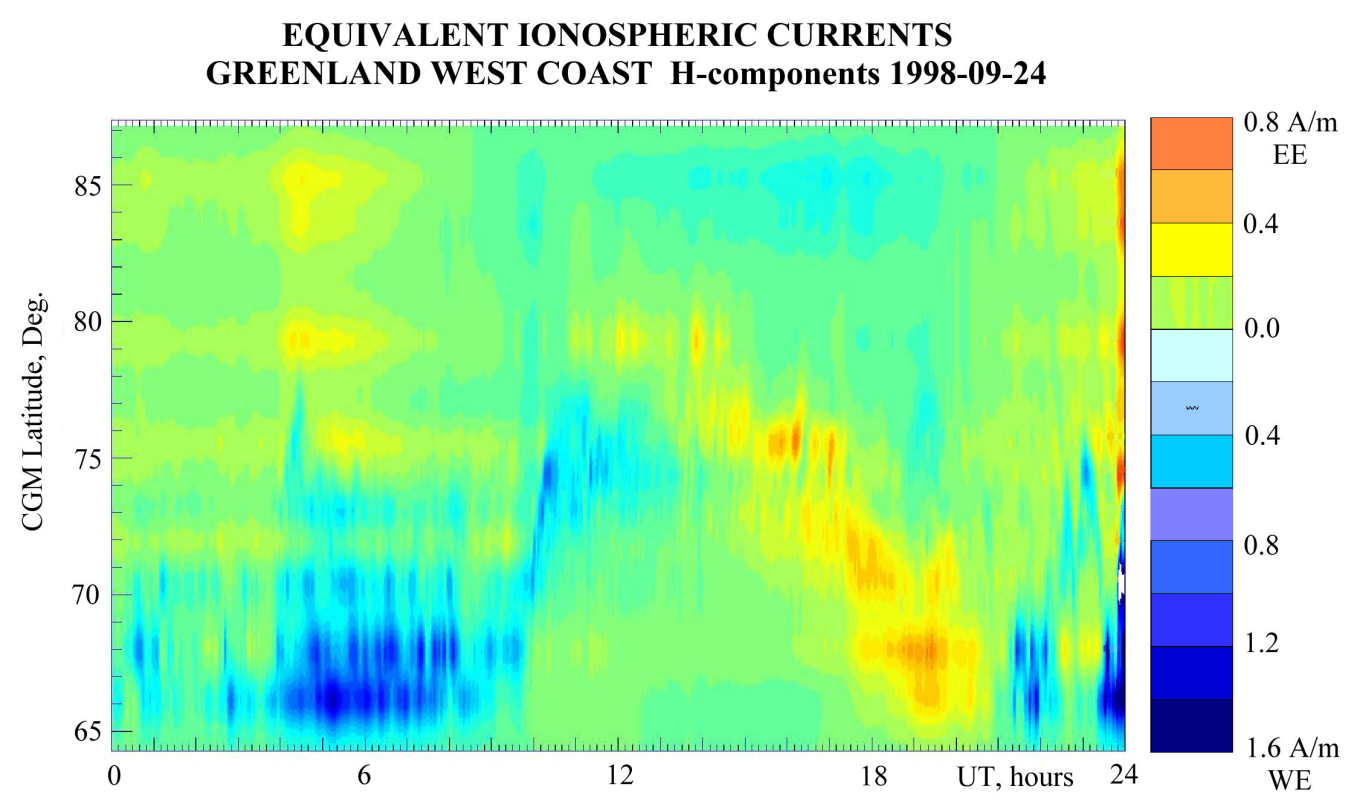

\section{TOTAL CURRENTS (Eastward - positive, Westward - negative), kA}

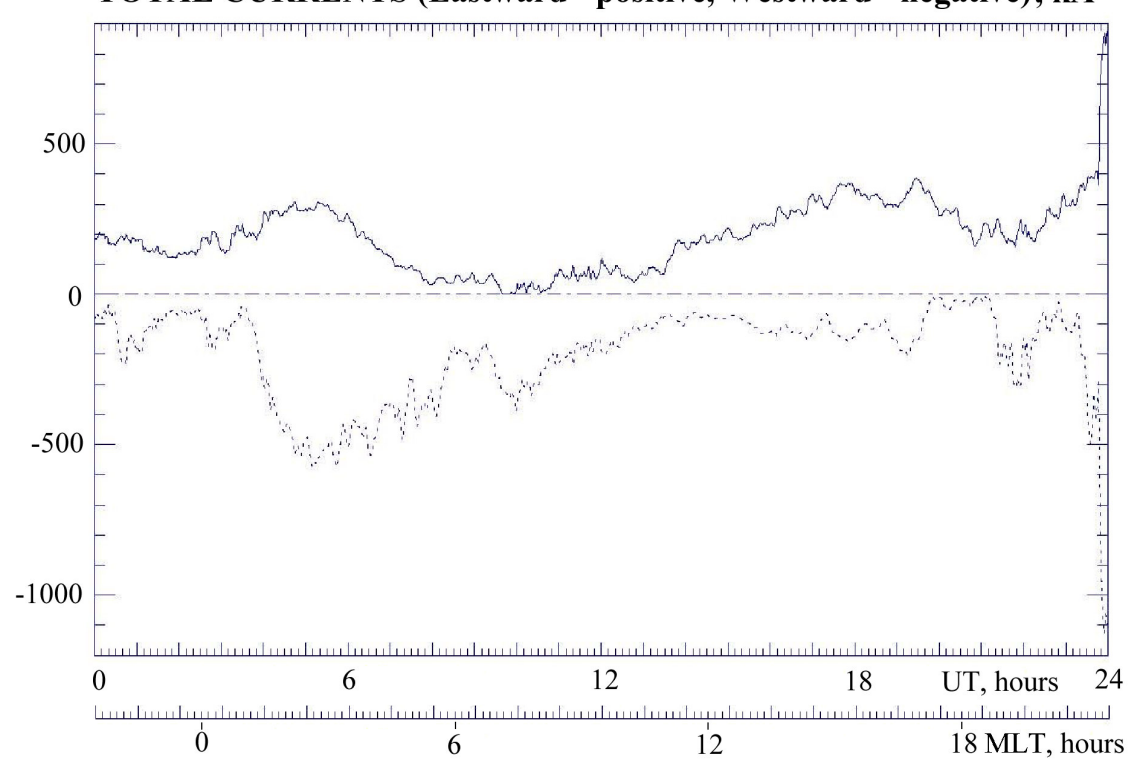

Fig. 2. The corrected geomagnetic latitude vs. UT plot of the eastward and westward equivalent ionospheric currents as calculated using $H$ component data on 24 September 1998 from the GWC meridian chain of magnetic observatories (top panel). Total intensity of the eastward (above) and westward (below) currents according to the GWC chain $H$ component (bottom panel).

subauroral latitudes. Based on the 25 September magnetic storm data the possible causes of these particular AU variations are discussed below.

3.2 Space-time characteristics of the magnetic variations at high latitude

The latitudinal distribution of the equivalent current density for eastward and westward currents based on $\mathrm{H}$ component data from the GWC chain is shown in Fig. 2 for 24 Septem- ber 1998. As a reference level, from which the field variation values were read, the field intensities at 11:00 UT on 24 September for the 24 September interval and at 21:00 UT on 25 September for the 25 September interval are used. Within the interval 00:00-09:00 UT on 24 September, the westward currents dominate at auroral zone latitudes $\Phi \sim 67^{\circ}$. Their linear density is $0.8 \mathrm{kA} / \mathrm{km}$ around midnight and in the early morning hours. These latitudes are typical for the location of the WE during magnetospheric substorms (Ahn et al., 2005). After 09:00 UT (6.5 MLT) the poleward shift (to $\Phi \sim 75^{\circ}$ ) 
of the westward current starts and then around 13:00 UT it decays.

The eastward current, with an intensity of $0.2-0.4 \mathrm{kA} / \mathrm{km}$, is found at $78^{\circ}<\Phi<80^{\circ}$ from 11:00 UT to 15:00 UT. Under relatively quiet magnetic conditions, these are typical cusp latitudes around noon. The DMSP F14 passes at 11:45 UT (15:00 MLT) and 13:29 UT (13:00 MLT) reveal that the LLBL (Low Latitude Boundary Layer) poleward boundary, i.e. the equatorward cusp (CU) boundary, is located at magnetic latitudes $77.4^{\circ}$ MLAT and $78.8^{\circ}$ MLAT, respectively (the coordinate system of magnetic latitude (MLAT) and magnetic local time (MLT) used for DMSP passes are corrected geomagnetic coordinates extended along magnetic field lines to altitudes of about $600 \mathrm{~km}$; e.g. see Baker and Wing, 1989). This eastward current is a manifestation of the PE which exists at CU latitudes. Both its intensity and direction are controlled by the IMF $B_{y}$ component (eastward for $B_{y}>0 \mathrm{nT}$ or westward for $B_{y}<0 \mathrm{nT}$ ) (Feldstein, 1976, and references therein). For the intervals considered, IMF $B_{y}>0 \mathrm{nT}$ and thus the PE is eastward.

In particular, Svalgaard (1968) was the first to indicate the existence of two characteristic types of magnetic field variations in the polar regions. The disturbances occurred simultaneously in the north and south polar caps and are controlled by the IMF sector polarity. The dependence of the magnetic field variations in the polar regions on the IMF sector polarity was independently obtained by Mansurov (1969). Friis-Christensen et al. (1972) and Sumaruk and Feldstein (1973), independently and simultaneously established that those magnetic field variations are controlled not by the IMF sector polarity, but by the direction of the IMF azimuthal $B_{y}$ component. Friis-Christensen and Wilhjelm (1975), Feldstein et al. (1975) used a regression method for extracting the $B_{y}$-controlled fraction of the high-latitude magnetic field variations and the corresponding equivalent DPC $\left(B_{y}\right)$ current system (Disturbed Polar Cap) was identified. The detailed description of this type of magnetic field variations and corresponding DPC $\left(B_{y}\right)$ current systems can be found in the review by Feldstein (1976, and references therein). The PE is a characteristic feature of DPC $\left(B_{y}\right)$, located in the daytime sector at $\Phi \sim 80^{\circ}$ under magneto-quiet conditions. During the summer season, under conditions of the IMF $B_{y} \sim 6 \mathrm{nT}$, the PE intensity is $\sim 1.8 \times 10^{5} \mathrm{~A}$ and its width equals $\sim 6^{\circ}$.

At 14:00 UT the EE appears equatorward of the PE at $\Phi \sim 76^{\circ}$. The EE monotonically shifts equatorward and its linear density increases to $0.5 \mathrm{kA} / \mathrm{km}$ at $\Phi \sim 67^{\circ}$ by 19:00 UT. During the evening hours the eastward currents are mainly observed at auroral latitudes. The westward currents with intensities up to $0.2 \mathrm{kA} / \mathrm{km}$ were observed more poleward, at $74^{\circ}<\Phi<76^{\circ}$ during 18:00-20:00 UT. At auroral latitudes $\Phi \sim 68^{\circ}$ their intensity was $0.6-0.8 \mathrm{kA} / \mathrm{km}$ during $22: 00$ 24:00 UT.

In Fig. 2 (bottom) the eastward and westward currents integrated along latitudes are shown. During 04:00-08:00 UT (night through early morning hours) westward currents are more intense than eastward currents and reach a value of $>0.6 \mathrm{MA}$ (we do not know how far the equatorward current extends), whereas during 15:00-21:00 UT (evening hours) the integrated eastward current with intensity of $\sim 0.3 \mathrm{MA}$ is stronger than the westward one.

The intensity relationship for eastward and westward currents in the evening sector characterizes the latitudinal cross sections for variations of magnetic components along GWC during 18:00-20:00 UT. The maximum current density of the EE was $\sim 0.5 \mathrm{kA} / \mathrm{km}$; its centre and poleward boundary were located at $68.0^{\circ}$ and $72.0^{\circ} \mathrm{CG}$ latitude, respectively. The EE equatorward boundary could not be determined, since that was outside of the magnetometer chain. The maximum WE current density was $\sim 0.2 \mathrm{kA} / \mathrm{km}$, and the WE centre was located at $\Phi \sim 76^{\circ}$.

The space-time distribution of the equivalent ionospheric currents calculated from the $Z$ component data from the meridian GWC chain for 24 September is in complete accordance with the above described development of currents obtained from the $H$ component.

Variations of the equivalent ionospheric currents, calculated using data from the other two meridian chains of observatories taken on 24 September 1998 (not shown), confirm the general characteristics derived from the analysis of the GWC chain. However, the changing longitudinal location of the observatory chains and their changing latitudinal locations reveal additional features in the dynamics of the ionospheric currents.

In fact, for the IMAGE chain the intense westward currents are observed at auroral latitudes $60^{\circ}<\Phi<67^{\circ}$ as early as from 20:00 UT. At 22:00 UT they spread into the latitude interval from $60^{\circ}$ to $75^{\circ}$ and their intensity is $\sim 1 \mathrm{kA} / \mathrm{km}$, with an integrated value of $1.7 \mathrm{MA}$. It is interesting that during these near-midnight hours eastward currents do not disappear and are observed equatorward of the westward currents, which are located at $\Phi \sim 59^{\circ}$. However, the eastward current is quite weak, $\sim 0.2 \mathrm{kA} / \mathrm{km}$. In other words, the equatorward shift of the eastward current on this meridian can be followed from $\Phi \sim 72^{\circ}$ at 16:00 MLT to $\Phi<60^{\circ}$ at 24:00 MLT. However, the eastward currents in the vicinity of the equatorial edge of the chain are unlikely to be a continuation of the EE to the near-midnight sector and further on to the morning sector. They are more likely to be equivalent currents, reflecting either fields of distant current sources, or currents spreading from the WE via lower latitudes. At such latitudes the particle participation, which is a necessary condition for the electrojet to exist, is absent near the midnight hours, before the magnetic storm commencement.

The CANOPUS meridian chain data show different features in comparison with IMAGE observations: during 18:00-24:00 UT most intense eastward currents shift from $\Phi \sim 72^{\circ}$ at $14: 00 \mathrm{MLT}$ to $64^{\circ}<\Phi<67^{\circ}$ at 18:00 MLT. Their linear density is $\sim 0.6 \mathrm{kA} / \mathrm{km}$ and the integrated intensity is $\sim 0.6 \mathrm{MA}$. 


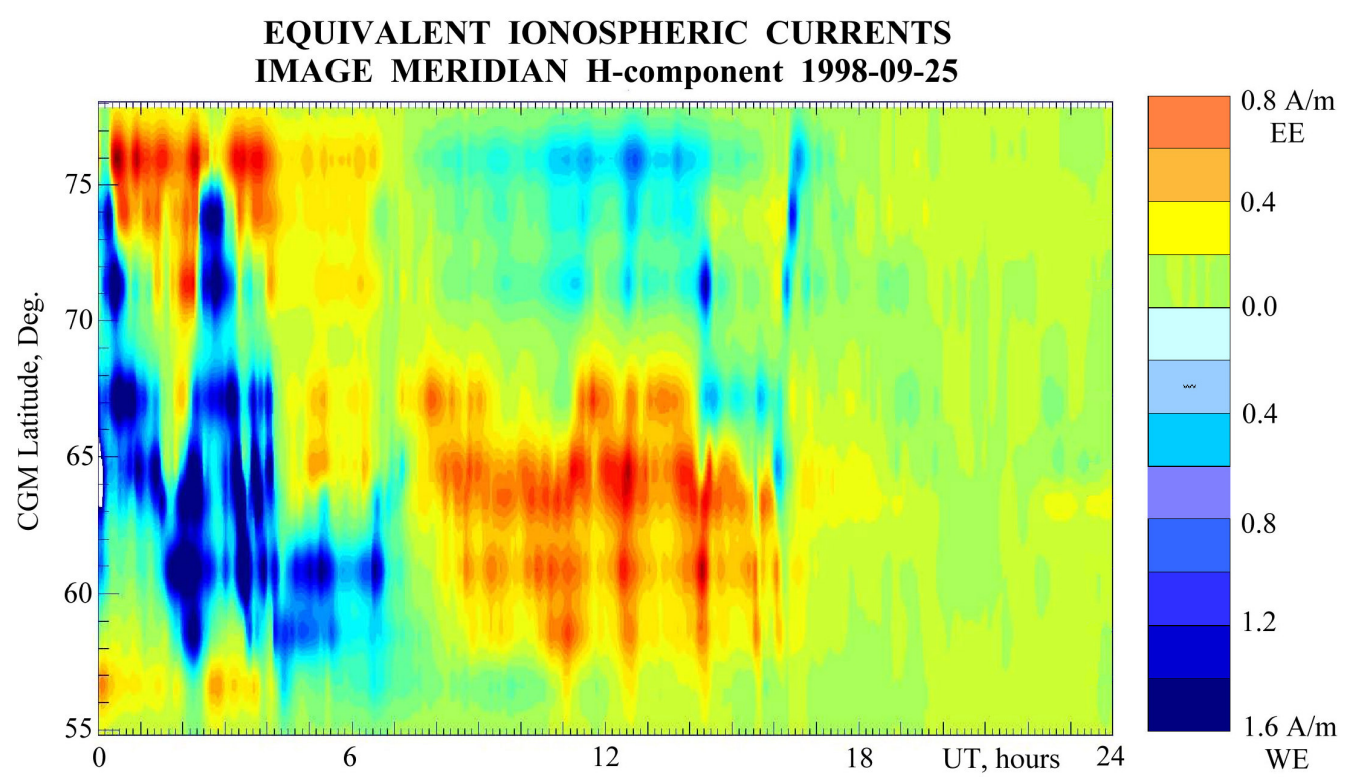

TOTAL CURRENTS (Eastward - positive, Westward - negative), kA

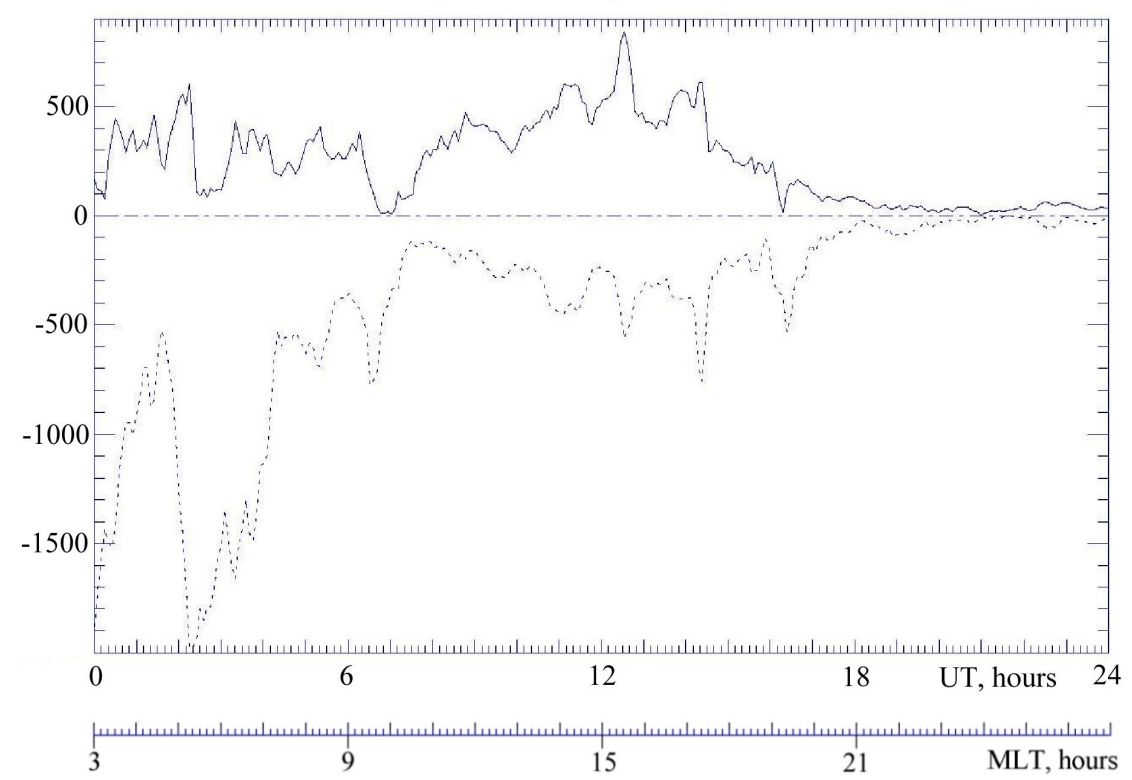

Fig. 3. As Fig. 2, but on 25 September 1998 for the IMAGE meridian chain of magnetic observatories.

The equatorward shift (with regard to MLT) of the location where the eastward currents culminate is also seen for a fixed UT, as the comparison of data from meridian chains located at different MLT show. For example, at 16:00 UT eastward currents culminate at $75^{\circ}$ and $67^{\circ}$, according to GWC and IMAGE chains (no EE according to the CANOPUS chain); at 18:00 UT the corresponding latitudes are $72^{\circ}, 70^{\circ}$, and $65^{\circ}$ for the CANOPUS, GWC, and IMAGE chains, respectively.

During magnetically disturbed intervals on 24 September, before the beginning of a magnetic storm, the characteristics of the eastward/westward currents as far as their intensity and location are concerned, can be summarized as follows:
- westward currents are most intense around the midnight hours at auroral latitudes of $65^{\circ}<\Phi<70^{\circ}$, and are shifted to cusp latitudes $\left(\Phi \sim 77^{\circ}\right)$ in the morning and evening sectors;

- eastward currents in the evening sector shift from cusp latitudes $\left(\Phi \sim 77^{\circ}\right)$ during the early afternoon MLT hours, reach the auroral latitudes by night hours and become more intense in the evening MLT;

- eastward currents are located just equatorward of the westward currents for evening hours where currents in opposite directions overlap in latitude; 


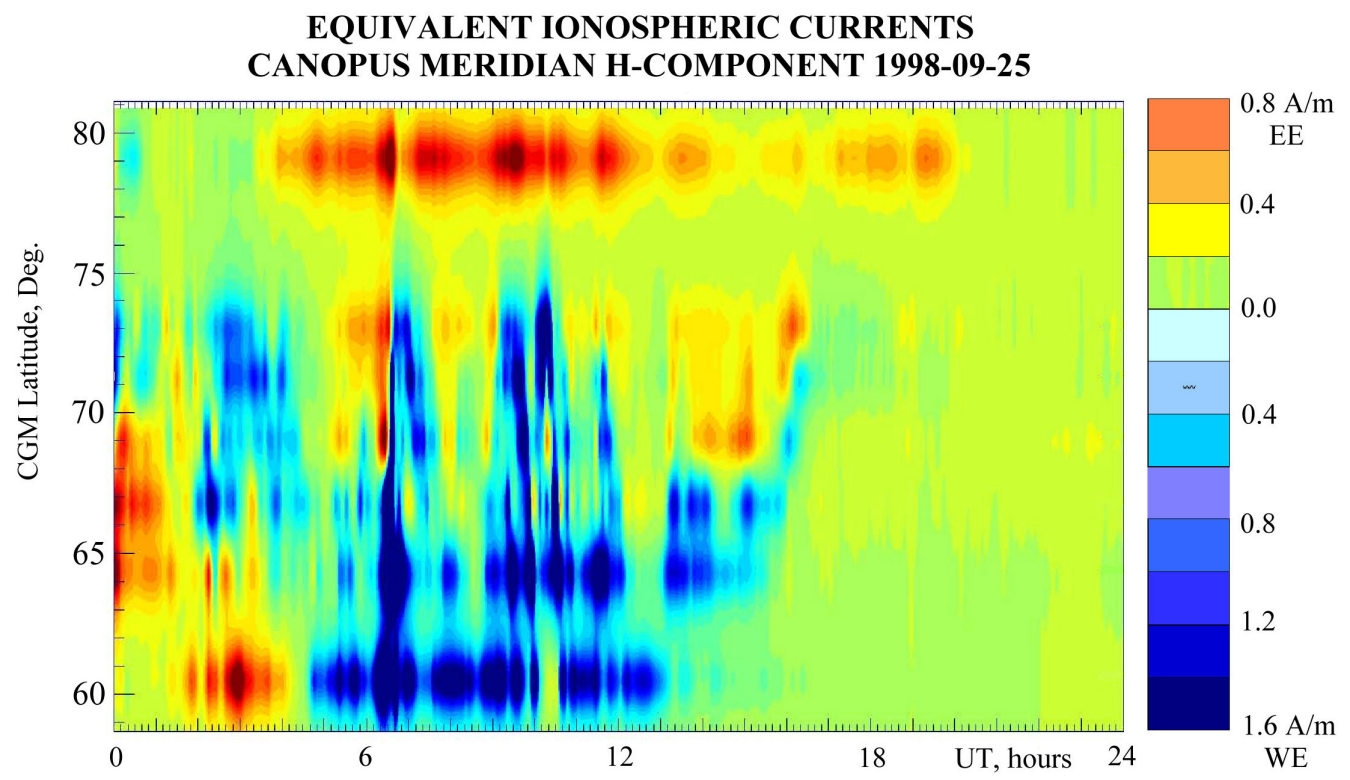

TOTAL CURRENTS (Eastward - positive, Westward - negative), kA

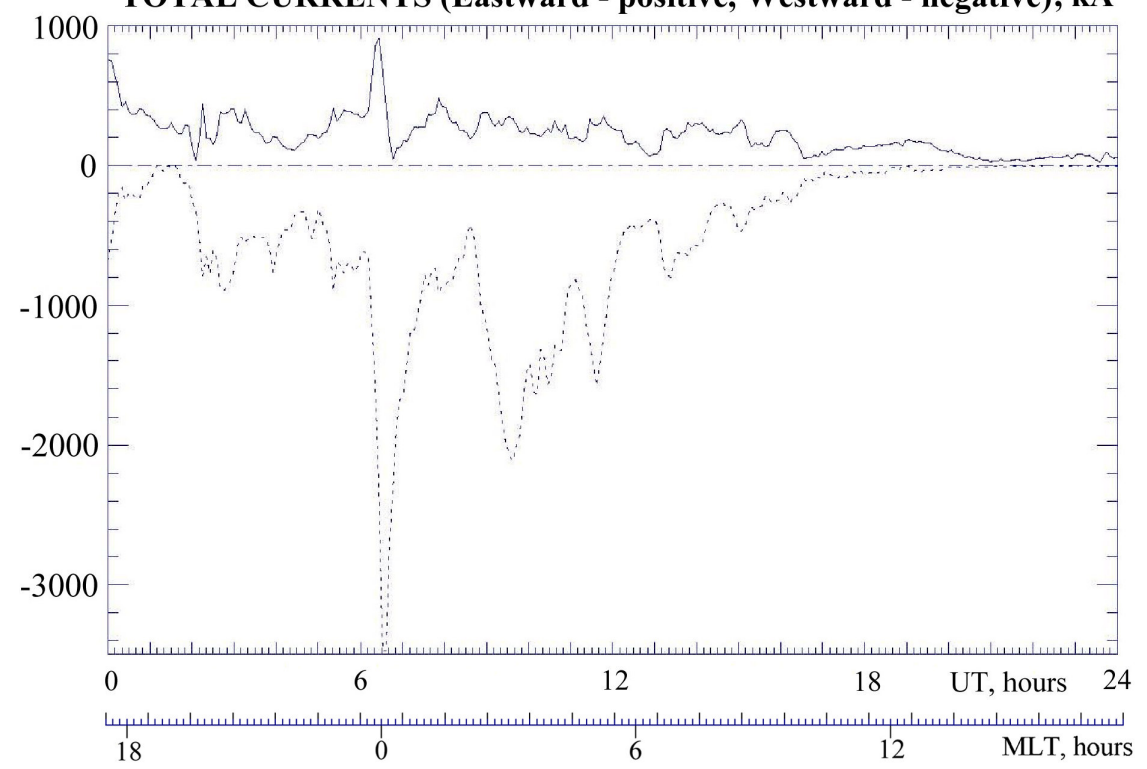

Fig. 4. As Fig. 3, but for the CANOPUS meridian chain of magnetic observatories.

- when overlapping occurs during evening hours the maximum eastward current intensity is higher than the westward current intensity, except during intense substorms;

- for intense substorms with $\mathrm{AE}$ index $\sim 13: 00 \mathrm{nT}$ the equivalent ionospheric current intensities are $\sim 0.6 \mathrm{kA} / \mathrm{km}(\sim 1.0 \mathrm{kA} / \mathrm{km})$ for eastward currents (westward currents), with integrated values of the currents of $\sim 500 \mathrm{kA}(\sim 1.5 \mathrm{MA})$, respectively.

During the storm main phase the auroral electrojets are located at latitudes not covered by the GWC chain. In order to describe their variations the $\Phi$-UT diagrams of the equivalent ionospheric currents distribution derived from $\mathrm{H}$ component development on 25 September 1998 are shown in Figs. 3 and 4 using data from the IMAGE and CANOPUS chains.

The enhancement of the ring current intensity (Sym-H index in Fig. 1) during 00:00-04:00 UT is accompanied by intense westward currents seen by the IMAGE chain during the nighttime and early morning MLT hours. During the substorm these currents cover the latitudinal range from $\Phi \sim 75^{\circ}$ to $\sim 57^{\circ}$ with maximum density about $1.2 \mathrm{kA} / \mathrm{km}$ and with an integrated value of about 1.5-2.0 MA. Under these conditions the eastward equivalent currents do not disappear. Rather, they persist in the near midnight-morning sector but are shifted to subauroral latitudes, $\Phi \sim 57^{\circ}$. As mentioned 
above, this equivalent current is likely to be the consequence of the outer sources or to be a current spreading out in the ionosphere from electrojet currents at higher latitudes. The signatures of the eastward equivalent current at subauroral latitudes $\Phi<57^{\circ}$ near the IMAGE meridian can be found in magnetograms from the Moscow observatory at CG latitude $\Phi=51^{\circ}$ (not shown). The two bursts of enhancements in the magnetic field $H$ component with extreme values of $60 \mathrm{nT}$ (between 01:00 and 02:00 UT) and 120 nT (between 02:20 and 03:30 UT) were measured by the storm-magnetograph at this observatory during the time interval 01:00-04:00 UT on 25 September 1998 . These bursts with positive $\Delta H$ occur on the background of the gradual field decrease associated with the storm main phase. The centre of the eastward equivalent current on this meridian is located poleward of the $\Phi=51^{\circ} \mathrm{CG}$ latitude, as can be seen by taking the magnetic field $Z$ component variations into account.

According to the CANOPUS chain, the eastward currents shift to $\Phi \sim 60.7^{\circ}$ during the late evening-pre-midnight MLT hours. Their intensity remains around $\sim 0.7 \mathrm{kA} / \mathrm{km}$. The existence of eastward currents at subauroral latitudes until 04:00 UT on 25 September for this meridian confirms that the absence of positive field values in the AU indices during the main phase of the intense magnetic storm is due not to a disappearance of eastward currents, but to their shifting equatorward from the auroral latitudes at which the magnetic observatories used for the AU index are located. At the CANOPUS meridian westward currents shift equatorward during the evening hours. During midnight-morning hours (until 07:00 MLT) they are located at latitudes from $\Phi<60.7^{\circ}$ to $75^{\circ}$. During intense substorms the linear current density increases to $1.6 \mathrm{kA} / \mathrm{km}$, and the integrated current reaches 23 MA.

The latitudinal range of westward currents (as seen by the IMAGE chain) becomes narrower (about $\sim 5^{\circ}$ ) by morning and before noon hours. According to the IMAGE magnetic data the eastward current (that could also be identified as the PE) appears at $\Phi \sim 66^{\circ}-68^{\circ}$ after 08:00 UT (11:00 MLT). Along the IMAGE meridian the PE persists up to 14:00 UT and intensifies repeatedly from $0.3-0.4 \mathrm{kA} / \mathrm{km}$ to $0.6 \mathrm{kA} / \mathrm{km}$. This PE is located in the CU-region. Actually, according to the DMSP F11, F12, and F14 data the poleward boundary of the LLBL shifts to $65^{\circ}-67^{\circ}$ MLAT during 08:00-15:00 UT, i.e. during the storm main phase and the beginning of the storm recovery phase. The positive IMF $B_{y}$ during this time interval is another indication that the eastward current is the PE.

Equatorward of the PE the EE is found as a wide strip directly adjoining the CU. During substorms the auroral electrojet can cover latitudes up to $\Phi \sim 57^{\circ}$. Its variations in intensity and latitudinal width are sawtooth-like. The weak westward currents poleward of the CU are a consequence of the magnetic field disturbances in the polar cap (PC) due to both the distant sources and spreading currents from the auroral electrojet.
The attenuation of magnetic disturbances after 14:00 UT is related to the usual location of equivalent currents in the evening sector when the westward current is located poleward of eastward one. The distinctive electrojets abruptly end at $\sim 17: 00$ UT and the current density is low. At this time the magnetic field recovery slows down, as seen in the Sym-H index (Fig. 1). During the main phase of the intense magnetic storm, the following characteristics of the electrojet dynamics are apparent:

- during evening hours both the EE and WE shift equatorward; around late evening-midnight hours the EE is located at subauroral latitudes, and thus not seen in the AU index;

- the eastward and westward current intensities in the evening sector imply that the EE cannot be the consequence of the WE closing through lower latitudes; it is likely that these electrojets are signatures of different geophysical phenomena;

- at the peak of the storm main phase and early recovery phase the equatorward boundary of the CU (and hence the PE) shifts to $65^{\circ}<\Phi<67^{\circ}$;

- at the main phase maximum the EE during near-noon hours adjoins the $\mathrm{CU}$ at $\Phi \sim 65^{\circ}$; its width is $\sim 8^{\circ}$, and the linear current density $\sim 0.8 \mathrm{kA} / \mathrm{km}$, the integrated current being $\sim 0.7 \mathrm{MA}$;

- the WE is absent in the daytime sector;

- the WE in the midnight and early morning sector is at least $15^{\circ}$ wide in latitude, current density is $\sim 1.6 \mathrm{kA} / \mathrm{km}$, and integrated current is $\sim 2-3 \mathrm{MA}$;

- when passing from midnight to morning hours the latitudinal width of the WE decreases, and the current shifts to higher latitudes.

Characteristic features of the auroral electrojet behaviour, as described above, can easily be followed in instantaneous space-time plots of magnetic disturbance intensities. Examples of such plots can be found in a number of papers using the AMIE technique for determination of ionospheric current systems at a specific UT. For instance, Kamide and Kokubun (1996) considered current distributions during magnetospheric substorms. The latitudinal overlapping of the electrojets in the evening sector, described above, can be clearly seen during the active phases of substorms; the latitudinal shifting of electrojets and variability of their intensity with MLT was also reported. 


\section{Auroral electrojets and plasma precipitation bound- aries}

\subsection{Data and method}

The auroral electrojets are a part of the complex system of ionospheric and magnetospheric currents. Their location and intensity are closely associated with the magnetospheric plasma structure and its dynamics during magnetic disturbances. As shown below, latitudinal cross sections of $\Delta H$ and $\Delta Z$ magnetic field components measured at meridional chains of observatories during magnetic disturbances can be used to determine the electrojet structure, namely centre location and poleward/equatorward boundaries of electrojets. The electrojet centre location is determined using both the maximum $\Delta H$ value and the change in the sign of $\Delta Z$ ( $\Delta Z<0$ poleward of and $\Delta Z>0$ equatorward of the latitude of the EE centre). Poleward and equatorward boundaries of the electrojets were defined on either side of an electrojet centre. Those correspond to latitudes where $\Delta Z$ reaches extreme values and $\Delta H \sim \Delta H \max / 2$.

The plasma structure of the magnetosphere can be reproduced from satellite measurements of energetic particles precipitating to ionospheric altitudes from the magnetosphere. The DMSP (Defense Meteorological Satellite Program) satellites provide measurements of precipitating particles (electrons and ions), ionospheric plasma flows, ion density, and magnetic field intensity. DMSP F12, F13 and F14 satellite observations of auroral energy plasma precipitations at the upper atmosphere altitudes were used to determine the spatial structure of the precipitation region and location of boundaries of various plasma domains during the 25 September 1998 magnetic storm. DMSP F8 satellite observations for 06 February 1994 and 10 May 1992 were also analysed.

The local times of the orbital planes of F12 2030/0830, F13 1711/0511, and F14 2035/0835 are favourable for investigations of various geophysical phenomena at the latitudes of the EE generation. The satellites are nadir-pointing with the particle detectors mounted so that their fields of view are centred on the local vertical.

The SSJ/4 instrument package includes curved plate electrostatic analyzers to measure electrons and ions from $32 \mathrm{eV}$ to $30 \mathrm{keV}$ at a rate of one complete electron and ion spectrum (20-points) per second. The locations of plasma precipitation region boundaries are obtained using the Newell et al. (1996) and Feldstein and Galperin (1996) classifications. Boundaries of regions with different physical characteristics of precipitating particle fluxes and their energy spectra were determined using low-altitude satellite measurements. The b1e and bli values are latitudes of the "zero-energy" electron and ion precipitation boundaries usually determined according to the softness channels. Those are regarded as the equatorward boundaries of the convection region in the midnight sector, where convection is from the magnetotail to the inner magnetosphere (to the plasmapause). The boundary b2e is a latitude where the electron energy does not increase with latitude (the same is valid on the earthward boundary of the central plasma sheet, CPS); b2 i is the latitude of precipitating ions with maximum energy flux and is also the isotropy boundary for ions with energy $>30 \mathrm{keV}$ (earthward boundary of the magnetospheric tail current sheet); b5e is the poleward boundary of the region where electron acceleration events are identified and the auroral electron energy flux (poleward boundary of the AO) abruptly decreases; b6 is the poleward boundary of the subvisual drizzle in the night sector (PC and also tail lobe boundary).

In this paper the Alfvén layer, the CPS and PSBL terms are commonly used to identify plasma domains in the night magnetosphere. The structure of both the auroral luminosity and auroral particle precipitation at low altitudes reflect the relationship of these phenomena with plasma domains in the night magnetosphere: i) between the structured $\mathrm{AO}$ (at latitudes between the $\mathrm{b} 2$ and $\mathrm{b} 5$ boundaries) and CPS; ii) between the diffuse luminosity (precipitation) equatorward of the AO (at latitudes between the b1 and b2 boundaries) and Alfvén layer, iii) between the diffuse luminosity (precipitation) poleward of the $\mathrm{AO}$ (at latitudes between the $\mathrm{b} 5$ and $\mathrm{b} 6$ boundaries) and PSBL (Galperin and Feldstein, 1996; Feldstein and Galperin, 1996). Such a relationship is used in our manuscript to define the source (and/or plasma domain) of particles precipitating into the upper atmosphere and to describe the corresponding precipitation regime.

The special sensor for ions, electrons, and scintillation (SSIES) provides measurements of the horizontal plasma flow and ion density at a rate of 6 samples per second. The triaxial fluxgate magnetometer (SSM) measures three components of the magnetic field vector at a rate of 12 readings per second. The spacecraft' axes are aligned such that $\mathrm{X}$ is downward and aligned to local vertical within $0.01^{\circ}, \mathrm{Y}$ is parallel to the velocity vector for the spacecraft with ascending node in the afternoon/evening sector, and $\mathrm{Z}$ is away from the solar panel and anti-parallel to the orbit normal vector.

The method used to derive field-aligned currents from magnetic field measurements is as follows. The main geomagnetic field determined from the IGRF model is subtracted from the magnetometer measurements leaving the local deflection vector, $\Delta B$. Both $\Delta B_{z}$ and $\Delta B_{y}$, indicate the presence of the FAC. If the current sheet extends in an east-west direction, the satellite crosses it perpendicularly and $\Delta B_{y}$ is small, and $\Delta B_{z}$ gives a measure of the intensity and direction of the FAC. Positive and negative gradients in $B_{z}$ indicate the satellite crossings of sheets with downward and upward flowing $\mathrm{FAC}$, respectively.

4.2 Latitudinal cross sections of the magnetic disturbance vector and boundaries of plasma regions of auroral precipitation to ionospheric altitudes

The interrelationship between the centre location, the poleward and equatorward boundaries of the electrojets and the 
characteristic regions of auroral precipitation under different geophysical conditions and various levels of disturbances are considered in this subsection. The latitudinal variations of the horizontal $\Delta H$ and vertical $\Delta Z$ components of the geomagnetic field along the IMAGE chain (at 16:30 UT, i.e. 19:30 MLT) during the substorm recovery phase, with maximal $\mathrm{AL}=-500 \mathrm{nT}$ at 16:10 UT on 24 September 1998, can be seen in Fig. 5 (bottom).

The centres of the EE and WE overlap latitudinally and are indicated by vertical arrows (upward and downward, respectively) at CG latitudes of $65.5^{\circ}$ and $74^{\circ}$. The maximum intensities of the electrojets are $100 \mathrm{nT}$ and $-160 \mathrm{nT}$. The EE poleward and equatorward boundaries are located at $70^{\circ}$ and $62.5^{\circ}$. The DMSP F14 passed above the magnetometer chain about 16:43 UT. Such a favourable situation to compare data on magnetic and plasma observations in the evening sector is possible only once every $24 \mathrm{~h}$ since the satellite orbit is fixed in local time and the magnetometer chain changes its location continuously due to the Earth's rotation. The boundaries of plasma regions, according to DMSP F14 data (passed above the auroral region at 16:39-16:46 UT, $\sim 20: 00$ MLT), are indicated in Fig. 5 (top). In the figure the dashed vertical lines depict the precipitation boundaries b1i and b2i.

In the evening sector the EE equatorward boundary is close to the b1i boundary (63.0 $0^{\circ}$ MLAT) and b1i is usually located equatorward of b1e. The difference between the b1i and the ble location is $1.3^{\circ}$ MLAT for this event. The EE centre is located close to b2e $\left(65.6^{\circ}\right.$ MLAT). The poleward boundary of the auroral plasma precipitation b6 $\left(73.2^{\circ}\right.$ MLAT) corresponds to the WE centre. In other words, for this event both electrojets in the evening sector were located in the region of particle precipitation. However, the EE location corresponds to the region of diffuse precipitation (equatorward of b2e up to b1i) and partially to the region of discrete precipitation. This is identical to the equatorward part of the $\mathrm{AO}$ of discrete auroral forms (poleward of b2e). This part of the AO is mapped to the earthward part of the CPS. The WE is located in the poleward part of the precipitation region that is magnetically connected with the CPS.

The DMSP F13 pass, which accurred approximately over the GWC chain at 19:49-19:56 UT (18:06 MLT), found that the b1i, b1e, b2e and b6 were located at $63.7^{\circ}, 64.5^{\circ}, 67.9^{\circ}$, and $79.2^{\circ}$ MLAT, respectively. In other words:

- the EE and WE are located entirely in the particle precipitation region;

- the EE equatorward part is located at latitudes of diffuse precipitation (between b1i and b2e), whereas the EE poleward part is in the region of weak discrete precipitation;

- the WE is entirely located in the region of intense discrete precipitation, which is evidence of different magnetospheric sources for the EE and WE;

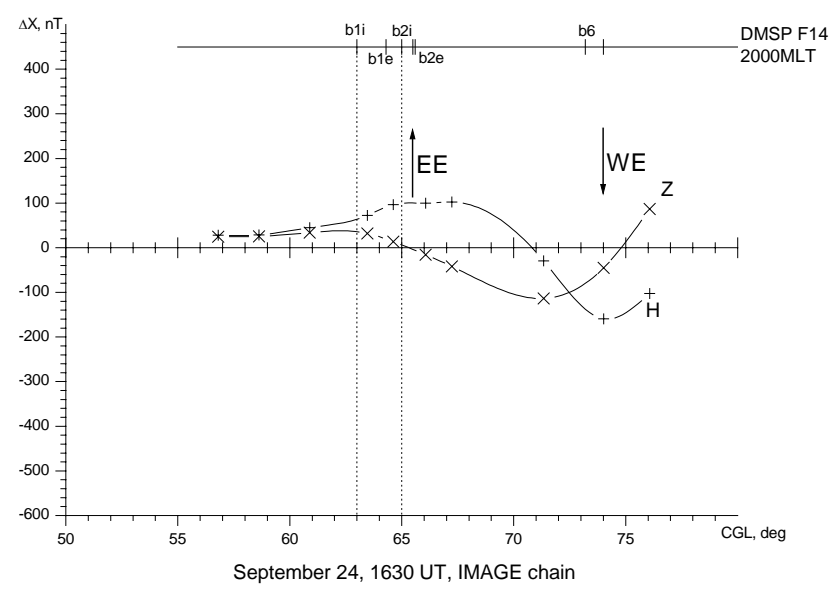

Fig. 5. Latitudinal cross sections of the magnetic disturbance $H$ and $Z$ components for the IMAGE chain at 16:30 UT on 24 September 1998 (bottom panel). The boundaries of particle precipitation regions within the close UT interval (top panel). Measurements from the DMSP F14 pass over auroral latitudes at 20:00 MLT were used. Dashed vertical lines depict the equatorward boundary b1i of auroral particle precipitation region and b2i magnetically mapped to the inner boundary of the magnetospheric tail current sheet.

- the boundary of particle convection from the magnetotail plasma sheet is closer to the Earth for ions than for electrons.

The interrelationship between electrojets and plasma precipitation during the 25 September magnetic storm is displayed in Figs. 6 and 7. In Fig. 6 the DMSP F13 pass at 12:4812:55 UT (about 17:00 MLT, i.e. the early evening sector) corresponds to the beginning of the $D_{s t}$ rapid recovery after the storm main phase. The latitudinal cross section of IMAGE during the intense substorm with $\mathrm{AL} \approx-1500 \mathrm{nT}$ (Fig. 6, bottom) reveals a wide EE (maximum $\Delta H \approx 390 \mathrm{nT}$ ). Its centre is at $\sim 63^{\circ} \mathrm{CG}$ latitude, and the equatorward boundary at $57.5^{\circ} \mathrm{CG}$ latitudes, respectively. The EE polar boundary is not defined using data from the latitudinal cross section of the magnetic field variations, since the EE adjoins the PE (with the same current direction) at the high-latitude boundary. The negative extreme value $\Delta H$ was $\sim-400 \mathrm{nT}$ at $73-76^{\circ}$ CG latitude. In Fig. 6 (top) the location of the boundaries (MLAT) can be seen: b1 $\mathrm{i}=59.5^{\circ}, \mathrm{b} 1 \mathrm{e}=59.8^{\circ}, \mathrm{b} 2 \mathrm{i}=61.7^{\circ}$, $\mathrm{b} 2 \mathrm{e}=63.8^{\circ}, \mathrm{b} 5 \mathrm{e}=69.4^{\circ}$, and $\mathrm{b} 6=70.5^{\circ}$. Hence, the particle precipitation is fully inside the EE, namely the equatorward part is between $b 2 e$ and b1e, and the poleward one is between b2e and b5e. The EE centre corresponds to the b2e boundary.

The location of the westward equivalent current coincides with the region of decreased energy flux of precipitating electrons (the flux of auroral ions is very low) within the narrow latitudinal strip (between b5e and b6), poleward of b5e. Moreover, the main part of the westward current is located poleward of b6, i.e. in the PC with extremely low ionospheric 


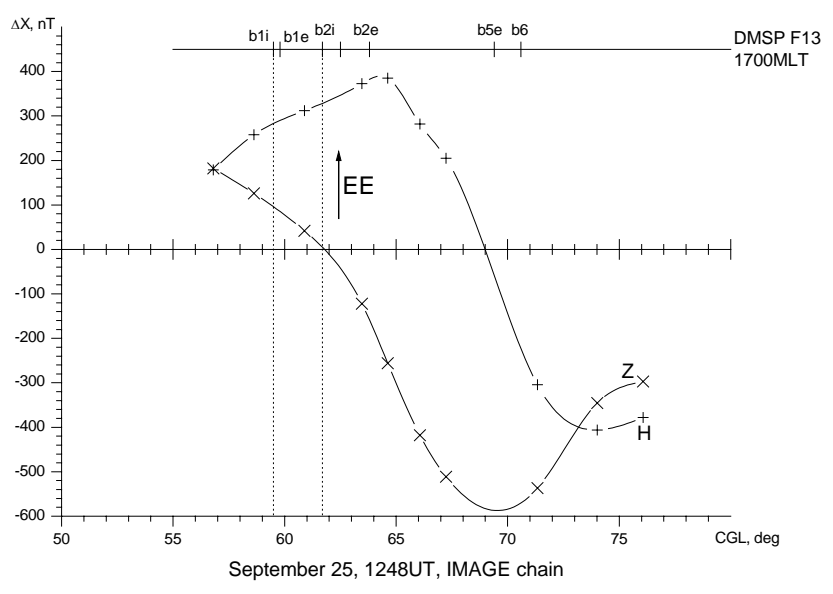

Fig. 6. As Fig. 5, but at 12:48 UT on 25 September 1998. Measurements from the DMSP F13 pass over auroral latitudes at 17:00 MLT.

conductivity values. This means that the equivalent current is likely to be due to distant magnetospheric sources.

In Fig. 7 the situation on 25 September at 16:28-16:37 UT (DMSP F14, evening sector 20:00 MLT), corresponding to the end of the $D_{s t}$ rapid recovery phase can be followed. According to the $\Delta H$ and $\Delta Z$ profiles (bottom), two electrojets exist simultaneously: the EE centred at $60^{\circ} \mathrm{CG}$ latitude and poleward /equatorward boundaries at the $63^{\circ} / 58^{\circ} \mathrm{CG}$ latitude and the WE with its centre at the $74^{\circ} \mathrm{CG}$ latitude and equatorward boundary at the $71^{\circ} \mathrm{CG}$ latitude (the poleward one, located at the $>76^{\circ} \mathrm{CG}$ latitude, is outside the magnetometer chain). The brief poleward spreading of the WE is a consequence of the substorm development (see Fig. 3). The WE intensity in its centre $(\Delta H=-540 \mathrm{nT})$ exceeds the AL value. Hence, when calculating the AL index the field variations at latitudes outside of the standard longitudinal chain of observatories need to be taken into account.

In comparison with the WE the EE intensity, maximising at $46 \mathrm{nT}$, is substantially weaker and the current weakens monotonically equatorward from the electrojet centre. The levels of auroral disturbances (AU and AL) on 24 and 25 September at 16:00 UT are approximately equal. However, in the evening sector the EE centre on 25 September was shifted more equatorward (of $\sim 5^{\circ}$ ) than on 24 September, due to the different $\Delta$ Hsym variation intensities, namely $86 \mathrm{nT}$ and $-20 \mathrm{nT}$ on 25 and 24 September. The location of the EE centre and its equatorward shifting obtained for the 24-25 September magnetic storm is in accord with the results reported for other storms (Feldstein et al., 1996).

The location (MLAT) of the precipitation boundaries obtained from the DMSP F14 satellite pass directly above the magnetometer chain during 16:28-16:37 UT ( $20: 00$ MLT) is: $\mathrm{b} 1 \mathrm{i}=55.5^{\circ}, \mathrm{b} 1 \mathrm{e}=55.8^{\circ}, \mathrm{b} 2 \mathrm{i}=61.7^{\circ}, \mathrm{b} 2 \mathrm{e}=62.5^{\circ}, \mathrm{b} 5 \mathrm{e}=77.9^{\circ}$, and $b 6=80.1^{\circ}$. It is important to stress that the b1e and b1i locations for this DMSP pass are consistent with earlier observations during times when the Alfvén layer boundary lo-

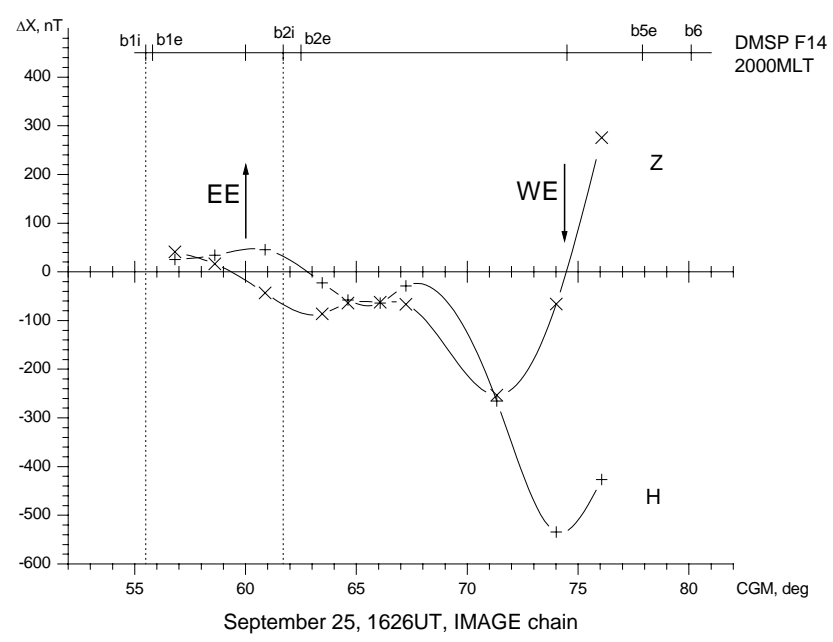

Fig. 7. As Fig. 5, but at 16:26 UT 25 September 1998. Measurements from the DMSP F14 pass over auroral latitudes at 20:10 MLT

cation for ions is equatorward of that for electrons. Between the $b 6$ and b5e boundaries the soft diffuse electron precipitation from PSBL, characteristic of the Polar Diffuse Zone (PDZ), is observed. The auroral precipitation regions span latitudes of both electrojets. The latitudes of diffuse precipitation (between b1e and b2e) and the latitudes of the AO (up to its boundary b5e) correspond to the $\mathrm{EE}$ and $\mathrm{WE}$, respectively.

In the morning sector, as a rule, only the WE exists. It was impossible to follow the precipitation structure just above the electrojet for the September magnetic storm, since the DMSP orbits were oriented in the evening-morning direction during 24-25 September. In Fig. $8 \Delta H$ and $\Delta Z$ variations along the IMAGE chain at 00:24 UT (03:30 MLT, $D_{s t}=-$ $4 \mathrm{nT}$ ) can be seen. The WE, with its centre at $68^{\circ} \mathrm{CG}$ latitude, poleward and equatorward boundaries of $74^{\circ}$ and $65^{\circ}$ CG latitude, and intensity of $\Delta H \sim-1000 \mathrm{nT}$, is characteristic for the intense substorm of $\mathrm{AL} \sim-1000 \mathrm{nT}$. The plasma boundary locations (MLAT), according to DMSP F14 data at 01:06-01:14 UT (20:30 MLT), are also shown (Fig. 8, top): $\mathrm{b} 1 \mathrm{i}=59.7^{\circ}, \mathrm{b} 1 \mathrm{e}=59.9^{\circ}, \mathrm{b} 2 \mathrm{i}=62.5^{\circ}, \mathrm{b} 2 \mathrm{e}=63.4^{\circ}$, and $\mathrm{b} 6=80.8^{\circ}$. The westward equivalent current is located within the entire region of auroral precipitation. Weak, positive $\Delta H$ variations on the equatorward boundary of the magnetometer chain, close to the Alfvén layer boundary, are not associated with precipitation.

During the storm development the WE location is observed at gradually lower latitudes. Data from the IMAGE chain at 02:10 UT on 25 September $\left(D_{s t}=-85 \mathrm{nT}\right)$ show the WE centre to be at $61.5^{\circ} \mathrm{CG}$ latitude. The location of the poleward and equatorward electrojet boundaries are $65^{\circ}$ and $57^{\circ} \mathrm{CG}$ latitude, respectively, which is as much as $7^{\circ}$ more equatorward, compared to 00:24 UT. For the next hours, when the ring current increases, the WE intensity along the IMAGE meridian decreases since the chain moves into the 


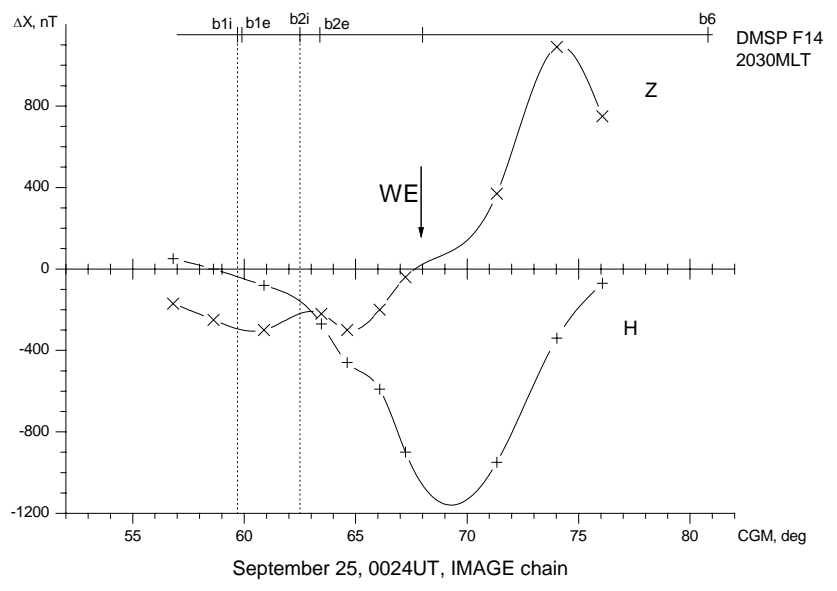

Fig. 8. As Fig. 5, but at 00:24 UT 25 September 1998. Measurements from the DMSP F14 pass over auroral latitudes at 20:30 MLT.

dawn sector. The ring current reaches its maximum during 06:00-08:00 UT on 25 September when the CANOPUS chain shifts to the midnight-dawn sector. For this time interval the CANOPUS data finds the maximum WE intensity at the latitude of the most equatorial station, Pinawa $\left(60.7^{\circ}\right.$ CG latitude). After 07:00 UT, when no intense substorms are present, the WE centre is located at $\Phi<60.7^{\circ} \mathrm{CG}$ latitude.

In Fig. 9 the location of both the EE (its centre and boundaries) and corresponding particle precipitation boundaries during the magnetic storms on 6 February 1994 and 10 May 1992 is shown ( 2 top panels). The data used in this figure were obtained by Feldstein et al. (1999) in their study of the interrelationship between electrojet dynamics and the auroral precipitation structure. In Fig. 9 ( 2 bottom panels) the WE location is also shown in a similar way. The measurements for intervals, when DMSP F8 passed over the IMAGE chain, were analysed and data from three Russian observatories were added (to cover the latitudes to $51^{\circ} \mathrm{CG}$ latitude). The 6 February magnetic storm was moderate but the second one on 10 May was severe. For this storm the equatorward shifting of the centres of both electrojets (EE and WE) is in accord with earlier results (Feldstein et al., 1996, 1997, 1999).

For storms with different intensity the EE covers a narrow band of $4^{\circ}-7^{\circ}$ in the equatorward part of a wide latitudinal interval (of $17^{\circ}-19^{\circ}$ ) of auroral precipitation. The EE centre is located between b2i and b1i (i.e., in the inner magnetosphere between the plasmapause and the tail current sheet boundary). The EE equatorial boundary practically coincides with b1i and the poleward boundary coincides with b2i (b2e). Thus, at ionospheric altitudes in the dusk sector, the EE comprises the region of diffuse auroral particle precipitation. It is mapped along magnetic field lines into the inner magnetosphere between the plasmapause and inner CPS boundary. Most of the particle energy flux intrusion into the ionosphere is at higher latitudes than the EE.
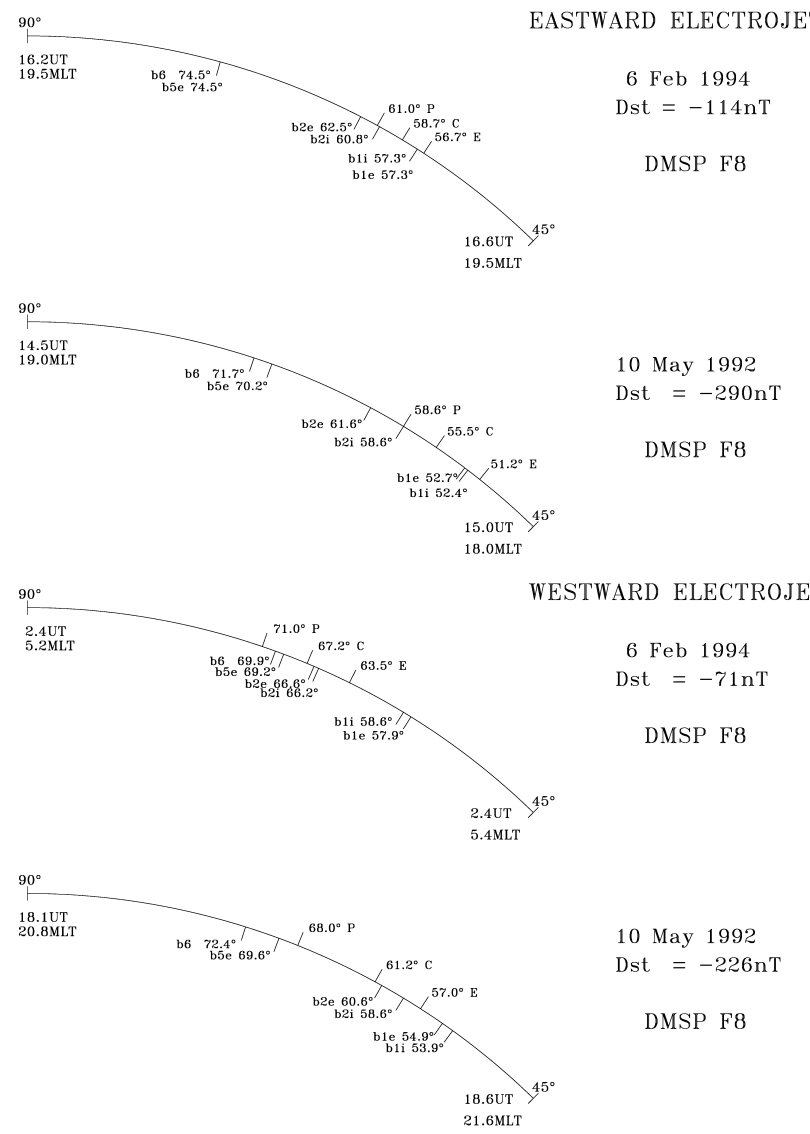

Fig. 9. Comparison of the location of auroral electrojets (their polar, P, and equatorial, E, boundaries, and centre, C) and particle precipitation boundaries (b1e, b1i, b2i, b2e, b5e, and b6) during the moderate (6 February 1994) and severe (10 May 1992) magnetic storms: the eastward (first and second panels) and westward (third and forth panels) electrojets. Corresponding UT and MLT for the electrojets according to IMAGE chain are indicated to the left and those for the precipitation boundaries during the DMSP F8 passes over electrojets are indicated to the right (each panel). The latitudinal range considered is $45^{\circ}-90^{\circ} \mathrm{CG}$ latitude. Hourly $D_{s t}$ values correspond to a given UT.

The WE is located along the AO (between b2e and b5e). The WE centre is positioned near the b2e boundary but a little poleward $\left(0.6^{\circ}\right)$, whereas the poleward and equatorward WE boundaries are located in the vicinity of b5e and b2i, respectively. Thus, the WE projection in the magnetosphere nightdawn sector is located in the CPS at greater geocentric distances than the magnetospheric projection of the ionospheric particle precipitation boundaries ble and b1i.

The results of the analysis of latitudinal variations of the geomagnetic field $\Delta H$ and $\Delta Z$ components, measured along the magnetometer chains with regard to the auroral (electrons and ions) precipitation structure (DMSP data), can be summarized with regard to evening/morning sectors: 


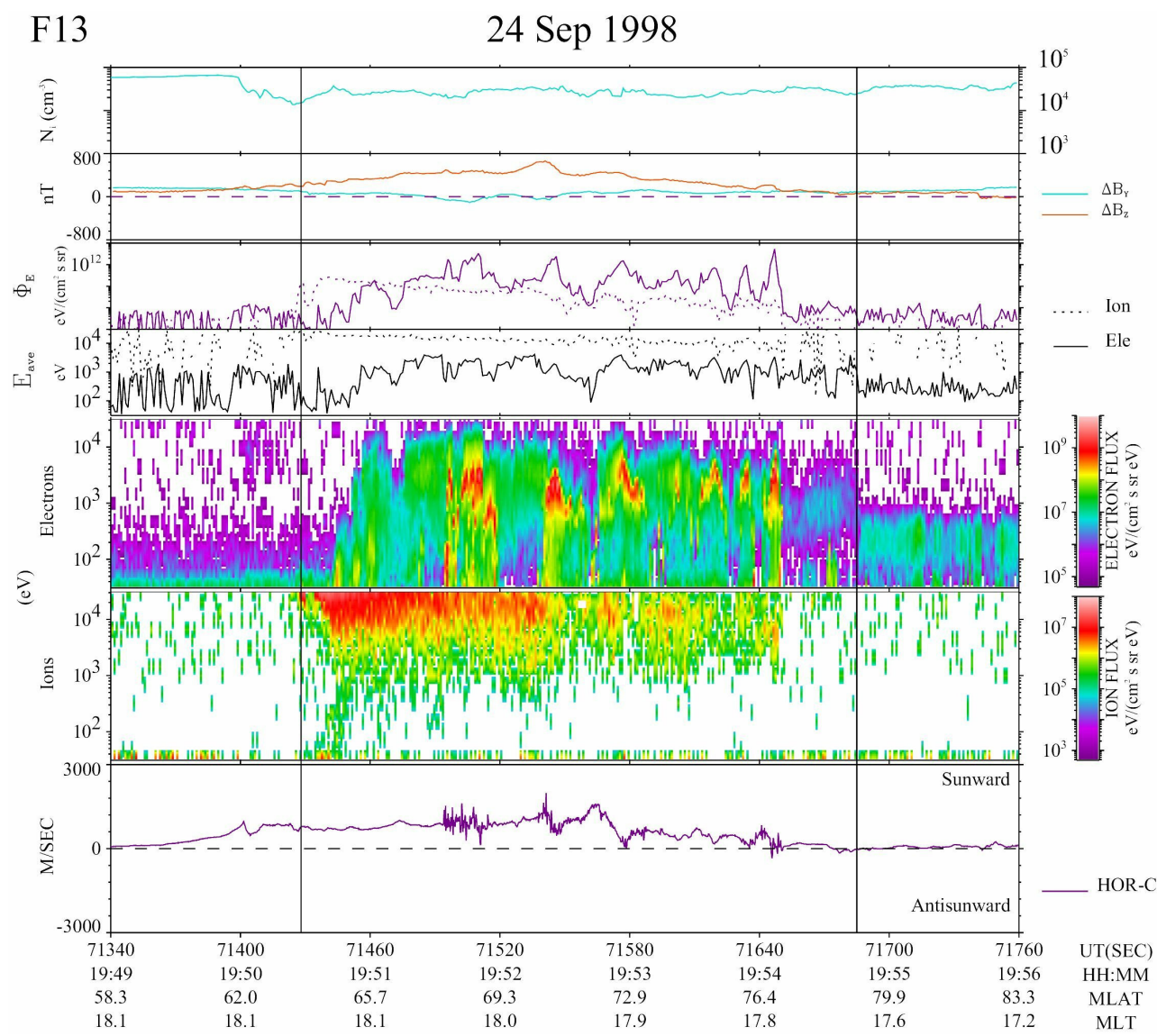

Fig. 10. Plasma measurements within the 19:49-19:56 UT interval on 24 September 1998 from the DMSP F13 pass over auroral latitudes. From top to bottom: ion density (first panel); variations of the magnetic field east-west $\left(B_{z}\right.$, brown) and north-south ( $B_{y}$, green) components (second panel); energy flows and mean energy of electrons and ions (third and fourth panels); energy spectrograms of electrons and ions (fifth and sixth panels); plasma drift velocity (seventh panel).

In the evening sector when the EE and WE are latitudinally overlapping:

- the EE is located entirely in the auroral plasma precipitation region: the equatorward part of the electrojet is located at latitudes of diffuse precipitation between the b1i and b2e, whereas the narrow poleward part is in the region of discrete precipitation;

- the EE centre corresponds to the b2e boundary;

- the Alfvén layer boundary for ions (b1i) is usually located equatorward of that for the electrons (b1e);

- the WE is located in the region between the AO boundary b5 and the PC boundary b6.

In the morning sector where only the WE exists:

- the westward current is located within the entire region of auroral plasma precipitation;
- the WE is located between the b2e and the b5e boundaries at latitudes of maximum energy fluxes of auroral electrons.

4.3 Particle precipitation, field-aligned currents, and polarization jets in the ionosphere

4.3.1 The inner magnetosphere during a magnetospheric substorm

We first consider the electromagnetic and plasma conditions before the beginning of the 25 September 1998 magnetic storm using DMSP F12-F14 data. The DMSP F12-F14 spectrograms in Figs. 10-14 include (from top to bottom): (1) plasma density $(N i)$, (2) magnetometer $\Delta B_{z}$ and $\Delta B_{y}$ measurements, (3) electron and ion integral energy flux, (4) electron and ion average energy, (5) precipitating electron spectrogram, (6) precipitating ion spectrogram, (7) crosstrack horizontal plasma drift. The vertical lines depict the equatorward (b1i) and polar (b6) boundaries of the auroral precipitation region. 
In Fig. 10 data from the DMSP F13 pass on 24 September 1998 (19:49-19:56 UT) are shown from a time of a substorm with AL $-550 \mathrm{nT}$. At $18.1 \mathrm{MLT}$ the bli precipitation boundary $\left(63.7^{\circ} \mathrm{MLAT}\right)$ is located within the ionospheric trough where the cold plasma density minimises. The trough is outside of the plasmapause. The radial size of the plasmasphere is determined by a marked increase in the magnetospheric convection velocity. The convection velocity in the evening sector is sunward for all the DMSP F13 passes and increases to $V \sim 1 \mathrm{~km} / \mathrm{s}$ at MLAT of $\sim 63^{\circ}$.

The recovery of the total ion density occurs at latitudes of ion precipitation (poleward of the b1i) and then continues poleward of the electron precipitation boundary b1e $\left(64.5^{\circ}\right.$ MLAT). At latitudes of structured electron precipitation (the CPS regime) the large amplitude oscillatory fluctuations of convection velocity are observed (Fig. 10). When DMSP F13 moves to the PC (the b6 boundary at $79.2^{\circ}$ MLAT) the convection velocity decreases to the level measured at subauroral latitudes.

The satellite magnetic field data indicate a quite simple system of large-scale FACs: at $62^{\circ}<\mathrm{MLAT}<70^{\circ}$ there is a downward current and at $70^{\circ}<\mathrm{MLAT}<78^{\circ}$ the current is upward. Some smaller scale changes of FAC superposed on the large-scale currents are associated with electron precipitation.

FACs are responsible for electrodynamic connection between different plasma regions of the near-Earth environment (a source of global ionospheric current systems) which are detectable in variations of the magnetic field on the Earth's surface. The FACs and the corresponding magnetic disturbances are especially intense during magnetospheric substorms and magnetic storms.

The current flowing into the ionosphere (Region 2 FAC) can be seen first in the ionospheric trough equatorward of the region that separates boundaries of ion and electron precipitation. In between the precipitation boundaries of differently charged particles, no increase in the drift velocity (i.e. no enhancement of the electric field) was registered. According to GWC meridian magnetometer data the EE location corresponds to the Region 2 FAC at a given UT. The Region 1 FAC with outflowing current is located poleward up to the highlatitude boundary of the CPS regime, i.e. in the region of the auroral electron precipitation. According to GWC data, there is the WE at very high latitudes during these evening hours.

If the field-aligned current is assumed to flow on an infinite 2-D plane surface oriented east-west and the magnetic field variations measured by DMSP are caused by FAC only, then the current density $j_{\| \mid}$can be determined from the following relationship:

$\frac{d \Delta B_{z}}{d x}=\mu_{0} j_{\|}$,

where $\mu_{0}=4 \pi \times 10^{-7} \mathrm{H} / \mathrm{m}$ is the magnetic permeability in vacuum. The current sheets are approximately oriented along magnetic shells with the east-west directions as seen in
Fig. 10 for the DMSP F13 pass. Actually, this is confirmed by the substantially smaller (up to few times) gradient of the north-south field in comparison with east-west field gradient:

$\frac{d \Delta B_{y}}{d x}<\frac{d \Delta B_{z}}{d x}$.

The magnetic field variations associated with FAC during this substorm interval are $\Delta B_{z} \sim 700 \mathrm{nT}$ and $\Delta B_{y} \sim 300 \mathrm{nT}$. Under the assumptions above the current densities of inflowing (Region 2) and outflowing (Region 1) FAC are $0.37 \mu \mathrm{A} / \mathrm{m}^{2}$ and $0.54 \mu \mathrm{A} / \mathrm{m}^{2}$, and the linear currents densities are $0.45 \mathrm{~A} / \mathrm{m}$ and $0.45 \mathrm{~A} / \mathrm{m}$, respectively.

4.3.2 The inner magnetosphere at the beginning of the storm main phase

The DMSP F14 pass on 25 September 1998 at 02:4702:53 UT, i.e. 19:30 MLT (Fig. 11) is related to the beginning of the storm main phase when $\mathrm{AL}=-750 \mathrm{nT}$ and Sym-H $=-80 \mathrm{nT}$. The latitudes of the Alfvén layer boundaries for ions and electrons, b1i and b1e, are practically identical (54.8 MLAT) and located in the ionospheric trough, just near the minimum of the plasma density. At the same subauroral latitudes $\left(53^{\circ}<\mathrm{MLAT}<55^{\circ}\right)$ a velocity burst of sunward convection $(\sim 2 \mathrm{~km} / \mathrm{s})$ was registered. Moreover, in addition to this burst, a structured velocity burst of sunward convection $(>4 \mathrm{~km} / \mathrm{s})$ was observed at $61^{\circ}<\mathrm{MLAT}<63^{\circ}$.

The velocity burst of convection at subauroral latitudes is characteristic for the generation of the PJ or SAPS during magnetic storms. The PJ (Galperin et al., 1974; Galperin, 2002) or SAPS (Foster and Burke, 2002; Foster and Vo, 2002) is a composite part of a magnetic storm. During the storm main phase the fast (with drift velocities of several $\mathrm{km} / \mathrm{s}$ ) westward ion convection is observed at altitudes of the ionospheric F-layer (at a few hundred $\mathrm{km}$ ). The electric field (tens of $\mathrm{mV} / \mathrm{m}$ ) corresponding to the SAPS appears not far from the equatorward boundary of diffuse auroral precipitation during the magnetic storm.

The main (more intense) convection velocity burst is associated with the auroral precipitation from the CPS regime (poleward of its equatorial boundary b2e at $61.7^{\circ}$ MLAT). Poleward of this precipitation, the antisunward convection, with velocities of $\sim 600 \mathrm{~m} / \mathrm{s}$, is observed. This convection is near the PC boundary b6 (68.4 $4^{\circ}$ MLAT) in the region of soft diffuse electron precipitation in the PDZ.

At the beginning of the storm main phase DMSP observes a magnetic effect of $\Delta B_{z}$ to $\sim 1400 \mathrm{nT}, \Delta B_{y}$ to $\sim 500 \mathrm{nT}$, due to Region 1 and Region 2 FAC (Fig. 11). Those FACs flow in a sheet deflected $24^{\circ}$ northward relative to the eastwest direction. The inflowing Region 2 and outflowing Region 1 current densities can be approximated with the average values $0.65 \mu \mathrm{A} / \mathrm{m}^{2}$ and $3.1 \mu \mathrm{A} / \mathrm{m}^{2}$, the linear current densities are $0.79 \mathrm{~A} / \mathrm{m}$ and $1.03 \mathrm{~A} / \mathrm{m}$. The current density in Region 2 varies substantially with latitude, with its magnitudes of $0.39 \mu \mathrm{A} / \mathrm{m}^{2}$ at $52.4^{\circ}<\mathrm{MLAT}<57.4^{\circ}, 2.96 \mu \mathrm{A} / \mathrm{m}^{2}$ at 


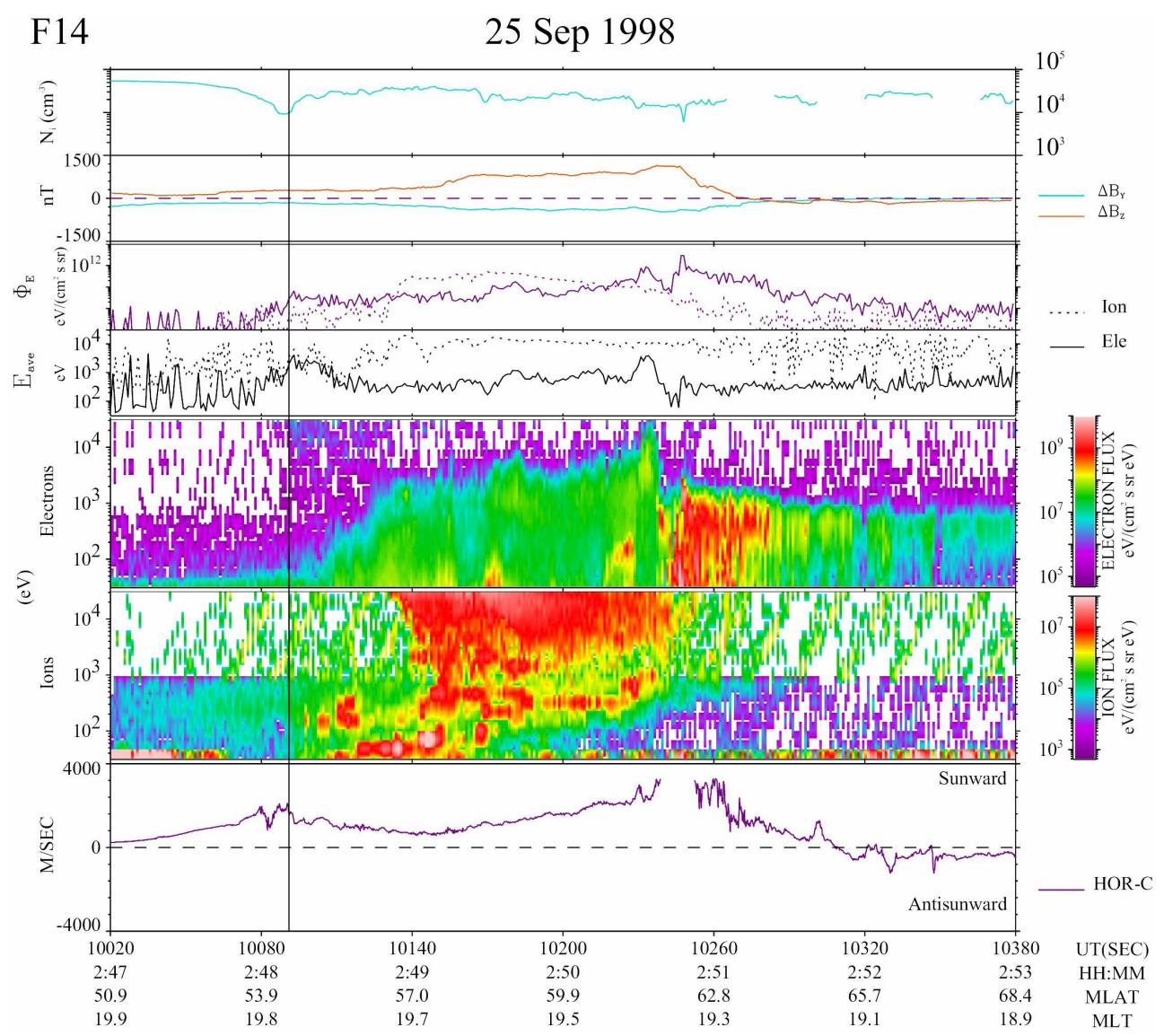

Fig. 11. As Fig. 10, but within the 02:47-02:53 UT interval on 25 September 1998 from the DMSP F14 pass over auroral latitudes.

$57.4^{\circ}<$ MLAT $<58.3^{\circ}, 0.1 \mu \mathrm{A} / \mathrm{m}^{2}$ at $58.3^{\circ}<\mathrm{MLAT}<61.4^{\circ}$, $2.48 \mu \mathrm{A} / \mathrm{m}^{2}$ at $61.4^{\circ}<\mathrm{MLAT}<61.9^{\circ}$. The Region 1 and Region 2 currents are located at latitudes with sunward convection and are regions of precipitation from the Alfvén layer and CPS regimes. Poleward of the Region 1 FAC at latitudes $66^{\circ}<$ MLAT $<68.4^{\circ}$ an FAC flowing into the ionosphere is present (Region 3 FAC). Its density is $0.32 \mu \mathrm{A} / \mathrm{m}^{2}$ and linear density is $0.16 \mathrm{~A} / \mathrm{m}$. Magnetic field variations associated with Region 3 currents cause $\Delta B_{z} \sim 200 \mathrm{nT}, \Delta B_{y} \sim 0 \mathrm{nT}$. This current is inflowing at the PDZ latitudes. The triple structure of this FAC is accompanied by a complex structure of ionospheric currents with overlapping EE and WE during evening hours. Actually, along the CANOPUS chain (Gill station, $\Phi=66.8^{\circ}$ ) a westward ionospheric current was observed. Its location was poleward of the eastward current which was observed on stations at lower latitudes. The overlapping of electrojets in the evening sector is accompanied with an increase in the disturbance level and the appearance of the third FAC, inflowing to the ionospheric altitude along the CPS regime periphery.

The SAPS was registered from the beginning of the storm within the interval of the abrupt increase in solar wind pressure. During the DMSP F14 pass on 25 September at 01:05-
01:15 UT (20:30 MLT) (not shown) a velocity burst up to $3.5 \mathrm{~km} / \mathrm{s}$ in the ion drift velocity was observed at latitudes $58.8^{\circ}<$ MLAT $<59.5^{\circ}$, i.e. just in the region of minimum density in the ionospheric trough. The SAPS was located equatorward of the latitudes of diffuse precipitation from the Alfvén layer, adjoining to boundaries b1i $=\mathrm{b} 1 \mathrm{e}=60.0^{\circ}$, identi$\mathrm{cal}$ with the outer edge of the ionospheric trough. The minimum latitude, from which an abrupt increase in the drift velocity starts, is $\sim 56^{\circ}$, where formation of the Region 2 FAC inflowing into the ionosphere takes place. The Region 1 FAC and Region 2 FAC become multilayered. In addition, the Region 3 FAC flowing into the ionosphere appears poleward of the Region 1 FAC at latitudes with diffuse precipitation from the PDZ, $76.9^{\circ}<\mathrm{MLAT}<77.6^{\circ}$.

\subsubsection{The inner magnetosphere near the maximum of the storm main phase}

The characteristic features of the magnetospheric structure become more distinctive at gradually lower latitudes during a developing magnetic storm. The signatures of these features are more intense in comparison with intervals of magnetospheric substorms. In Fig. 12 the results of DMSP F12 observations at 09:04-09:13 UT on 25 September (near 


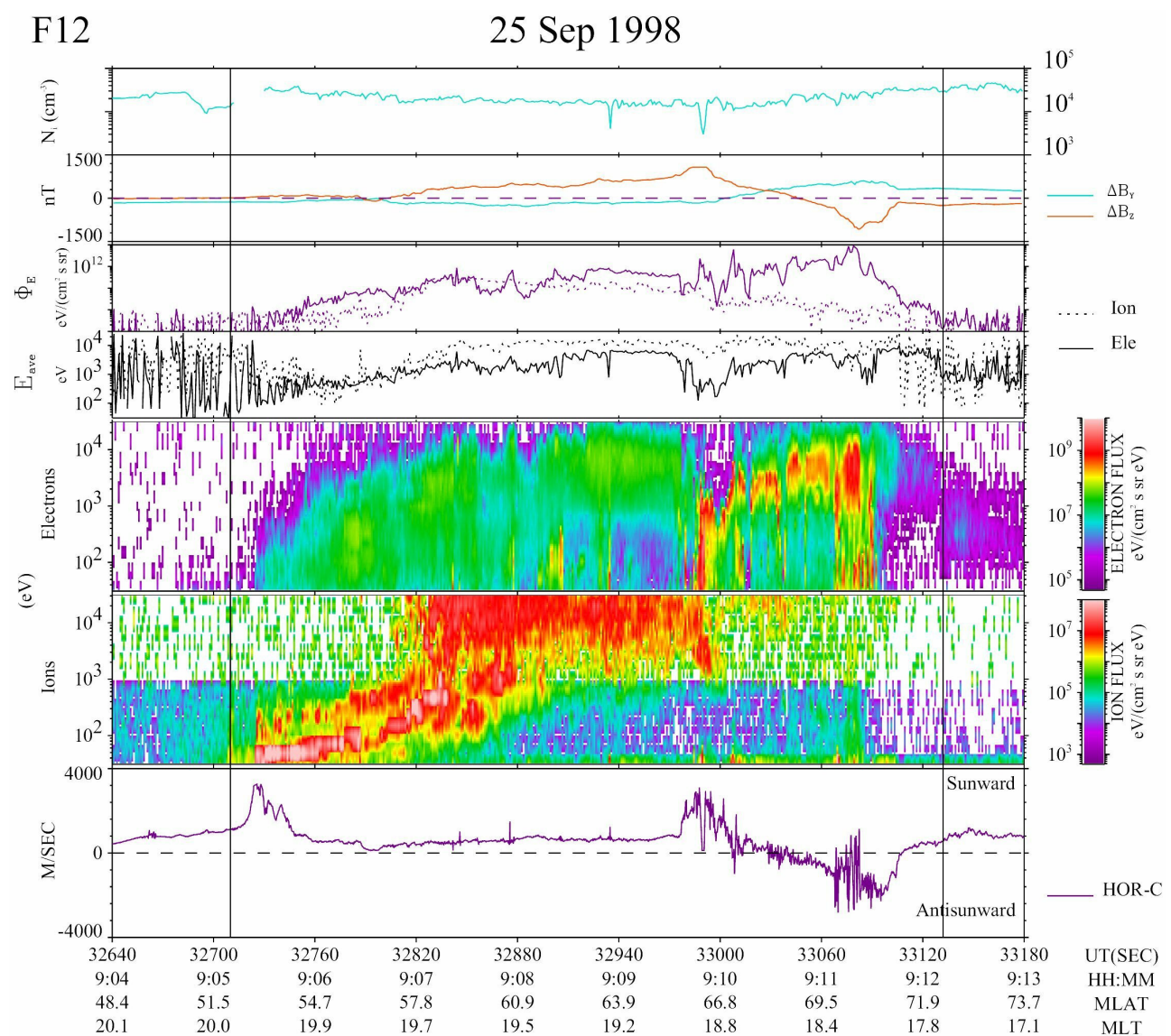

Fig. 12. As Fig. 10, but within the 09:04-09:13 UT interval on 25 September 1998 from the DMSP F12 pass over auroral latitudes.

the main phase maximum) are shown in the evening sector, when $\mathrm{AL}=-1030 \mathrm{nT}$ and Sym-H=-147 nT. The equatorward boundaries of the Alfvén layer regime are located at $\mathrm{b} 1 \mathrm{i}=52.0^{\circ}$ and $\mathrm{b} 1 \mathrm{e}=52.8^{\circ}$. At these subauroral latitudes a velocity burst in the westward ion drift (sunward convection) was observed. The location of maximum drift velocity ( $V \sim 3.4 \mathrm{~km} / \mathrm{s}$ ) coincides with the ble boundary. The equatorward part of the latitudinal interval with the velocity burst is located between b1i and b1e, i.e. in the region mapped to the magnetosphere where the electric field is due to the charge separation. This burst in the sunward convection is superposed on the steady pattern of sunward convection in the Alfvén layer regime $(V \sim 0.7 \mathrm{~km} / \mathrm{s})$. The second burst of sunward convection has irregular velocity variations up to $3 \mathrm{~km} / \mathrm{s}$ and appears at the CPS regime (b2e $=66.0^{\circ}$ ), for which structured electron precipitations are characteristic. In the vicinity of the CPS high-latitude boundary $\left(b 5 e=70.3^{\circ}\right)$ the convection becomes antisunward (Fig. 12). Its maximum velocity $(V \sim 2 \mathrm{~km} / \mathrm{s}$ ) was measured at the diffuse precipitation latitudes known as PDZ, i.e. at $70.3^{\circ}<\mathrm{MLAT}<71.4^{\circ}$. In the $\mathrm{PC}$ the direction of convection changes to sunward again.

The DMSP F14 measurements (19:20 MLT), just 30 min after the DMSP F12 pass, confirm the occurrence of the
SAPS in the evening sector with characteristic features similar to those described above. The two bursts with maximum ion drift velocity of $3 \mathrm{~km} / \mathrm{s}$ were observed at MLAT of $53.6^{\circ}$ and $60.7^{\circ}$. The first velocity burst located at $53.6^{\circ}$ (the b1e boundary) is the SAPS. The Alfvén layer boundary for ions b1i $\left(52.6^{\circ}\right)$ is located equatorward of the b1e. Therefore, the equatorial portion of the SAPS (that occurred equatorward of the burst peak), seen during the passes of both satellites, is located in the latitudinal range between b1i and b1e. The second velocity burst is located within the region of structured precipitation of auroral electrons from the CPS regime.

The magnetic field variations for individual DMSP passes confirm the dominant azimuthal (east-west) orientation of current layers, since $\left|\Delta B_{z}\right|>\left|B_{y}\right|$. The intensity of field variations $\Delta B_{z}$ are $\sim 1.2 \times 10^{3} \mathrm{nT}, \sim 2.2 \times 10^{3} \mathrm{nT}$, and $\sim 0.94 \times 10^{3} \mathrm{nT}$ for the Region $2 \mathrm{FAC}$, Region $1 \mathrm{FAC}$, and Region 3 FAC, respectively (Fig. 12). The triple structure of the large-scale FAC, characteristic for strong disturbed periods, is distinctively identified by the $\Delta B_{z}$ gradients. The mean values of the FAC density and FAC linear density (if non-monotonic field changes in the Region 2 FAC are neglected) are as follows:

Region 1: $3.29 \mu \mathrm{A} / \mathrm{m}^{2}, 1.81 \mathrm{~A} / \mathrm{m}$ 


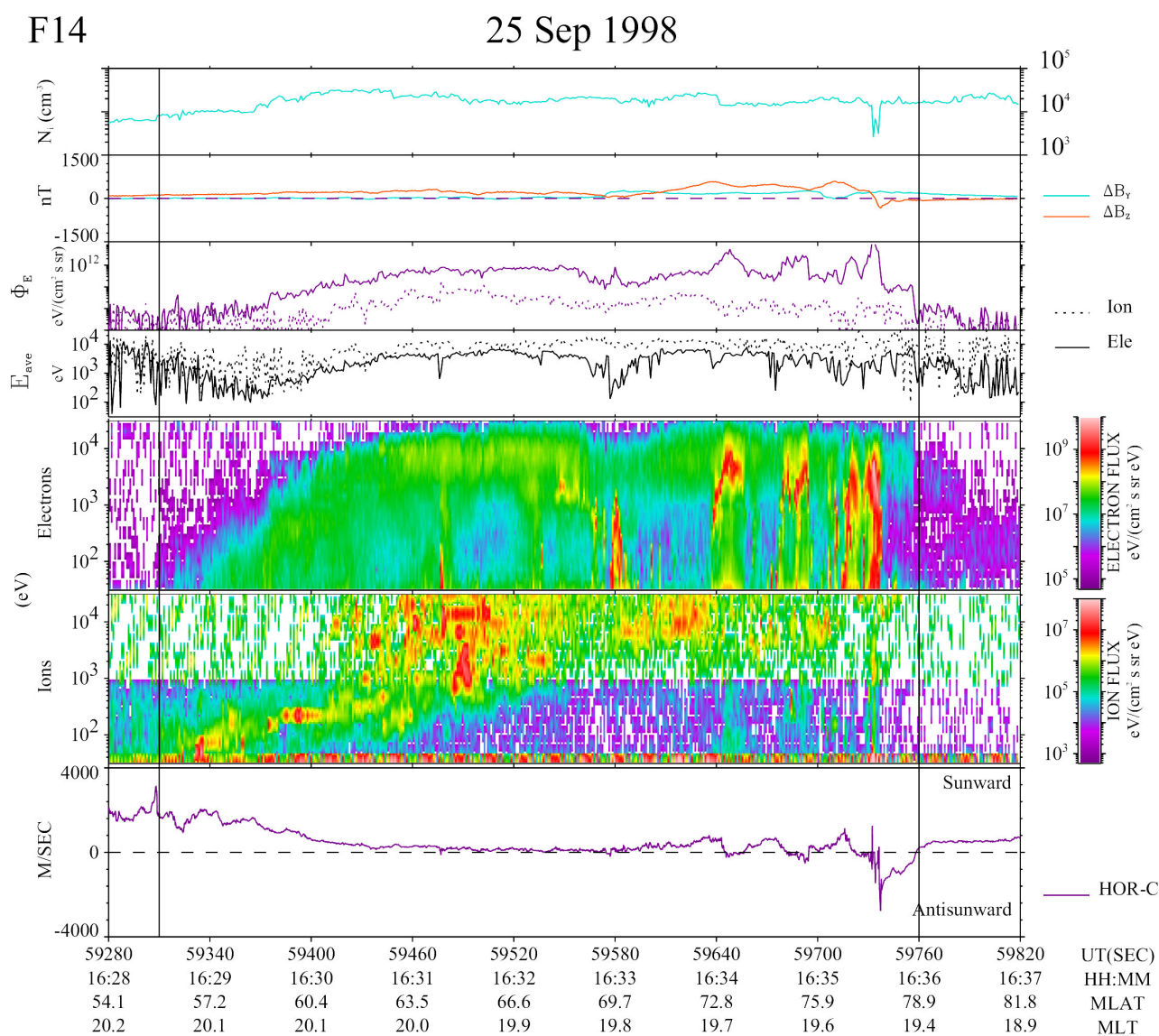

Fig. 13. As Fig. 10, but within the 16:28-16:37 UT interval on 25 September 1998 from the DMSP F14 pass over auroral latitudes.

Region 2: $0.8 \mu \mathrm{A} / \mathrm{m}^{2}, 0.95 \mathrm{~A} / \mathrm{m}$

Region 3: $6.47 \mu \mathrm{A} / \mathrm{m}^{2}, 0.74 \mathrm{~A} / \mathrm{m}$.

The triple structure of the large-scale FAC is closely associated with magnetospheric plasma domains. As mentioned above, the current flows into the ionosphere at Alfvén layer latitudes (Region $2 \mathrm{FAC}$ ), flows away from the ionosphere at CPS regime latitudes (Region 1 FAC), and flows into the ionosphere at PDZ latitudes (Region 3 FAC magnetically mapped to the PSBL at the outer periphery of the CPS).

The $\Delta B_{z}$ changes weakly at SAPS latitudes $\left(52^{\circ}<\right.$ MLAT $\left.<55^{\circ}\right)$, which testifies to rather a low intensity of the FAC at latitudes of the PJ. However, the $\Delta B_{z}$ intensity starts to increase abruptly for latitudes poleward of $56.2^{\circ}$ MLAT (where the SAPS burst ends). Hence, the characteristic appearance of SAPS during the storm main phase is not accompanied by the generation of intense FAC at these latitudes. For the storm analyzed, the densities of the inflowing and outflowing currents at SAPS latitudes are $0.39 \mu \mathrm{A} / \mathrm{m}^{2}$ and FAC linear densities are $0.1 \mathrm{~A} / \mathrm{m}$.

During the magnetic storm in the evening sector, the inflowing Region 2 FAC is located equatorward of the outflowing Region 1 FAC. Such a configuration of the FAC is favourable for the existence of both a poleward-directed elec- tric field and an eastward ionospheric current. However, during the storm main phase, the FAC system Region 3-Region 1 is favourable for the appearance of both an equatorwarddirected electric field and a westward ionospheric current. As a consequence, the overlapping of the EE and WE takes places during intense disturbances, which was discussed in Sect. 3 and Sect. 4.2.

4.3.4 The inner magnetosphere during the storm recovery
phase

For the storm analysed, there are two stages in the recovery process to quiet conditions: fast recovery until 16:00 UT and succeeding slow changes of the geomagnetic activity indexes after the main phase. During the first stage the appearance of substorms continues and the interrelationship of the geophysical events resembles that of the storm main phase described in Sect. 4.3.3. However, the intensity of the characteristic features diminishes significantly. This is illustrated by data from the DMSP F14 pass at auroral latitudes on 25 September at 16:28-16:37 UT during the early recovery phase (Fig. 13). As identified, the magnetospheric convection was sunward at latitudes of auroral precipitation 


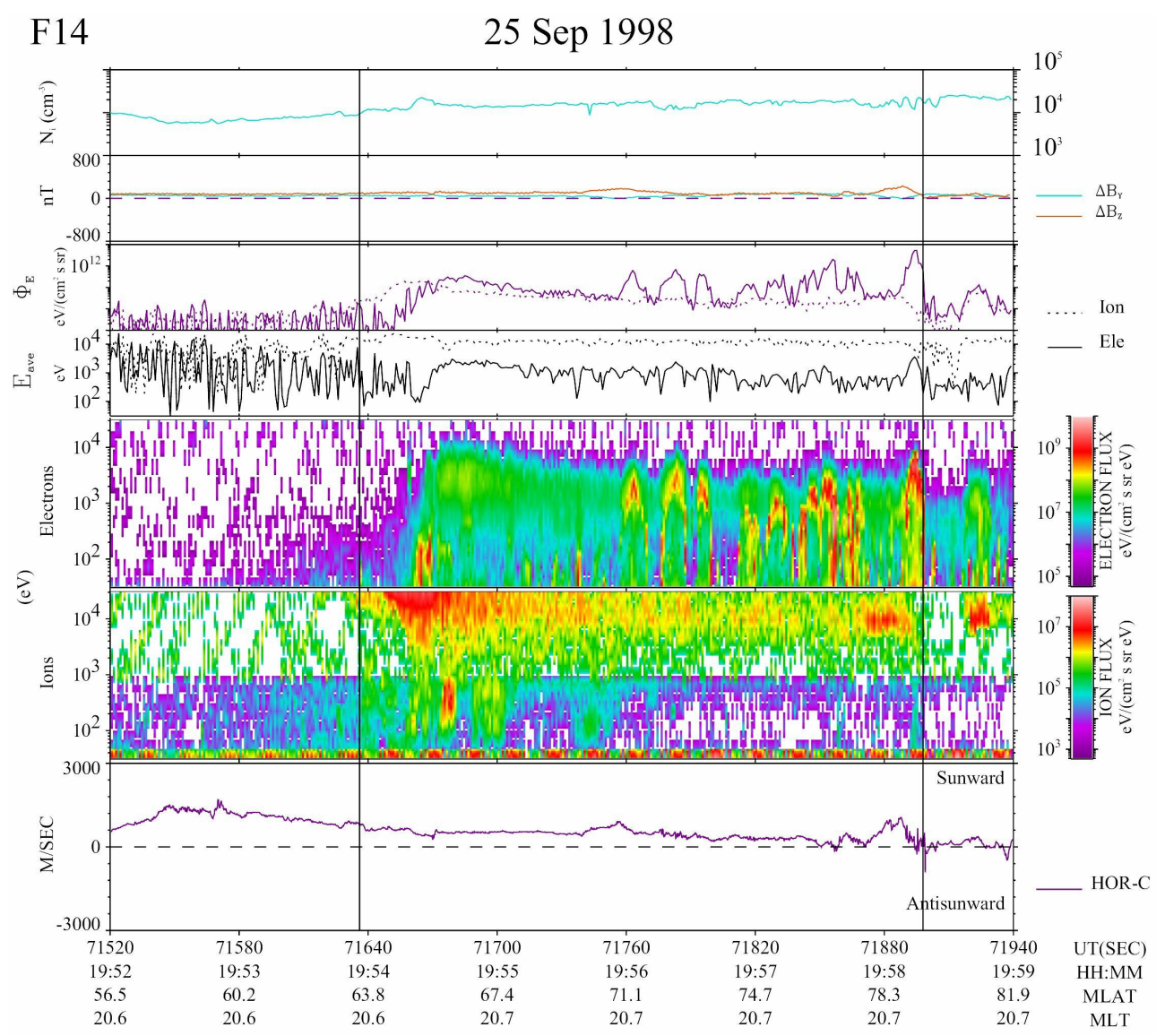

Fig. 14. As Fig. 10, but within the 19:52-19:59 UT interval on 25 September 1998 from the DMSP F14 pass over auroral latitudes.

from the Alfvén layer and the CPS regimes, located between the b1i $\left(55.5^{\circ}\right)$ and $\mathrm{b} 2 \mathrm{e}\left(62.5^{\circ}\right)$ boundaries and between the b2e and b5e $\left(77.9^{\circ}\right)$ boundaries, respectively. The magnetospheric convection was antisunward at latitudes of auroral precipitation from the PSBL regime, i.e. between the b5e and b6 $\left(78.9^{\circ}\right)$ boundaries. The intense velocity bursts in the sunward convection were identified at subauroral latitudes related to the ionospheric trough region $\left(<60^{\circ}\right.$ MLAT) and to intense structured precipitation from the CPS regime $\left(72^{\circ}<\right.$ MLAT $\left.<77.9^{\circ}\right)$. The magnetic field intensity variations in the Region $2 \mathrm{FAC}$ on the b2e boundary were $\Delta B_{z} \sim 300 \mathrm{nT}, \Delta B_{y} \sim 0 \mathrm{nT}$, the FAC density and linear density were $0.13 \mu \mathrm{A} / \mathrm{m}^{2}$ and $0.15 \mathrm{~A} / \mathrm{m}$. Above the PDZ the FAC flows into the ionosphere with density $4.96 \mu \mathrm{A} / \mathrm{m}^{2}$ and linear density $0.25 \mathrm{~A} / \mathrm{m}$. Such features in the FACs are favourable for the appearance of a westward ionospheric current in the evening sector, poleward of the EE.

By 20:00 UT (25 September) signatures of the magnetic storm attenuate in the inner magnetosphere. In Fig. 14 observations during the DMSP F14 pass at 19:52-19:59 UT are shown. As seen, the magnetospheric convection is sunward at all auroral precipitation latitudes. The convection bursts are found at latitudes of structured auroral precipitation. The increase in the convection velocity to $\sim 1.2 \mathrm{~km} / \mathrm{s}$ at the subauroral $\sim 61^{\circ}$ MLAT is of a monotonic character (without any velocity bursts). This is related to latitudes of the ionospheric trough and occurs more equatorward of the b1i $\left(63.6^{\circ}\right)$ and b1e $\left(64.0^{\circ}\right)$ boundaries. The $B_{y}$, and $B_{z}$ magnetic field components and their gradients reveal significant weakening of the FAC in the Region 1 and Region 2, whereas the Region 3 FAC is absent.

The relationship of geophysical phenomena during intense magnetic disturbances can be summarized as follows:

- In the evening sector a triple FAC structure arises. In addition to the Region 1 FAC and Region 2 FAC, the Region 3 FAC (flowing into the ionosphere) appears, located on the poleward boundary of the auroral precipitation region. As a result, the necessary prerequisites for overlapping auroral electrojets are created. At ionospheric latitudes the Region 3 FAC coincides with the PDZ and with the antisunward convection magnetically mapped to the PSBL in the magnetotail (Figs. 11-13).

- During the storm main phase and early recovery phase, the sunward convection is characterized by two velocity bursts of $2-4 \mathrm{~km} / \mathrm{s}$ at distinctive latitudes. The 
burst at subauroral latitudes is located in the ionospheric trough region, at the latitude of the electron precipitation boundary ble or equatorward of it. The FAC flows into the ionosphere at SAPS latitudes with densities $0.39 \mu \mathrm{A} / \mathrm{m}^{2}$ and $0.1 \mathrm{~A} / \mathrm{m}$, i.e. weaker than the Region 2 FAC (Figs. 11, 12).

- As a rule, the SAPSs appear at latitudes of the ionospheric trough, where no ionization is caused by corpuscular radiation (Figs. 11, 13). The direction of the electric field necessary to generate the SAPS in the evening sector is the same as that created by charge separation in the magnetosphere, which appears because of different locations of ion and electron convection boundaries from the magnetotail (b1i is usually closer to the Earth than b1e). This electric field projects along magnetic field lines to the ionospheric altitudes. However, the latitudinal range between b1i and ble is essentially less than the SAPS latitudinal scale but coincides with the latitude of the maximum drift velocity in the SAPS.

\section{Discussion}

The electrojets at high latitudes and a magnetic field depression at low latitudes are characteristic features of the magnetic field variations during magnetic storms. A huge amount of studies exist on space-time development of electrojets, on mechanisms of their generation, and their association with other geophysical phenomena. Therefore a short overview of the most essential paradigms, in the authors' opinion, extended in literature nowadays is presented and then the results obtained are discussed.

\subsection{Presentation of electrojets by means of equivalent iono-} spheric current systems

An equivalent ionospheric current system is usually used for a generalized presentation of the distribution of perturbed geomagnetic field vectors on the Earth's surface. Shown schematically in Figs. 15a, b, c are the current system patterns reported earlier. They can be compared with patterns modified according to our results (Figs. 15d, e). The twovortex classical current system (Fukushima, 1953) (Fig. 15a), the single-vortex system with a WE along the $\mathrm{AO}$ and closure currents through the PC and middle latitudes (Fig. 15b), reported by Feldstein (1963) and Akasofu et al. (1965), and the two-vortex system with a WE within the boundaries of the $\mathrm{AO}$ and with an EE in the evening sector at $\Phi \sim 65^{\circ}$ (Feldstein and Zaitzev, 1965) (Fig. 15c), are widely known. It was concluded that during substorms the WE extends to all longitudes along the $\mathrm{AO}$ and its intensity decreases from midnight to noon hours. The EE, as a separate current system rather than a return current from the WE, is located at $\Phi \sim 65^{\circ}$ in the evening sector.
The modification of these patterns is considered below for substorm and storm intervals. The space-time distribution of currents (ionospheric altitudes) and their structure at high latitudes during the magnetospheric substorm with the intensity of AL $-800 \mathrm{nT}$ is shown in Fig. 15d. The location of the WE (red strip) can be easily seen. Its latitudinal width is $\sim 6^{\circ}$ during midnight-dawn hours. During evening and prenoon hours, the WE extends from subauroral latitudes to the CU. As seen in Fig. 15d the WE does not cover all MLT hours (contrary to Figs. 15b, c) during the substorm, but is seen only within the evening-night-morning hours. During the before-noon and late afternoon hours, the WE adjoins the $\mathrm{CU}$, i.e. is magnetically mapped to the magnetopause. The narrow strip $\left(2^{\circ}-3^{\circ}\right.$ along latitude $)$ of the $\mathrm{PE}$ is located at the latitudes of the ionospheric projection of the CU. The direction and current intensity in the PE is controlled by the IMF $B_{y}$ component. It is likely that the WE continuity over all longitudes (Feldstein, 1963; Akasofu et al., 1965) was obtained because most of the data used was related to IMF $B_{y}<0 \mathrm{nT}$. As a result, the WE and PE currents could not be distinguished and only one current strip was reported. In addition, during substorms, the location of the most intense ionospheric currents is significantly asymmetric with regard to the noon-midnight meridian. In the noon sector the currents are located more poleward $\left(\sim 8^{\circ}\right)$ than in the midnight sector.

The detailed consideration of the interrelation between auroral luminosity, diffuse and structured auroral particle precipitation, FAC and PE during magnetic disturbances in the dayside sector was given by Sandholt et al. (2004). As shown, the strong convection channel is located on the dawn side of the polar cap for IMF $B_{y}>0$ and it is located on the dusk side for IMF $B_{y}<0$ conditions. The electron precipitation in the regime of the convection channel in the morning sector is a band $(\sim 500 \mathrm{~km})$ of structured precipitation. The $\mathrm{PE}$ is located on the high-latitude boundary of the structured luminosity region in the vicinity of the strong flow channel of the magnetic convection close to the bright auroral arc. When $B_{y}>0$ this channel is located in the morning sector on the PC boundary, where the FACs outflow from the ionosphere (on the PC boundary) and flow into the ionosphere, equatorward of the PC boundary, and this is one reason that the eastward PE exists.

The EE comprises the evening sector from early evening to midnight hours and is located at lower latitudes closer to midnight. During midnight the EE latitude is the same as that of the WE equatorward edge. Both the EE width and its intensity reach maximum during dusk hours. The EE shown in Fig. 15d is not a closure current for the WE at higher latitudes, contrary to Fig. 15b, and is not located in the auroral zone $\left(\Phi \sim 65^{\circ}\right)$, contrary to Fig. 15c. According to Fig. $15 \mathrm{~d}$ the EE latitude increases from night to evening hours. During early evening hours, the EE adjoins the ionospheric projection of the CU, i.e. the EE is magnetically mapped to the magnetopause during this MLT interval. 
a)

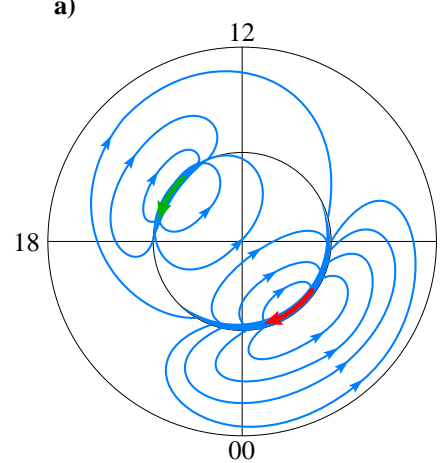

d)

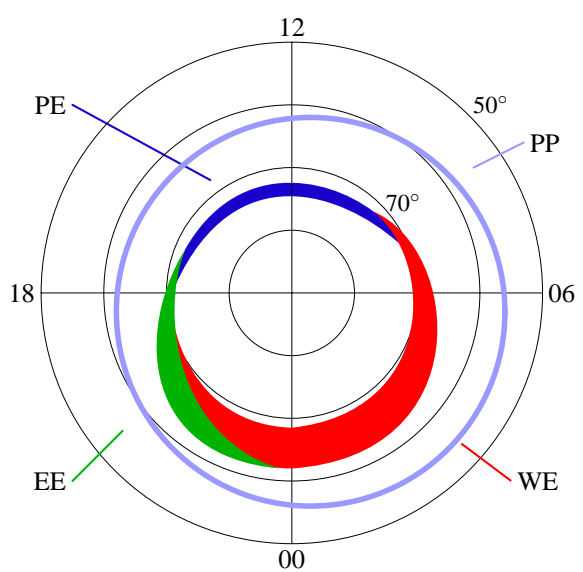

b)

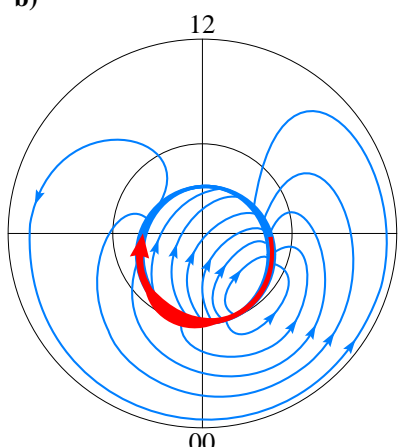

c)

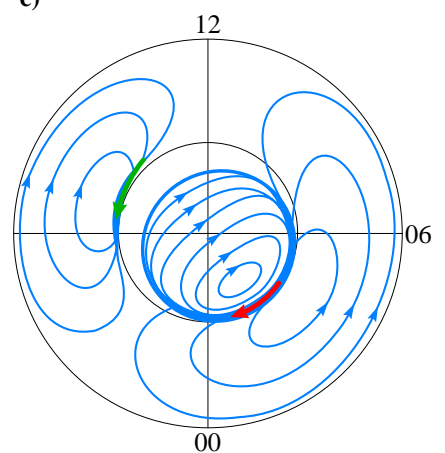

e)

$\mathrm{AL}=-1200 \mathrm{nT}, \mathrm{Dst}=-150 \mathrm{nT}$

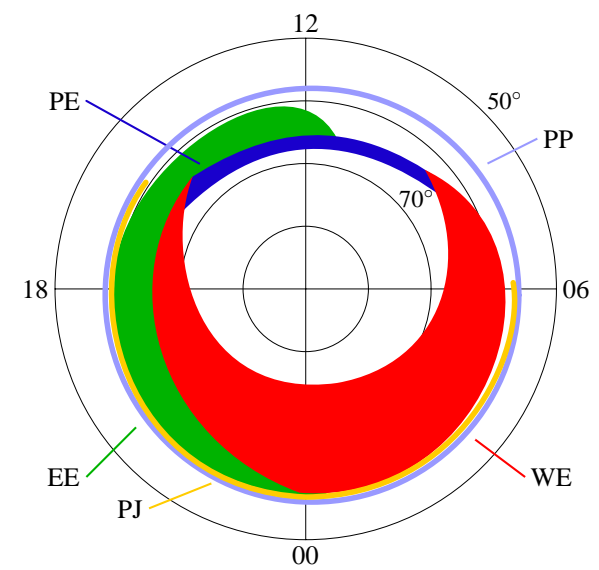

Fig. 15. Schematic view of the electrojets space-time distribution at ionospheric altitudes: (a) classical current system according to Fukushima (1953); (b) single-vortex system with westward electrojet along the AO according to Akasofu et al. (1965); (c) double-vortex system with westward electrojet along the auroral oval and eastward electrojet in the evening sector at the latitude of the auroral zone according to Feldstein and Zaitsev (1965); (d, e) substorm and strom conditions are considered separately: the magnetospheric substorm with $\mathrm{AL} \sim-800 \mathrm{nT}(\mathrm{d})$ and the magnetic storm main phase with $\mathrm{AL} \sim-1200 \mathrm{nT}, D_{s t} \sim 150 \mathrm{nT}(\mathrm{e})$.

In Fig. 15d the location of the projection of the plasmapause (PP) to ionospheric altitudes is indicated by the quasicircle (blue). There is a latitudinal slit (of a few degrees) between the PP and EE that decreases when reaching the night hours. During substorms this latitude slit is comparable to the EE width.

In Fig. 15e the distribution of equivalent currents and their structure during the storm main phase with activity indices of $\mathrm{AL} \sim-1200 \mathrm{nT}$ and $D_{s t}=-150 \mathrm{nT}$ are shown. The intensity of the electrojets increases. They are shifted to lower latitudes in comparison to substorm conditions (Fig. 15d). The westward current during the morning hours can be seen starting from $\Phi \sim 57^{\circ}$ within a latitudinal interval of $\sim 15^{\circ}$. During the late morning and early evening hours, the westward currents adjoin the PE. The PE during day hours is shifted equatorward to $\Phi \sim 67^{\circ}$ and the width of its narrow strip is $2^{\circ}-3^{\circ}$. The WE asymmetry with regard to the noon-midnight meridian is valid for storm intervals (similarly to the substorm intervals). However, the asymmetry pattern changes essentially; in the night sector the WE poleward boundary is located at higher latitudes than the PE in the noon sector.

The EE envelops the WE along its equatorward boundary not only during the evening-early dawn hours. The EE exists at latitudes between the PE and PP up to noon during the main phase of the intense storm. The latitudinal slit between the EE equatorward boundary and PP is only one-tenth of a degree in the night sector.

During the main phase of the 25 September 1998 storm, the bursts of the ion drift velocity of as much as $\sim 4 \mathrm{~km} / \mathrm{s}$ (SAPS) occur at subauroral latitudes (outside of the plasmapause) in the region of the ionospheric trough. In Fig. 15e the location of the SAPS is indicated by a line (yellow), the longitudinal prolongation of which is adapted from Foster and Vo (2002). 
5.2 The structure of the magnetic field variations in the EE region

A synthesis of numerous observations of electric fields and ionospheric currents at high latitudes during substorms was carried out by Kamide and Kokubun (1996). It was shown that time variations of the current patterns over the entire polar region consist of two components. The first is related to the magnetospheric electric fields and is represented by a two-cell convection pattern with cells on the morning and evening sides. The second component is represented by the WE in the dark sector and is related to the ionospheric conductivity intensification which is favourable for the generation of the 3-D wedge current system. Within the frame of such a model the EE is presented as a part of the evening convection cell and therefore flows from the PC to the evening side of the auroral zone. The observed complex variability of the magnetic field of auroral electrojets is attributed to a superposition of these two components changing on their own spatial and temporal scale and depending on the substorm phase.

Grafe (1994) carried out the complex study of the EE structure. The explosive component along with the convection-like one in the EE magnetic field variations were reported based on magnetic, ionospheric, radar and satellite data. Grafe and Feldstein (2000) stressed the differences in the EE and WE development in relation to the magnetic storm phases. Recent investigations indicate that during magnetic storms the ring current is formed due to the joint influence of two factors: the large-scale electromagnetic convection and the repeated electric field pulses related to substorm activation under stormy conditions. According to model calculations reported by Ganushkina et al. (2005), the contribution of plasma sheet particles, accelerated by electromagnetic pulses to energies of $>80 \mathrm{keV}$, to the total ring current energy, is quite significant. Such impulsive input of energy into the inner magnetosphere occurs not only during ring current formation, but also during PRC formation, and therefore influences the PRC and EE structure.

Most ionospheric models assume the existence of the EE convection-like component. The existence of the EE explosive component is quite uncommon and needs some additional arguments. Among those is the occurrence of positive bursts $\Delta H>0 \mathrm{nT}$ during the storm at noon hours when the EE is present. As seen in Fig. 3 the bursts occur within the latitudinal range $58^{\circ}<\Phi<66^{\circ}$. The distinctive peaks in the total intensity profile of eastward currents are indications of the occurrence of bursts (Fig. 3, bottom part). The mean duration of individual bursts is $\sim 0.5 \mathrm{~h}$; spacing is $\sim 1.5-2.0 \mathrm{~h}$. Comparing bursts along the IMAGE meridian with those measured along the GWC chain during 11:00-16:00 UT on 25 September 1998 makes it possible to estimate an approximate longitudinal size of the region where the bursts occurred. Within this interval, there is a superposition of "smoothed" intensity variations related to the convection-like component and of short-lasting bursts (as a signature of the explosive component). On the IMAGE meridian the amplitude of these bursts is $\sim 300 \mathrm{kA}$, whereas that on the GWC meridian is $\sim 150 \mathrm{kA}$. It is likely that the two-fold decrease of the current intensity in the burst characterizes the scale of the burst current system. The longitudinal extent of its ionospheric part is $\sim 60^{\circ}$.

The $\Delta H$ bursts are accompanied by specific spectra of precipitating ions, as seen in DMSP spectrograms in the evening sector. Within the disturbed intervals (but not including the storm main phase) the main energy flux of ions (of $\sim 10 \mathrm{keV}$ ) precipitating into the upper atmosphere is $J \sim 10^{7} \mathrm{eV} /\left(\mathrm{cm}^{2} \mathrm{~s}\right.$ $\mathrm{sr} \mathrm{eV}$ ) and is observed at $>64^{\circ}$ MLAT. During the storm main phase ions of $\sim 10 \mathrm{keV}$ precipitate at $58^{\circ}<\mathrm{MLAT}<67^{\circ}$ and $J$ is similar, i.e. $\sim 10^{7} \mathrm{eV} /\left(\mathrm{cm}^{2} \mathrm{~s} \mathrm{sr} \mathrm{eV}\right)$. The energy flux of ions with the energy from $32 \mathrm{eV}$ to $1 \mathrm{keV}$ is $J \sim 10^{8} \mathrm{eV} /\left(\mathrm{cm}^{2}\right.$ s sr eV).

We conclude that the currents in the WE and EE are generated by three external sources. The first one is the large-scale convection in the magnetosphere which drives the two-vortex current system at high latitudes with westward (morning sector) and eastward (evening sector) ionospheric currents at auroral latitudes. During the magnetically disturbed interval, additional currents contribute to the magnetic fields associated with the auroral electrojets. The WE increases abruptly due to a current wedge appearance. The eastward electrojet increases due to closure of the PRC via the ionosphere in the evening sector.

5.3 Electric fields and field-aligned currents in the dusk sector of the inner magnetosphere

The electric fields and the FAC of the inner magnetosphere are two of the most important features to be taken into account for understanding the existence and development of the EE. During magnetospheric disturbances, the fields and currents are caused by an intensification of the solar-winddriven convection electric field. Both the earthward plasma motion from the magnetotail and the existence of FAC in the inner magnetosphere, along with the associated ionospheric currents, are attributed to the convection field. In case of nonzero ionospheric conductivity the electric fields appear in the ionosphere and they are mapped magnetically into the magnetosphere. The resulting electric fields in the magnetosphere are significantly more complex than the simple dawnto-dusk field often assumed as a first approximation. The electric field peak occurs in the dusk sector of the magnetosphere at $L \sim 4$, i.e. quite far inside of the location of the driving source of the convection.

A physical model of the inner magnetosphere that includes the coupling with the ionosphere is the Rice Convection Model (RCM) (Gardner et al., 2004). It describes adiabatically drifting isotropic particle distributions in a selfconsistently computed electric field, including the flow of electric currents along magnetic field lines to and from the 
coupling ionosphere. Positive ions are responsible for most of the Region 2 FAC and carry most of the storm-time ring current, while electrons are the principal source of enhanced ionization in the auroral ionosphere. Pressure gradients associated with the Alfvén layer produce Region 2 FAC (into the ionosphere in the dusk sector and away from the ionosphere in the dawn sector). The equatorward auroral ion boundary in the dusk-pre-midnight region coincides with the equatorward Region 2 boundary. In addition, the latitudinal extension of the Region 2 FAC coincides with the region in which there is a slope in the ion energy density. The poleward boundary of the Region 2 FAC is approximately at latitudes of the peak of the ion energy density. For intervals of magnetic storms, the RCM predicts the existence of the region where the electric field is poleward and very strong $(\sim 100 \mathrm{mV} / \mathrm{m})$, which results in a rapid westward plasma drift known as the SAPS. The SAPS is generated at latitudes equatorward of the electron precipitation boundary b1e, but poleward of the ion precipitation boundary b1i. The downward Region 2 FAC flows at latitudes where the ionospheric conductivity is lower. The SAPS generation in the RCM is based on charge and energydependent drift trajectories of magnetospheric particles. The positive ions, much hotter than the electrons, come closer to the Earth on the dusk side. Therefore, on the dusk side, the equatorward edge of the FAC is closer to the Earth than the diffuse aurora. The horizontal ionospheric closure current across the narrow region between b1i and b1e, with very low conductivity (inside the ionospheric through), requires a large electric field.

Using the hydromagnetic approximation the FAC and plasma motion in the magnetosphere are described by the expression:

$J_{\|}=-\left(B_{m} / 2 B_{e}^{2}\right) \boldsymbol{B}_{e} \cdot(\operatorname{grad} P \times \operatorname{grad} V)$,

where $J_{\|}$is the FAC density at ionospheric altitudes, $\boldsymbol{B}_{e}$ and $B_{m}$ refer to the magnetic field in the magnetospheric equatorial plane and at the ionospheric mirror point, $P$ and $V=\int d l / B$ are the plasma pressure in the equatorial plane and the flux tube volume, respectively.

The plasma pressure and the flux tube volume have both radial and azimuthal gradients. If $\operatorname{grad} P$ and $\operatorname{grad} V$ are decomposed into radial and azimuthal components, then the relationship:

$$
\begin{aligned}
J_{\|}= & -\left(B_{m} / 2 B_{e}^{2}\right) \boldsymbol{B}_{e} \cdot\left[(\operatorname{grad} P)_{r} \times(\operatorname{grad} V)_{\phi}\right. \\
& \left.+(\operatorname{grad} P)_{\phi} \times(\operatorname{grad} V)_{r}\right]
\end{aligned}
$$

is obtained from Eq. (1). Toward midnight the components of the flux tube volume gradient are positive, $(\operatorname{grad} V)_{r}>0$, $(\operatorname{grad} V)_{\phi}>0$. In the Alfvén layer $(\operatorname{grad} P)_{r}>0$. Moreover, in the Alfvén layer the first term in Eq. (2) gives the FAC outflowing from the ionosphere. The current (Region 2) inflowing at corresponding ionospheric altitudes is represented by the second term in Eq. (2), i.e. by both the azimuthal plasma pressure gradient and radial gradient of the flux tube volume.
This component of the Region 2 FAC characterizes its regular part.

Next we compare the results of model calculations with DMSP data in the evening sector. Both the location of the ion plasma sheet boundary earthward of the electron plasma sheet boundary and the existence of a region between these boundaries with the poleward electric field are predicted by the model quite correctly. According to model results, the ionospheric trough with its decreased ionization density is located equatorward of b1e. On the other side, the burst of the westward ion drift velocity is within the ionospheric trough boundaries; the peak velocity corresponds to the ble boundary or occurs more equatorward, being between ble and bli. However, the SAPS with high ion drift velocities is observed on both sides of the burst peak, outside of the ble and b1i boundaries. It means that further improvements of the RCM model are necessary to interpret high ion drift velocities out of the region where the electric field is due to charge separation.

In fact, according to the RCM model, generation of the northward electric field in the ionosphere is a reason for the SAPS occurrence. As model calculations show, this field in the evening sector is a result of a separation of hot particles of opposite charges in the magnetosphere. The different latitudes of precipitation of ions and electrons of auroral energies were confirmed by observations of auroral luminescence. As known, in the evening sector the hydrogen luminescence is located at latitudes equatorward of the electron luminescence. However, in the morning sector the situation is the opposite (hydrogen luminescence is located poleward according to Wiens and Vallance Jones, 1969; Evlashin and Maltsev, 2004). DMSP and Viking measurements also have revealed (Vorobjev et al., 2000; Feldstein et al., 2001) that in the morning sector the equatorward boundary of hot electron precipitation is located at latitudes lower than that of ions, which has to be a reason for the occurrence of the southward electric field. If the ion drift direction in SAPS is assumed to be controlled by the hot particles' charge-separation electric field, then the drift in the morning sector has to be eastward. The existence of westward ion drift in the SAPS within the entire longitude interval from dusk to dawn MLT hours, can be considered as a confirmation of the fact that the SAPS westward ion drift in the dawn sector outside the plasmapause is controlled by other mechanisms of the electric field generation. The injection of low-energy ions into the nightside inner magnetosphere is among of them. Such ions can stay at the low $L$-shells for a long time, and due to the corotation electric field, can be moved to the morning sector. There, their location is closer to the Earth than that of the electrons.

The closure of inflowing currents via the region of low ionospheric conductivity appears to be the other possibility. Such currents are likely to flow into the ionosphere near the low-latitude boundary of the particle precipitation region. Both assumptions regarding the reasons of the westward ion drift presence in the morning sector must be verified using 
observational data during various phases of magnetic storms.

Processes of the ring current development and decay during a magnetic storm, caused by the exposing magnetic cloud influence were modelled by Jordanova et al. (1998). The storm-time enhancement of the plasma sheet ion population contributed significantly to the ring current buildup. The energy losses due to ion precipitation increase during active periods, reaching maximum values during the storm main phase. During this phase the ion precipitation; along with charge exchange become an important mechanism of the ring current decay. For the 25 September storm, the significant (in intensity) ion fluxes precipitating from the magnetosphere to upper atmosphere altitudes were observed. In Figs. 1114 (corresponding panels) the integral energy fluxes of these ions $(E<30 \mathrm{keV})$ are shown, along the DMSP passes during different storm phases. It is worth noting that their energy is lower than the characteristic energy of the RC ions. At the beginning of the storm and at the maximum of the main phase the main energy flux of ions is concentrated between the $\mathrm{b} 2 \mathrm{i}$ and $\mathrm{b} 2 \mathrm{e}$ boundaries, i.e. related to the region between boundaries of current and plasma sheets in the magnetotail reaching the maximum value $\sim 5 \times 10^{11} \mathrm{eV} /\left(\mathrm{cm}^{2} \mathrm{~s}\right.$ sr) on the current sheet boundary, where the pitch-angle distribution changes from isotropic to anisotropic. At the recovery phase this value decreases to $\sim 10^{11} \mathrm{eV} /\left(\mathrm{cm}^{2} \mathrm{~s} \mathrm{sr}\right)$.

Liemohn et al. (2001a) simulated the near-Earth ring current particle flow in the inner magnetosphere using a kinetic transport RAM model (Ring current - Atmosphere interaction Model). The algorithm solves the time-dependent gyration and bounce averaged kinetic equation for the phasespace distribution function. The code includes collisionless drifts, energy loss and pitch-angle scattering due to Coulomb collisions with the thermal plasma, charge exchange loss with the hydrogen geocorona, and precipitative loss to the upper atmosphere. The simulations use geosynchronous plasma sheet measurements as the outer boundary condition. The geosynchronous orbit $(\mathrm{L}=6.6)$ is the outer boundary of the simulation domain.

The drift trajectories were distinguished as open and closed. The trajectories were considered as closed for those that remained within the simulation domain. The calculations reported by Liemohn et al. (2001b) show that $\sim 80 \%$ of the particle energy in the vicinity of the magnetic storm peak is on open drift paths, intersecting the simulation domain boundaries. The conclusion was stated that the basic contribution to the $D_{s t}$ variation is due to the PRC field and in comparison with this PRC field the symmetric RC field and the tail current (TC) field are only small additions. During the storm main phase of intense magnetic storms, the magnetopause is usually intersected by geosynchronous orbit. During these intervals energetic ions of the ring current leave the magnetosphere along open drift paths in the daytime sector.

Using the relationship (1) Liemohn et al. (2001b) obtained integrated values of FACs flowing into and out of the ionosphere in the Northern Hemisphere. The correspond- ing current densities were also calculated at $120 \mathrm{~km}$ altitude. For the 25 September 1998 magnetic storm, the current density for the Region 2 FAC increases from the value of $0.1 \mu \mathrm{A} / \mathrm{m}^{2}$ at 01:00 UT to $1 \mu \mathrm{A} / \mathrm{m}^{2}$ at 03:00 UT, then decreases to $0.3 \mu \mathrm{A} / \mathrm{m}^{2}$ at 08:00 UT. At 15:00 UT the current changes direction and the outflowing current density is $-0.1 \mu \mathrm{A} / \mathrm{m}^{2}$. The total current for the Region $2 \mathrm{FAC}$ is $3 \times 10^{6} \mathrm{~A}$ at 01:00 UT, $14 \times 10^{6} \mathrm{~A}$ at 03:00 UT, $7 \times 10^{6} \mathrm{~A}$ at 08:00 UT, and $2 \times 10^{6} \mathrm{~A}$ at 15:00 UT.

Quite intense FAC can be generated during the storm main phase due to turbulent pitch-angle diffusion of energetic ions by ion cyclotron waves (Trakhtengerts and Demekhov, 2004). The ion cyclotron instability occurs as a result of the interaction of energetic ions with the cold magnetospheric plasma because of the dependence of the cyclotron resonance condition on the cold plasma density. Grafe et al. (1996) estimated the FAC intensity for the inflowing current near the plasmapause, where the hot and cold plasma meet. The FAC is formed by precipitated energetic ions but the FAC closure in the ionosphere is due to cold particles. For strong pitchangle diffusion, isotropic pressure in the precipitation region and a Maxwellian distribution function with effective temperature $T=m v_{0}^{2} / 2$, the drift current density $J_{\|}$at the ionospheric level is equal to

$J_{||}=0.5 \pi^{-1 / 2} e N_{0} v_{0}$,

where $N_{0}$ is the ring current ion density in the equatorial plane. The total inflowing current

$I_{\text {tot }} \approx 8 \times 10^{7}\left(\beta \Delta L / L_{p p}^{3}\right)$,

where $\beta=8 \pi P_{0} / B_{L p}^{2}, B_{L p}$ is the equatorial magnetic field value at $L=L_{p p}, L_{p p}$ is the plasmapause magnetic shell position, and $P_{0}$ is the ion ring current pressure in the front of the cyclotron instability region. For $\beta=0.3, \Delta L \sim 1$, $L_{p p}=3$, and $I_{\text {tot }} \approx 0.9 \mathrm{MA}$. According to more precise calculations (Trakhtengerts and Demekhov, 2004), $I_{\text {tot }} \approx 0.23 \mathrm{MA}$ if $L_{p p}=4$.

Grafe et al. (1996) assumed that the generation of fieldaligned currents takes place in the vicinity of the plasmapause. Observations of the energetic neutral atom (ENA) content in the 16-119 keV energy range obtained by the highenergy neutral atom imager on board the IMAGE satellite made it possible to define the spatial distribution of the ring current ions (Burch et al., 2002; Brandt et al., 2002b). Images of the plasmasphere in extreme ultraviolet reveal a spatial relation between ENA emissions and plasmaspheric tails (Burch et al., 2001; Brandt et al., 2002a). During the main phase of intense magnetic storms electric field bursts occur repeatedly. This is favourable for the formation of plasma density discontinuities in the inner magnetosphere. Using IMAGE measurements Burch et al. (2001) confirmed the development of plasma tails in the dusk hemisphere during the geomagnetic storms on 24 May 2000 and 20 July 2000. They also revealed the existence of a sharp azimuthal plasma density gradient on the night-side. Using Millstone Hill radar 
data, as well as low and high-altitude satellite measurements of the outer plasmasphere during the 31 March 2001 magnetic storm, Foster et al. (2002) showed that during the storm main phase an enhanced density and plumes of greatly elevated total electron content appear. The appearance of such regions of enhanced density of cold plasma is attributed to erosion of the outer plasmasphere due to strong sub-auroral polarization electric fields. Regions with enhanced cold plasma density can last for some time. Because of turbulent pitch-angle diffusion of energetic ions by ion cyclotron waves, the preconditions for the Region 2 FAC spatial distribution pattern exist not only on the plasmapause, but also within a wide range of L-shells. Such a structure of the Region 2 FAC characterized by a number of field-aligned currents is actually observed within some portions of the main phase of the 25 September magnetic storm.

As usually accepted, at auroral latitudes the ionospheric part of the 3-D PRC current system is represented by the EE. The EE magnetic field at the Earth's surface is positive $(\Delta H>0 \mathrm{nT})$. As known, the maximum values $\Delta H$ measured by the longitudinal chain of magnetic observatories at auroral latitudes $\Phi \sim 65^{\circ}$ are used to calculate AU. In fact, the value of the $\mathrm{AU}$ geomagnetic activity index is controlled by the EE intensity. In other words, the AU values appear to be tightly associated with the PRC intensity. Thus, it can be assumed that the EE monitoring is allowed following the appearance and development of the PRC during the storm main phase.

The main phase portions of some intense magnetic storms, within which the AU index is about zero or even negative, are of special interest. During these time intervals the longitudinal chain of magnetic observatories does not reveal the EE existence. Actually, in case of the 25 September 1998 magnetic storm, AU $<0$ nT during 02:00-07:30 UT. Can the absence of the AU positive values at auroral magnetic observatories during parts of the storm main phase be the consequence of the PRC absence in the inner magnetosphere for these time intervals (as Skoug et al., 2003, reported for another intense magnetic storm)? Other plausible reasons for the EE absence at auroral latitudes include:

- an equatorward shifting of the EE during the storm main phase (discussed in Sect. 3.2);

- weakening of the eastward Hall current in the ionospheric E-layer, created by a northward electric field at latitudes between field-aligned currents (Region 2 and Region 1).

In case of the 25 September 1998 magnetic storm, the AU negative values during the main phase are not attributed to the absence of the PRC in the inner magnetosphere. It is worth stressing that the longitudinal asymmetry pattern of the magnetic field reported by Clauer et al. (2001) gives evidence of the PRC existence. Actually, ground-based measurements along the longitudinal chain of 19 mid- and low-latitude ob- servatories showed that the magnetic field depression was not uniform around the Earth.

Within the development of the main phase at 02:30 UT the depression of $-150 \mathrm{nT}$ was largest at 19:30 MLT, whereas the minimum depresion of $-40 \mathrm{nT}$ was seen from 02:00 MLT to 05:00 MLT. Throughout the main phase until 05:30 UT the enhanced depression of the field remained centered slightly post-dusk, with the value at 04:30 UT of about $-250 \mathrm{nT}$ at 21:00 MLT and -110 nT at 04:00 MLT.

As to the main phase maximum, the largest depression shifts to the early post-noon sector (within the interval from 10:00 MLT to 17:00 MLT at 07:00 UT). At the beginning of the recovery phase the largest field depression shifts to the evening hours (from 16:00 MLT to 22:00 MLT at 10:00 UT). Such patterns of the asymmetry give evidence for the PRC of significant intensity which exists along with the RC, TC, and FAC currents. This pattern is due to the PRC during the main phase of this storm. Hence, the EE should exist as well, as that is an ionospheric part of the three-dimensional PRC current system. The abrupt decrease in the AU value observed during the main phase appears to be related to an equatorward shifting of the EE, which was characterized by AU 250 nT at 21:00-23:00 UT on 24 September before the storm main phase and then decreased to $\mathrm{AU}<0 \mathrm{nT}$. This means that the EE (at all longitudes in the dusk sector from noon to night) shifts to latitudes $\Phi<65^{\circ}$. Moreover, southward magnetic fields were observed by auroral observatories in the evening sector. This is evidence of the WE shifting to auroral latitudes in the dusk sector. Usually its location in the evening sector is poleward of the EE, i.e. at $\Phi \sim 70^{\circ}$. The ionospheric Hall currents in the 02:00-07:30 UT interval are relatively intense, as well. This is confirmed by variations of the AL index, which reach values from $-1000 \mathrm{nT}$ to $-2000 \mathrm{nT}$ during this time intreval.

During the storm recovery after 07:30 UT on 25 September, the AU index does gradually increase to positive values. At 08:00-15:00 UT AU 200 nT, which is consistent with the usual EE location. In addition, during the storm recovery phase, the weakening of the PRC current system intensity is compensated by substorm ionospheric Hall currents in the EE.

Another indirect argument for the existence of the PRC from the very beginning of the 25 September magnetic storm is the quite high intensity of the large-scale FAC flowing into the ionosphere in the region of the EE (Region 2 FAC). The 3 -D current loop is formed by these currents along with the PRC and EE. Below in Table 2 the estimates of total current intensities $\boldsymbol{I}_{\text {tot }}$ flowing into and out of the ionosphere are shown. To calculate these currents the assumption has been used that the linear density of the FAC $J_{\|}$is a function of longitude:

$\boldsymbol{J}_{\|}=\boldsymbol{J}_{0} \sin \varphi$.

Here $\boldsymbol{J}_{0}$ is a linear current density at the longitude of the DMSP satellite pass in the dusk sector, i.e., 17:00- 
Table 2. The total FAC intensity (MA) during different phases of a magnetic storm. The longitudinal extent (hours) of the corresponding FAC-regions (R1 - Region 1, R2 - Region 2, R3 - Region 3) is indicated in brackets.

\begin{tabular}{|c|c|c|c|c|c|c|c|}
\hline \multirow[b]{2}{*}{$\begin{array}{l}\text { UT and related } \\
\text { disturbances }\end{array}$} & \multicolumn{7}{|c|}{ FAC } \\
\hline & $\mathrm{R} 2$ & $\mathrm{R} 1$ & $\mathrm{R} 3$ & $\begin{array}{l}\text { Alfvén layer } \\
\text { (b1i,e-b2i) }\end{array}$ & $\begin{array}{l}\text { Current sheet } \\
\text { mapped to } \\
\text { (b2i-b2e) }\end{array}$ & SAPS & $\begin{array}{c}\text { FAC } \\
\text { (Liemohn et } \\
\text { al., 2001b) }\end{array}$ \\
\hline $\begin{array}{l}\text { 24 Sep 1998 } \\
\text { 19:49-19:56 UT } \\
\text { substorm before } \\
\text { magnetic storm }\end{array}$ & $\begin{array}{c}0.52 \\
(5)\end{array}$ & $\begin{array}{l}0.45 \\
(5)\end{array}$ & - & 0.19 & 0.3 & & 2 \\
\hline $\begin{array}{l}25 \text { Sep } 1998 \\
02: 47-02: 56 \text { UT } \\
\text { storm main phase }\end{array}$ & $\begin{array}{c}2.45 \\
(7)\end{array}$ & $\begin{array}{l}2.66 \\
(7)\end{array}$ & $\begin{array}{l}0.18 \\
(5)\end{array}$ & 0.66 & 1.79 & & 8 \\
\hline $\begin{array}{l}25 \text { Sep } 1998 \\
\text { 09:04-09:13 UT } \\
\text { early recovery phase }\end{array}$ & $\begin{array}{l}4.17 \\
(9)\end{array}$ & $\begin{array}{l}6.29 \\
(9)\end{array}$ & $\begin{array}{l}1.4 \\
(7)\end{array}$ & 1.22 & 2.95 & $0.81(10)$ & 4 \\
\hline $\begin{array}{l}25 \text { Sep } 1998 \\
\text { 16:28-16:37 UT } \\
\text { recovery phase in progress }\end{array}$ & $\begin{array}{l}0.26 \\
(6)\end{array}$ & & $\begin{array}{l}0.1 \\
(5)\end{array}$ & 0.14 & 0.12 & & 1.5 \\
\hline
\end{tabular}

19:00 MLT (Figs. 10-14), $\phi$ is longitude. On the satellite pass meridian $\varphi=90^{\circ}$. The $\boldsymbol{I}_{\text {tot }}$ value was calculated for the Northern Hemisphere using the relationship:

$\boldsymbol{I}_{\text {tot }}=2 \int_{0}^{\varphi_{1}} \boldsymbol{J}_{0} \sin \varphi d \varphi=2 R\left(1-\cos \varphi_{1}\right) \sin \theta$,

where $\varphi_{1}$ is the geomagnetic longitude of the FAC boundary, $R$ is the radius of the DMSP orbit $\left(R=7.37 \times 10^{6} \mathrm{~m}\right)$, and $\theta$ is a polar angle of the center of the corresponding FAC. The longitudinal extent of the FAC was from 5 to $9 \mathrm{~h}$, depending on the geomagnetic activity level and current configuration, which can be seen in Table 2. The FAC intensity data in the evening sector, summarized in Table 2, imply:

- during substorms FAC intensities $\boldsymbol{I}_{\text {tot }}$ are $\sim 0.5 \mathrm{MA}$ with differences less than 0.2 MA. The intensities $\boldsymbol{I}_{\text {tot }}$ in Region 1 and Region 2 increase by an order of magnitude during the storm main phase and in addition the Region 3 current appears;

- the highly intense (several MA) Region 2 FAC flowing into the ionosphere from the inner magnetosphere during the storm main phase gives evidence of PRC existence;

- the attenuation of the FAC during the storm recovery phase and its enhancement during the main phase occur at comparable rates;

- $\boldsymbol{I}_{\text {tot }}$ for Region 1 FAC flowing from the ionosphere into the CPS is equal to the sum of the intensities of inflowing currents from the inner magnetosphere (Region 2 FAC) and from the PSBL (Region 3 FAC);
- Region 2 FAC flows into the ionosphere (from the inner magnetosphere) near the earthward side of the b2e boundary, i.e. just in the region of diffuse precipitation. $\boldsymbol{I}_{\text {tot }}$ of the FAC inflowing from the region of anisotropic pitch-angle distribution of energetic ions (between the b1i and b2i boundaries) is two to three times lower than $\boldsymbol{I}_{\text {tot }}$ of the FAC inflowing from the region of the isotropic one (between the b2i and b2e boundaries);

- at the $D_{s t}$ minimum, FACs with intensities $\boldsymbol{I}_{\text {tot }} \sim 0.8 \mathrm{MA}$ flow in and out at SAPS latitudes; these currents are an order of magintude weaker than the FACs in Region 1 and Region 2;

- Region 2 FAC intensities determined from DMSP measurements of magnetic field variations are equal to model values at the $D_{s t}$ minimum, as obtained by Liemohn et al. (2001b). But during the substorm intervals the observed FAC intensity is several times lower than that for the model, both for the main phase beginning and for the recovery phase of the 25 September storm;

- the observed Region 2 FAC intensities are several times greater than model values based on pitch-angle diffusion of ions into the loss-cone due to wave-particle interactions of ions with ion-cyclotron waves (Trakhtengerts and Demekhov, 2004). According to these calculations, the inflowing to the ionosphere FACs are approximately equal to FACs between the b1 $\mathrm{i}$ and $\mathrm{b} 2 \mathrm{i}$ boundaries (Table 2). 
It is likely that the PRC formation already at the beginning of the analyzed storm is not typical for the main phase development of all storms. For example, Skoug et al. (2001) analysed both ENA flux measurements and ground-based magnetic field measurements during the main and recovery phases of the 31 March 2001 magnetic storm. Its main phase started at 05:00 UT, whereas the maximum depression $\left(D_{s t}=-350 \mathrm{nT}\right)$ was reached within 07:00-09:00 UT. The satellite observations of energetic ion distribution in the magnetosphere revealed that magnetotail currents were the main source of $D_{s t}$ variations at the initial stage of the main phase of this storm. The ion ring current started to form in the magnetosphere as late as after 06:30 UT, when highenergy ions began to drift duskward, forming a PRC. The ground-based measurements along the chain also showed that before 06:30 UT the magnetic field depression maximised ( $-400 \mathrm{nT})$ at 00:00-02:00 MLT. The least depression ( $\sim 150 \mathrm{nT})$ occurred at 18:00-21:00 MLT. Such a magnetic field asymmetry is characteristic of the magnetic effect of the tail current system. During 07:00-09:00 UT, in addition to the extreme value enhanced up to $\sim-500 \mathrm{nT}$ during nighttime, a new extreme value appears $(\sim-400 \mathrm{nT})$ at 15:00-18:00 MLT. After 09:00 UT the field depression was asymmetric with a maximum field decrease of $\sim-300 \mathrm{nT}$ in the dusk sector, which is characteristic of the PRC field.

The AU index variations during the storm main phase reflect the complex structure and dynamics of the sources of the magnetic field variations. At 02:00-04:00 UT AU values range between 200 and $400 \mathrm{nT}$, i.e. the $\mathrm{EE}$ is quite intense due to the substorm Hall currents. When the storm starts, AU decreases and becomes negative by 05:40 UT, attributed to the joint effect of three factors: the EE equatorward shifting, the absence of the PRC current system, and Hall currents relaxation in the EE. After 05:40 UT the AU increase begins, which cannot be explained only by the EE returning to auroral latitudes, since an abrupt enhancement of the RC intensity continues. Rather, the recovery of the AU positive values is attributed to both the Hall current enhancement and possible occurrence of the PRC current system. The following time interval between 06:30 and 08:00 UT with $\mathrm{AU}>0 \mathrm{nT}$ is due to the substorm Hall current fields and plausible development of the PRC current system. During the storm recovery phase during 09:00-12:00 UT, the AU intensity decrease is observed, which is associated with absence of substorms and with a weakening of PRC fields. To follow FAC variations during this storm would be of interest, but such data are not available to us.

The complicated multiparametric dependence of the AU intensity on fields of different current systems discussed above means that this index cannot determine the existence or absence of the PRC current system and its magnetic effects.
5.4 The magnetosphere domains structure and the 3-D current systems

To show the structure of magnetospheric plasma domains and the 3-D current systems, the cross section of the Earth's magnetosphere is displayed in Fig. 16. It is shown in the meridian midday-midnight and equatorial planes, using ground-based observations of different types of auroral luminescence and auroral precipitation (Galperin and Feldstein, 1991). The majority of plasma domains seen in the figure are directly related to large-scale current systems in the magnetosphere.

The magnetopause, a boundary of the magnetosphere, separates it from the solar wind. The LLBL, the outer boundary which separates the regions with closed and open magnetic field lines, adjoins the magnetopause on the dayside. Between closed and open field lines, there is the cusp (CU) or polar cusp, a region via which solar plasma and solar wind electric fields can reach the inner magnetosphere. On the nightside in the antisunward direction, the geomagnetic field geometry is tail-like. Tail lobes with extremely low plasma density are mapped along magnetic field lines to the polar caps (PC). The main plasma reservoir in the magnetosphere, CPS (or plasma sheet shortly), with particle energies of a few $\mathrm{keV}$, is located between the northern and southern lobes. At the outer periphery of the CPS adjoining to the lobes, there are both the narrow layer of soft electrons (PSBL) and specific VDIS-2 (Velocity Dispersed Ion Structures of the second type) (Galperin and Feldstein, 1996). The magnetospheric convection brings plasma from the CPS earthward to the inner magnetosphere. The azimuthal component of the drift increases as a result of the growing strength of the magnetic gradient and curvature forces. This enhancement is also due to the increasing corotation electric field. The closer to the Earth, the lower the energy is of the convecting plasma.

The plasmapause, a boundary of the plasmasphere, where the magnetospheric electric fields do not penetrate, is also a boundary of convection of electrons with zero energy. The magnetic shell on the nightside, from which the decrease in the CPS electron energy starts, is a CPS boundary. The region in the inner magnetosphere between the plasmasphere and the CPS is commonly referred to as the Alfvén layer where magnetic field lines are closed. On magnetic shells of this layer there is not only low energy plasma, but also high energy electrons of the radiation belt and energetic ions trapped by the geomagnetic field. These ions are the main carriers of plasma energy in the inner magnetosphere during magnetic storms. Their azimuthal drift forms a RC, acting as a source of intense global magnetic field variations.

The 3-D structure of currents in the near-Earth space is enclosed by the magnetopause. The currents screening magnetic fields in the inner magnetosphere from penetrating into the solar wind are located on the magnetopause. These eastward Chapman-Ferraro (CF) currents screen the dipole field. The magnetopause screening currents for the RC fields are 


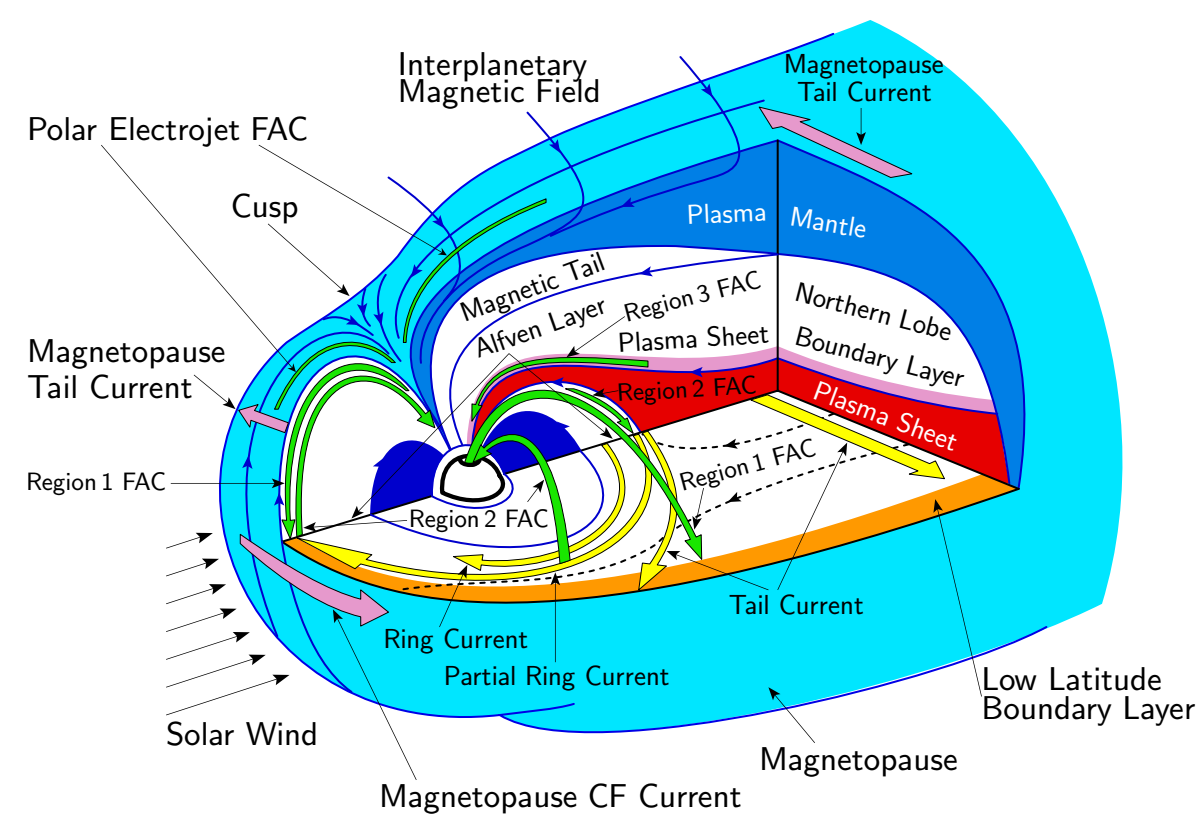

Fig. 16. The 3-D system of electric currents in the magnetosphere during a magnetic storm.

in the same direction, but their intensity is an order of magnitude weaker. The TC in the CPS is in the dawn-dusk direction. At midnight the near-Earth boundaries of plasma (b2e) and current (b2i) sheets coincide. At the dusk meridian b2i is closer to the Earth than b2e. The closure of the TC is attributed to currents on the magnetopause which exist not only on the nightside, as well established, but on the dayside as well. In Fig. 16 the TC in the equatorial plane of the magnetosphere is indicated by two vectors. At midnight one of them is located in the innermost part of the current sheet, the other along its boundary. Their continuation on the magnetopause can be seen. However, the first remains in the tail and the second reaches the dayside of the magnetopause where the directions of the CF and TC are opposite, as seen in Fig. 16. Since CF currents are always more intense than TC closure currents, the resulting current on the dayside is always eastward.

The FAC flowing into and out of the ionosphere in the vicinity of the PE are located on the CU surface. In Fig. 16 PE FAC are indicated by two green lines (not vectors) along the magnetic field. The PE FAC direction is not shown, since it is controlled by the IMF $B_{y}$ component: under $B_{y}>0 \mathrm{nT}$ $\left(B_{y}<0 \mathrm{nT}\right)$ the current flows into (out of) the ionosphere along the cusp inner surface and out of (into) it along its outer surface. The ionospheric closure of the inflowing and outflowing PE FAC is by Pedersen current. Its direction in the ionosphere is identical with the direction of the solar wind electric field component $V \times B_{y}$, i.e. under $B_{y}>0 \mathrm{nT}$ $\left(B_{y}<0 \mathrm{nT}\right)$ the electric field in the cusp is poleward (equatorward) at ionosphere altitudes. In the cusp the Hall current in the form of the PE, spreading in the ionosphere (out of the cusp) is generated by this electric field. The PE is eastward (westward) under $B_{y}>0 \mathrm{nT}\left(B_{y}<0 \mathrm{nT}\right)$.

The Region 1 FAC in the dusk sector is usually believed to be mapped magnetically from the ionosphere to the LLBL, i.e. to the periphery of the magnetosphere, in the vicinity of its boundary with the solar wind. Such a pattern is valid for Region 1 FAC during day-time hours only and is shown by a current arrow, resting against the LLBL. During the dusk and before midnight hours, where Region 1 FAC is located at AO latitudes, FACs inflow to the CPS, i.e. into the deep magnetosphere. In Fig. 16 the second current arrow of the Region 1 FAC crosses the equatorial cross section of the magnetosphere in the dusk sector of the CPS behind the TC vector that depicts the current along the TC boundary.

The Region 2 FAC flows into the ionosphere from the Alfvén layer periphery where the PRC is located. In Fig. 16 Region 2 FACs are indicated by three vectors for day, dusk and night hours. It is generally believed that the Region 2 FAC is located in the inner magnetosphere and is a part of the single current system with the EE and PRC. As seen in Fig. 16 the Region 2 FAC flowing into the ionosphere during evening hours is located in the magnetosphere at $L \sim 4$. In the early afternoon sector, where the EE adjoins the PE, the Region 2 FAC in the equatorial plane of the magnetosphere is near the LLBL.

The RC and PRC are formed by westward drifting (around the Earth) energetic ions. In the RC-region ions circulate many times around the Earth. In the PRC-region the drift is interrupted before a full rotation and the ions depart the magnetosphere, either precipitating into the ionosphere or reaching the magnetopause around noon. The main loss of ions is 
likely to take place due to various processes of ion dissipation from the magnetosphere to the ionosphere. To fulfill the requirement for the PRC-Region 2 FAC-EE current system closure, a field-aligned current from the ionosphere into the magnetosphere at about midnight is needed. Such a current exists at near-midnight hours and is shown by the vector in Fig. 16.

The auroral electrojets present a continuation of the FACs at ionospheric altitudes. Eastward/westward electrojets are connected with magnetospheric plasma domains (the Alfvén layer/the CPS) via FAC. In known models of the EE the Pedersen current in the ionosphere along with the Region 2 FAC constitute Boström's Case I current system (Boström, 1964). At the same time the Region 2 and Region 1 FAC in the evening sector constitute Boström's Case 2 current system. The northward electric field between these FACs leads to Hall currents along the EE. Hence, the EE is the joint effect of Pedersen and Hall currents in the ionosphere.

As mentioned above, a characteristic morphological feature of auroral electrojets exists in the evening sector, namely their overlapping. This is due to the additional Region 3 FAC current flowing into the ionosphere from the PSBL (Fig. 16) during intense magnetic disturbances. A southward electric field, favorable for the appearance of westward ionospheric Hall currents near the PC boundary, appears between the Region 3 FAC and Region 1 FAC. As a result the spatial overlapping of electrojets takes place. Also worth noting is that the WE is the resultant effect of Pedersen and Hall currents in the ionosphere.

The current wedge in the night-time sector of auroral latitudes is not shown in Fig. 16.

\section{Summary}

Auroral electrojets and boundaries of plasma domains in the magnetosphere during magnetically disturbed periods were studied in this paper. The main results obtained are listed below.

- The currents in the westward and eastward electrojets are generated by three external sources. The first one is the large-scale convection in the magnetosphere which drives the two-vortex current system at high latitudes with westward (morning sector) and eastward (evening sector) ionospheric currents at auroral latitudes. During magnetically disturbed times, the westward electrojet increases abruptly due to currents from the magnetospheric tail, whereas the eastward electrojet increases due to the partial ring current closure via the ionosphere in the evening sector.

- The eastward electrojet location in the evening sector changes with local time from the cusp latitudes around early afternoon to the latitudes of diffuse auroral precipitation equatorward of the auroral oval before midnight.
During the main phase of the intense magnetic storm, in late evening-midnight hours, the eastward current is located at subauroral latitudes, and thus not seen in the AU index.

- The westward electrojet is located along the auroral oval from evening through night to the morning sector. It is adjoined to the polar electrojet at cusp latitudes in the dayside sector.

- The polar electrojet in the dayside sector is located at cusp latitudes. The direction of this electrojet current depends on the sign of the IMF azimuthal component. For $B_{y}<0 \mathrm{nT}$ the current in the polar electrojet is westward and therefore it seems that the westward electrojet is continuous at all longitudes along the auroral oval.

- During the main phase of intense magnetic storms the polar electrojet in the dayside sector shifts from its usual latitude $\Phi \sim 77^{\circ}$ to $\Phi \sim 67^{\circ}$. The region of plasma precipitation through the cusp also shifts from $\Phi \sim 77^{\circ}$ to $\Phi \sim 67^{\circ}$.

- The eastward electrojet in the evening sector is accompanied by the particles precipitation mainly from the Alfvén layer and partially from the near-Earth part of the central plasma sheet. The electrojet centre projects magnetically to the earthward boundary of the central plasma sheet. In the lower-latitude part of the eastward electrojet the field-aligned currents flow into the ionosphere (Region 2 FAC), at its higher latitude part the field-aligned currents flow out of the ionosphere (Region $1 \mathrm{FAC})$.

- The eastward electrojet is the joint result of Pedersen (as part of a partial ring current system) and Hall (between Region 2 and Region 1 FAC) currents in the ionosphere.

- During intense magnetic disturbances the eastward and westward electrojets overlap in the evening sector. The overlapping is caused by the triple structure of fieldaligned currents: Region 3 FAC flowing into the ionosphere from plasma sheet boundary layer appears in addition to Region 1 and Region 2 FAC. The westward electrojet at the high-latitudinal periphery of the plasma precipitation region is a Hall current between Region 1 and Region 3 FAC.

- In the midnight-dawn sector the westward electrojet covers the whole latitudinal interval of particle precipitation. It is mainly a Hall current between Region 1 FAC and Region 2 FAC.

- In the evening sector the Alfvén layer equatorial boundary for ions is located more equatorward than for electrons. This may favour the northward electric field generation between these boundaries and may cause high speed westward ions drift (SAPS). The SAPS peak is 
located at the Alfvén layer boundary for electrons or somewhat equatorward. Intense ionospheric currents are absent at these latitudes.

- SAPS exists at ionospheric trough latitudes with low ionospheric conductivity, in the Region 2 FAC. High speed ion drifts cover wider range of latitudes than the distance between the equatorward boundaries of ions and electrons precipitation.

\section{List of acronyms}

$\begin{array}{ll}\text { AO } & \text { auroral oval } \\ \text { CF } & \text { Chapman-Ferraro currents } \\ \text { CPS } & \text { central plasma sheet } \\ \text { CU } & \text { cusp or polar cusp } \\ \text { EE } & \text { eastward electrojet } \\ \text { FAC } & \text { field-aligned current } \\ \text { LLBL } & \text { low-latitude boundary layer } \\ \text { PC } & \text { polar cap } \\ \text { PDZ } & \text { polar diffuse zone } \\ \text { PE } & \text { polar electrojet } \\ \text { PJ } & \text { polarization jet } \\ \text { PP } & \text { plasmapause } \\ \text { PRC } & \text { partial ring current } \\ \text { PSBL } & \text { plasma sheet boundary layer } \\ \text { SAPS } & \text { subauroral polarization stream } \\ \text { TC } & \text { tail current } \\ \text { WE } & \text { westward electrojet }\end{array}$

Acknowledgements. We are grateful to the IMAGE, CANOPUS and GWC teams for the use of their data. IMAGE data are collected as an international project headed by the Finnish Meteorological Institute, CANOPUS instrument array constructed, maintained and operated by the Canadian Space Agency, provided the data used in this study, Greenland West Coast magnetometers are operated by the Danish Meteorological Institute. We gratefully acknowledge the William B. Hanson Center for Space Sciences at the University of Texas at Dallas for providing the DMSP SSIES data, D. A. Hardy (Phillips Laboratory) and F. J. Rich (AFRL, Hanscom AFB) who designed and built the DMSP SSJ/4 particle detectors and DMSP SSM/4 magnetometer employed in this study. We would like to thank WDC C2 for Geomagnetism, Kyoto for the provisional AU, $\mathrm{AL}$ and $D_{s t}$ indices data. One of the authors (Y. I. Feldstein) is grateful to M. Foerster, A. Grafe, A. Nishida for comments and constructive discussions. The study was carried out INTAS grant N03-51-5359 and the RFBR grant 05-05-65196 to IZMIRAN, grant 2/5121 from Slovak Academy of Sciences. Portions of this work were done at the Jet Propulsion Laboratory, California Institute of Technology under contract with NASA. The collaboration between IZMIRAN and the Alfvén Laboratory was supported by a grant from the Royal Swedish Academy of Sciences. The authors are grateful to the staff of the International Space Science Institute, Bern, Switzerland for their support.

Topical Editor I. A. Daglis thanks J. Watermann and P. E. Sandholt for their help in evaluating this paper.

\section{References}

Ahn, B.-H., Chen, G. X., Sun, W., Gjerloev, J. W., Kamide, Y., Sigwarth, J. B., and Frank, L. A.: Equatorward expansion of the westward electrojet during magnetically disturbed periods, J. Geophys. Res., 110, A01305, doi:10.1029/2004JA010553, 2005.

Akasofu, S.: Polar and magnetospheric substorm, D. Reidel Dordrecht-Holland, 1968.

Akasofu, S.-I.: Exploring the secrets of the aurora, Dordrecht, Kluwer Academic Publ., 2002.

Akasofu, S.-I, Chapman, S., and Meng, C.-I.: The polar electrojet, J. Atmos. Terr. Phys., 27, 1275-1305, 1965.

Baker, K. B. and Wing, S.: A new magnetic coordinate system for conjugate studies at high latitudes, J. Geophys. Res., 94, 91399143, 1989.

Baumjohann, W., Untiedt, J., and Greenwald, R. A.: Joint twodimensional observations of ground magnetic and ionospheric electric fields associated with auroral zone currents. 1. Threedimensional current flows associated with a substorm-intensified eastward electrojet, J. Geophys. Res., 83, 1963-1978, 1980.

Boström, R.: A model of the auroral electrojets, J. Geophys. Res., 69, 4983-4994, 1964.

Brandt, P. C., Mitchel, D. G., Ebihara, Y., Sandel, B. R., Roelof, E. C., Burch, J. L., and Demajistre, R.: Global IMAGE/HENA observations of the ring current: examples of rapid response to IMF and ring current-plasmasphere interaction, J. Geophys. Res., 107, SMP12, 1359, doi:10.1029/2001JA000084, 2002a.

Brandt, P. C., Ohtani, S., Mitchel, D. G., Fok, M.-C., Roelof, E. C., and Demajistre, R.: Global ENA observations of the storm main phase ring current: implication for skewed electric fields in the inner magnetosphere, Geophys. Res. Lett., 29, doi:10.1029/2002GL015160, 2002b.

Burch, J. L., Mitchel, D. G., Sandel, B. R., Brandt, B. C., and Wuest, M.: Global dynamics of the plasmasphere and ring current during magnetic storms, Geophys. Res. Lett., 38, 11591162, 2001.

Burch, J. L., Lewis, W. S., Immel, T. J., Anderson, P. C., Frey, H. U., Fuselier, S. A., Gerard, J.-C., Mende, S. B., Mitchell, D. G., and Thomsen, M. F.: Interplanetary magnetic field control of afternoon sector detached proton auroral arcs, J. Geophys. Res., 107, 1251, doi:10.1029/2001JA007554, 2002.

Chapman, S.: The electric current system of magnetic storm, Terr. Magn. Atmos. Elec., 40, 349-370, 1935.

Clauer, C. R., Alexeev, I. I., Belenkaya, E. S., and Baker, J. B.: Special features of the September 24-27, 1998 storm during high solar dynamic pressure and northward interplanetary magnetic field, J. Geophys. Res., 106, 25 695-25 711, 2001.

Evlashin, L. S. and Maltsev, Yu. P.: Dependence intensity of different types auroral emission from geomagnetic activity, (in Russian), Geomagn. Aeron., 44(3), 311-315, 2004.

Feldstein, Y. I.: The morphology of aurora and geomagnetism, Aurora and Airglow, The Academy of Sciences of the U.S.S.R., (in Russian), 10, 121-126, 1963.

Feldstein, Y. I.: Magnetic field variation in nearpole region during magnetically quiet periods and interplanetary magnetic fields, Space Sci. Rev., 18, 777-861, 1976.

Feldstein, Y. I. and Galperin, Yu. I.: Structure of the auroral precipitations in the nightside sector of the magnetosphere, Cosmic Research, 34(3), 209-227, 1996.

Feldstein, Y. I. and Zaitzev, A. N.: The current system of SD- 
variations in high latitudes for the winter season during the IGY, Geomagn. Aeron., 5, 1123-1128, 1965.

Feldstein, Y. I., Sumaruk, P. V., and Shevnina, N. F.: To the diagnostics of the azimuthal component of the interplanetary magnetic field, C. R. Acad. Sci. USSR, 222, 833-836, 1975.

Feldstein, Y. I., Gromova, L. I., Popov, V. A., and Grafe, A.: Auroral electrojet dynamics during magnetic storms, Proc. ICS-3, Versailles, May, 1966, ESA SP-389, 75-80, 1996.

Feldstein, Y. I., Grafe, A., Gromova, L. I., and Popov, V. A.: Auroral electrojets during geomagnetic storms, J. Geophys. Res., 102, 14 223-14 235, 1997.

Feldstein, Y. I., Gromova, L. I., Grafe, A., Meng, C.-I., Kalegaev, V. V., Alexeev, I. I., and Sumaruk, V. P.: Auroral electrojet dynamics during magnetic storms, connections with plasma precipitation and large-scale structure of the magnetospheric magnetic field, Ann. Geophys., 17, 497-507, 1999,

http://www.ann-geophys.net/17/497/1999/.

Feldstein, Y. I., Gromova, L. I., Woch, J., Sandahl, I., Blomberg, L., Marklund, G., and Meng, C.-I.: Structure of the auroral precipitation region in the dawn sector: relationship to convection reversal boundaries and field-aligned currents, Ann. Geophys., 19, 495-519, 2001, http://www.ann-geophys.net/19/495/2001/.

Foster, J. C. and Burke, W. J.: SAPS: A new characterization for subauroral electric field, Eos. AGU Trans., 83, 393-394, 2002.

Foster, J. C. and Vo, H. B.: Average characteristics and activity dependence of the subauroral polarization stream, J. Geophys. Res., 107, 1475, doi:10.1029/2002JA009409, 2002.

Foster, J. C., Erickson, P. J., Coster, A. J., Goldstein, J., and Rich, F. J.: Ionospheric signatures of plasmaspheric tail, Geophys. Res. Lett., 29, 1623, doi:10.1029/2002GL015067, 2002.

Friis-Christensen, E., Lassen, K., Wilhjelm, J., Wilcox, J. M., Gonzalez, G., and Colburn, D. S.: Critical component of the interplanetary magnetic field responsible for large geomagnetic effects in the polar cap, J. Geophys. Res., 77, 3371-3380, 1972.

Friis-Christensen, E. and Wilhjelm, J.: Polar currents for different directions of the interplanetary magnetic field in the Y-Z plane, J. Geophys. Res., 80, 1248-1260, 1975.

Fukushima, N.: Polar magnetic storms and geomagnetic bays, J. Fac. Sci., Tokyo Univ., 8, part 5, 293-412, 1953.

Galperin, Yu.: Polarization jet: characteristics and model, Ann. Geophys., 20, 391-404, 2002,

http://www.ann-geophys.net/20/391/2002/.

Galperin, Yu. and Feldstein, Y. I.: Auroral luminosity and its relationship to magnetospharic plasma domains, in: Auroral Physics, edited by: Meng, C.-I., Rycroft, M. J., and Frank, L. A., Cambridge UP, 207-222, 1991.

Galperin, Yu. and Feldstein, Y. I.: Mapping of the precipitation region to the plasma sheet, J. Geomag. Geoelectr., 48, 857-875, 1996.

Galperin, Yu., Ponomarev, V. N., and Zosimova, A. G.: Plasma convection in the polar ionosphere, Ann. Geophys., 30, 1-9, 1974, http://www.ann-geophys.net/30/1/1974/.

Ganushkina, N. Yu., Pulkkinen, T. I., and Fritz, T.: Role of substorm-associated impulsive electric fields in the ring current development during storms, Ann. Geophys., 23, 579-591, 2005, http://www.ann-geophys.net/23/579/2005/.

Gardner, T. W., Wolf, R. A., Spiro, R. W., Burke, W. J., Fejer, B. J., Sazukin, S., Roeder, J. L., and Hairston, M. R.: Magneto- spheric electric fields and plasma sheet injection to low L-shells during the 4-5 June 1991 magnetic storm: comparison between the Rice Convection Model and observations, J. Geophys. Res., 109, A02214, doi:10.1029/2003JA010208, 2004.

Grafe, A.: Freja electron precipitation as a hint for an explosive development of the eastward electrojet, in: Substorm 2, Proceedings University of Alaska, 391-398, 1994.

Grafe, A. and Feldstein, Y. I.: About the relationship between auroral electrojets and ring currents, Ann. Geophys., 18, 874-886, 2000 , http://www.ann-geophys.net/18/874/2000/.

Grafe, A., Trakhtengerts, V. V., Bespalov, P. A., and Demekhov, A. G.: Evolution of the low- latitude geomagnetic storm field and the importance of turbulent diffusion for ring current particle losses, J. Geophys. Res., 101, 24 689-24 706, 1996.

Harang, L.: The mean field of disturbance of polar geomagnetic storms, Terr. Magn. Atmos. Elec., 51, 353-371, 1946.

Harang, L.: The aurorae, The Intern. Astrophys. Series, Vol. I, edited by: Ellison, M. A. and Lovell, A. C. B. (General Eds.), London, Chapman and Hall Ltd., 1951.

Jordanova, V. K., Farrugia, C. J., Janoo, L., Quinn, J. M., Torbert, R. B., Ogilvie, K. W., Lepping, R. P., Steinberg, J. T., McComas, D. J., and Belian, R. D.: October 1985 magnetic cloud and accompanying storm activity: Ring current evolution, J. Geophys. Res., 103, 79-92, 1998.

Kamide, Y. and Akasofu, S.-I.: Latitudinal cross section of the auroral electrojet and its relation to the interplanetary magnetic field polarity, J. Geophys. Res., 79, 3755-3771, 1974.

Kamide, Y. and Kokubun, S.: Two-component auroral electrojet: importance for substorm studies, J. Geophys. Res., 101, 13027 $13046,1996$.

Kamide, Y., Richmond, A. D., and Matsushita, S.: Estimation of the ionospheric electric field, ionospheric currents and field aligned currents from ground magnetic records, J. Geophys. Res., 86, 801-813, 1981.

Kamide, Y., Ahn, B.-H., Akasofu, S.-I., Baumjohann, W., FriisChristensen, E., Kroehl, H. W., Maurer, H., Richmond, A. D., Rostoker, G., Spiro, R. W., Walker, J. R., and Zaitzev, A. N.: Global distribution of ionospheric and field-aligned currents during substorms as determined from six meridian chains of magnetometers: initial results, J. Geophys. Res., 87, 8228-8240, 1982.

Kivelson, M. G. and Russell, C. T.: Introduction to space physics, Cambridge, Cambridge University Press, 1995.

Kotikov, A. L., Bolotynskaya, B. D., Gizler, V. A., Troshichev, O. A., Pashin, A. B., and Tagirov, V. R.: Structure of auroral zone phenomena from the data of meridional chains of stations: magnetic disturbances in the night-time auroral zone and auroras, J. Atmos. Terr. Phys., 53, 265-277, 1991.

Liemohn, M. W., Kozyra, J. U., Thomsen, M. F., Roeder, J. L., Lu, G., Borovsky, J. E., and Cayton, T. E.: Dominent role of the asymmetric ring current in producing the stormtime Dst*, J. Geophys. Res., 106, 10 883-10 904, 2001a.

Liemohn, M. W., Kozyra, J. U., Clauer, C. R., and Ridlly, A. J.: Computational analysis of the near-Earth magnetospheric current system during two-phase decay storms, J. Geophys. Res., 106, 29531-29542, 2001b.

Mansurov, S. M.: New evidence of the relationship between magnetic field in space and on the Earth, (in Russian), Geomagn. Aeronom, 9, 768-773, 1969. 
Nagata, T. and Fukushima, N.: Constitution of polar magnetic storms, Rep. Ionos. Res. Japan, 6, 85-96, 1952.

Newell, P. N., Feldstein, Y. I., Galperin, Yu. I., and Meng, C.-I.: Morphology of nightside precipitation, J. Geophys. Res., 101, 10737-10748, 1996.

Olsen, N.: A new tool for determining ionospheric current from magnetic satellite data, Geophys. Res. Lett., 23, 3635-3638, 1996.

Popov, V. A. and Feldstein, Y. I.: About a new interpretation of "Harang discontinuity", Geomagn. Aeron., 36(1), 43-51, 1996.

Popov, V. A., Papitashvili, V. O., and Watermann, J. F.: Modeling of equivalent ionospheric currents from meridian magnetometer chain data, Earth Planets Space, 53, 129-137, 2001.

Richmond, A. D. and Kamide, Y.: Mapping electrodynamic features of the high-latitude ionosphere from localized observations: Technique, J. Geophys. Res., 93, 5741-5756, 1988.

Sandholt, P. E., Farrigua, C. J., and Denig, W. F.: Detailed dayside auroral morphology as a function of local time for southern IMF orientation: implications for solar wind-magnetosphere coupling, Ann. Geophys., 22, 3537-3560, 2004, http://www.ann-geophys.net/22/3537/2004/.

Skoug, R. M., Thomsen, M. F., Henderson, M. G., Funsten, H. O., Reeves, G. D., Pollock, C. J., Jahn, J.-M., McComas, D. J., Mitchell, D. G., Brandt, P. C., Sandel, B. R., Clauer, C. R., and Singer, H. J.: Tail-dominated storm main phase: 31 March 2001, J. Geophys. Res., 108, 1259, doi:10.1029/2002JA009705, 2003.

Sumaruk, P. V. and Feldstein, Y. I.: Sector structure of the interplanetary magnetic field and magnetic disturbances in nearpole region, (in Russian), Kosm. Issl., 11, 155-160, 1973.
Svalgaard, L.: Sector structure of the interplanetary magnetic field and daily variation of the geomagnetic field at high latitudes, Geophys. Papers R-6, Danish Meteorol. Inst., 1968

Tikhonov, A. N. and Arsenin, V. Ia.: Solution of ill-posed problem, Halsted Press, New York, 1977.

Trakhtengerts, V. Y. and Demekhov, A. G.: Partial ring current and polarization jet, in: Auroral phenomena and solar-terrestrial relations, Proceeding of the conference in memory of Yuri Galperin, 3-7 February 2003, edited by: Zelenyi, L. M., Geller, M. A., and Allen, J. A., 375-382, CAWSES Handbook-1, Boulder, 2004.

Tsurutani, B. T. and Zhou, X. Y.: Interplanetary shock triggering of substorms: Wind and Polar, Adv. Space Res., 31, 1063-1067, 2003.

Untiedt, J. and Baumjohann, W.: Studies of polar current systems using the IMS Scandinavian magnetometer array, Space Sci. Rev., 63, 245-390, 1993.

Vorobjev, V. G., Gromova, L. I., Rezhenov, B. V., Starkov, G. V., and Feldstein, Y. I.: The boundaries of plasma precipitation and auroral luminosity positions in night sector, (in Russian), Geomagn. Aeron., 40(3), 79-85, 2000.

Wiens, R. H. and Vallance Jones, A.: Stadies of auroral hydrogen emission in west-central Canada. 111. Proton and electron auroral ovals, Canad. J. Phys., 47, 1493-1498, 1969.

Zhou, X. Y. and Tsurutani, B. T.: Interplanetary shock triggering of nightside geomagnetic activity: Substorms, pseudobreakups, and quiescent events, J. Geophys. Res., 106, 18 957-18 967, 2001. 